Florida International University FIU Digital Commons

$11-13-2012$

\title{
Predictors of Adolescent Sexual Intentions and Behavior: Attitudes, Parenting, and Neighborhood Risk
}

Anne S. Frankel

Florida International University, annefrankel@gmail.com

DOI: $10.25148 /$ etd.FI12120415

Follow this and additional works at: https://digitalcommons.fiu.edu/etd

\section{Recommended Citation}

Frankel, Anne S., "Predictors of Adolescent Sexual Intentions and Behavior: Attitudes, Parenting, and Neighborhood Risk" (2012). FIU Electronic Theses and Dissertations. 771.

https://digitalcommons.fiu.edu/etd/771 


\section{FLORIDA INTERNATIONAL UNIVERSITY}

Miami, Florida

PREDICTORS OF ADOLESCENT SEXUAL INTENTIONS AND BEHAVIOR:

ATTITUDES, PARENTING, AND NEIGHBORHOOD RISK

A dissertation submitted in partial fulfillment of the

requirements for the degree of

DOCTOR OF PHILOSOPHY

in

PUBLIC HEALTH

by

Anne Sperling Frankel

2012 
To: Interim Dean Michele Ciccazzo

Robert Stempel College of Public Health and Social Work

This dissertation, written by Anne Sperling Frankel and entitled Predictors of Adolescent Sexual Intentions and Behavior: Attitudes, Parenting, and Neighborhood Risk, having been approved in respect to style and intellectual content, is referred to you for judgment.

We have read this dissertation and recommend that it be approved.

Jessy Dévieux

Elena Bastida

Luther Brewster

Robert Malow, Major Professor

Date of Defense: November 13, 2012

The dissertation of Anne Sperling Frankel is approved

Interim Dean Michele Ciccazzo Robert Stempel College of Public Health and Social Work

Dean Lakshmi N. Reddi

University Graduate School

Florida International University, 2012 


\section{DEDICATION}

This dissertation is dedicated to the 2004 seventh grade students of L.H. Marrero Middle School in Marrero, Louisiana and 2005 seventh grade students of Luis Muñoz Marín Elementary School in Philadelphia, Pennsylvania. When I became a teacher, I never anticipated learning so much. Your commitment to overcoming adversity inspired me in my difficult moments, and I hope that with this $\mathrm{PhD}$, I am able to make life better for the future generations of seventh graders. 


\section{ACKNOWLEDGMENTS}

I have many people to thank for helping me along the way as I worked to complete this dissertation. First, thanks to my major professor, Dr. Robert Malow, for unfailing positivity and support and for being a veritable library of information. To Dr. Jessy Dévieux for her discerning eye and guidance, and for repeatedly employing me, even after having a couple of kids! To Dr. Luther Brewster, my first mentor at FIU, for his unique perspective and creativity. And to Dr. Elena Bastida for her wealth of knowledge and commitment to students.

Next, thank you to all of the professors, staff, and fellow students at FIU that I have been fortunate enough to encounter. At the AIDS prevention program, a special thanks to Brenda Lerner, Michèle Jean-Gilles, and Maria del Carmen Santos for guidance

and support through the years. Thanks to my PhD cohort, Christi Navarro, Marie Severe, and Mike Melchior, without whom I would not have survived classes, comps, and certainly not the dissertation writing process.

A thousand thanks to my family and friends. Thanks, Mom and Dad, for the years of excellent education and for instilling in me an invaluable love of reading. Thank you to my sons Theodor and Ezra, for taking good naps so that I could write. More importantly, thank you for providing more laughter and love than I thought my heart could handle. Thank you to my amazing husband Caleb, for everything.

Finally, I would like to recognize the FIU Graduate School for financial support through the Presidential Fellowship and Dissertation Year Fellowship. 
ABSTRACT OF THE DISSERTATION

PREDICTORS OF ADOLESCENT SEXUAL INTENTIONS AND BEHAVIOR:

ATTITUDES, PARENTING, AND NEIGHBORHOOD RISK

by

Anne Sperling Frankel

Florida International University, 2012

Miami, Florida

Professor Robert Malow, Major Professor

The current study was a cross-sectional examination of data collected during an HIV risk reduction intervention in south Florida. The purpose of the study was to explore the relationships between neighborhood stress, parenting, attitudes, and adolescent sexual intentions and behavior. The Theory of Planned Behavior was used as a model to guide variable selection and propose an interaction pathway between predictors and outcomes.

Potential predictor variables measured for adolescents ages 13-18 $(n=196)$ included communication about sex, parent-family connectedness, parental presence, parent-adolescent activity participation, attitudes about sex and condom use, neighborhood disorder, and exposure to violence. Outcomes were behavioral intentions and sexual behavior for the previous eight months. Neighborhood data was supplemented with ZIP Code level data from regional sources and included median household income, percentage of minority and Hispanic residents, and number of foreclosures. Statistical tests included t-tests, Pearson's correlations, and hierarchical linear regressions.

Results showed that males and older adolescents reported less positive behavioral intentions than females and adolescents younger than 16. Intentions were associated with 
condom attitudes, sexual attitudes, and parental presence; unprotected sexual behavior was associated with parental presence. The best fit model for intentions included gender, sexual attitudes, condom attitudes, parental presence, and neighborhood disorder. The unsafe sexual behavior model included whether the participant lived with both natural parents in the previous year, and the percent of Hispanic residents in the neighborhood.

Study findings indicate that more research on adolescent sexual behavior is warranted, specifically examining the differentials between variables that affect intentions and those that affect behavior. A focus on gender and age differences during intervention development may allow for better targeting and more efficacious interventions. Adding peer and media influences to the framework of attitudes, parenting, and neighborhood may offer more insight into patterns of adolescent sexual behavior risk. 


\section{TABLE OF CONTENTS}

CHAPTER

PAGE

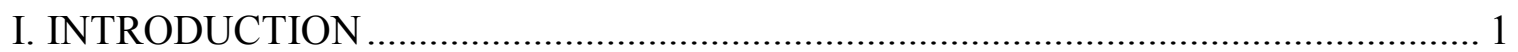

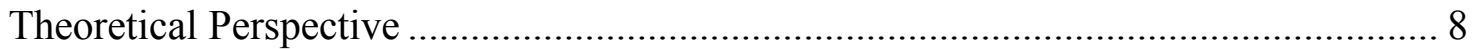

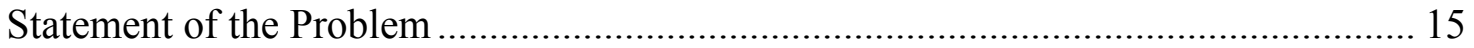

Research Questions/Hypotheses ............................................................................ 16

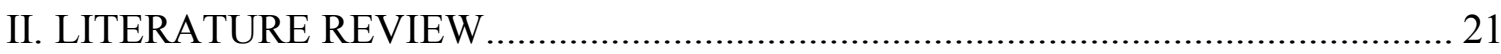

Epidemiology of Adolescent Risk Behavior .......................................................... 22

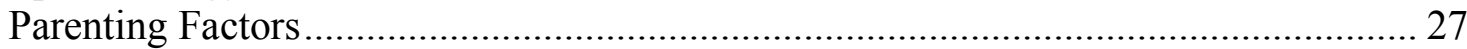

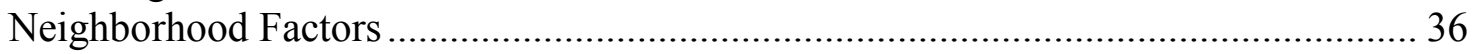

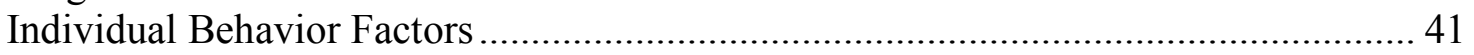

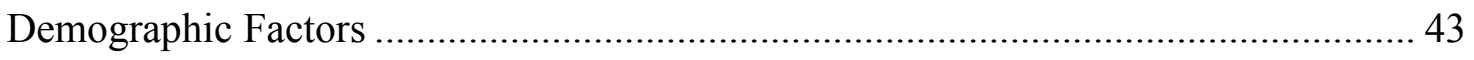

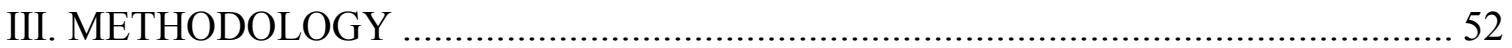

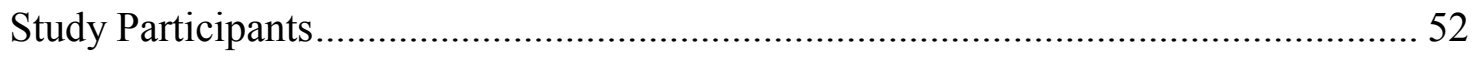

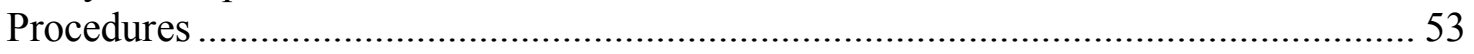

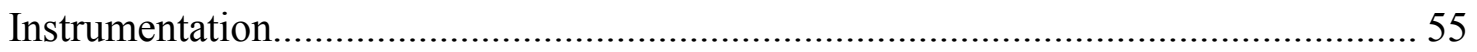

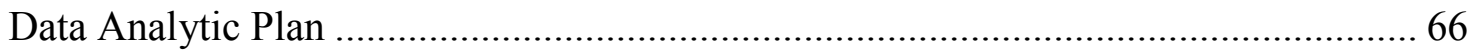

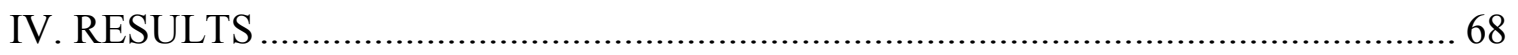

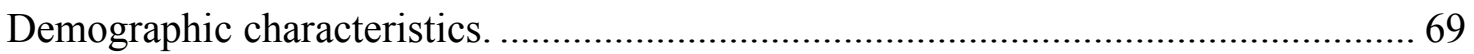

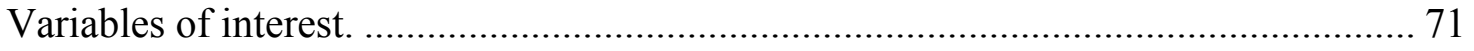

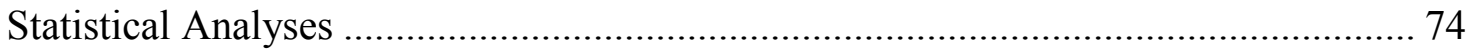

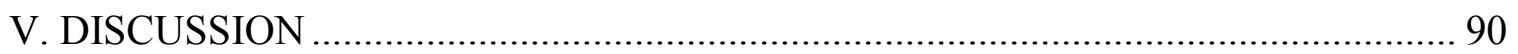

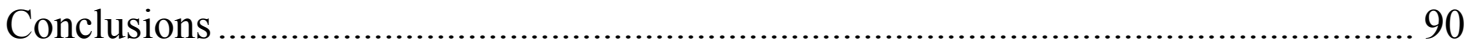

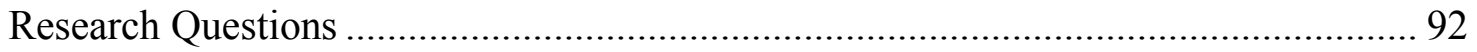

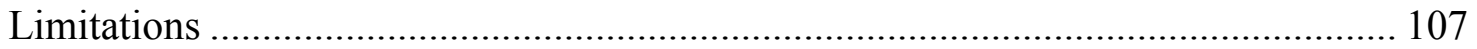

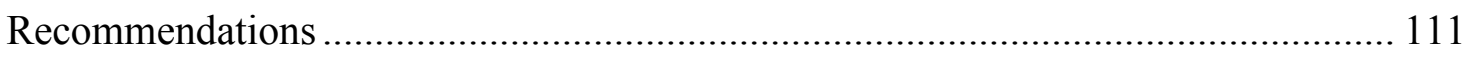

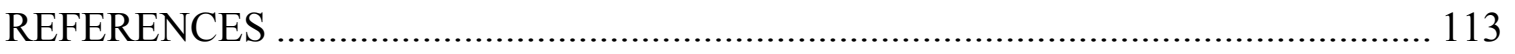

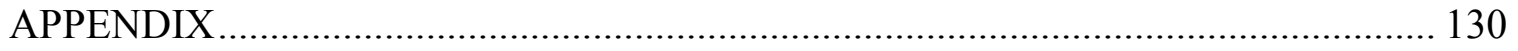

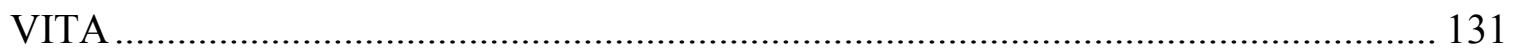




\section{LIST OF TABLES}

TABLE

PAGE

1.: Demographic Characteristics of South Florida Adolescents .................................. 70

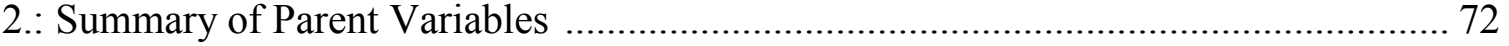

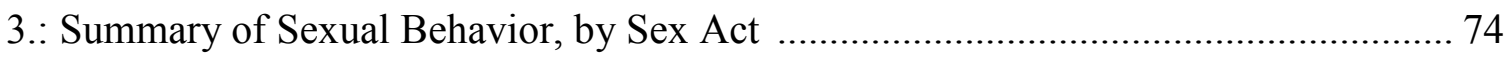

4.: Outcomes for Parent and Attitude Variables by Age, Gender, and Race .................. 76

5: Outcomes for Neighborhood Indices, Behavioral Intentions and Unsafe Sex ........... 84

6.: Multiple Regression Analysis for Behavioral Intentions...................................... 88

7.: Multiple Regression Analysis for Intentions, Including ZIP Code Data ................... 88

8.: Multiple Regression Analysis for Unsafe Sex, Including ZIP Code Data.................. 89 


\section{CHAPTER I}

\section{Introduction}

Societal concerns regarding adolescent pregnancy and sexual activity is not a new phenomenon. Researchers trace the emergence of serious public attention on adolescent pregnancy to the 1970s, when the word "epidemic" was first used in reference to the problem (Chase-Lansdale \& Vinovskis, 1993). Whether this was the first time that adolescent pregnancy had been regarded as an epidemic or not, it was the first time that an administration actively took steps to address the issue. In 1978, President Carter's administration proposed the Adolescent Health, Services, and Pregnancy Prevention Act, which later became law as the Adolescent Family Life Act, which aimed to reduce the nation's adolescent pregnancy rates (Dailard, 2000). This piece of legislation began the effort to curb adolescent pregnancy and, after the recognition of HIV and AIDS, sexually transmitted infections (STIs). Despite political progress and years of subsequent scholarly research, adolescents are still at a high risk for unplanned pregnancy and STIs (CDC, 2012). More research into individual, family, and societal factors that impact adolescent sexual behavior will help focus interventions for maximum efficacy and applicability to adolescents throughout the United States.

The current study is a cross-sectional examination of data collected during an HIV risk reduction intervention in Miami-Dade, Broward, and Palm Beach Counties, Florida. The purpose of the study is to explore the relationships between neighborhood stress, parenting, attitudes, and adolescent sexual behavior. The study will examine how parenting skills, including good communication, high levels of involvement and monitoring, and a close caring relationship, and adolescents' attitudes about sex and 
condoms impact their intentions and their behavior. The outcomes under investigation are sexual behavior intentions and risky sexual behaviors such as unprotected sex and sex concurrent with drug and alcohol use.

After basic relationships between parenting variables, attitude variables, and outcome variables have been established, the study will add a third group of predictor variables: neighborhood elements, including neighborhood disorder, exposure to violence, median household income, racial/ethnic diversity, and number of preforeclosures/number of bank-owned properties in the neighborhood.

Impact. The two most serious consequences of unprotected sexual activity, pregnancy and STIs, come at a great cost to adolescents, their families, and society (Miller, 2000). The cost of childrearing is perhaps most concrete and easier to measure than the cost of other outcomes. In order to calculate the true cost of risky sexual behavior, one must include both short-term and long-term effects. Short-term, the costs of prenatal care and raising an infant are a concern; long-term, the potential lost earnings of an abbreviated education (if a teenage mother were to drop out of school, for instance) results in more significant overall consequences. Similarly, the short-term effects of certain STIs may be mitigated by antibiotics or other curative therapies, but for STIs such as HPV and HIV/AIDS, the medical outcomes could last for a lifetime. As such, several studies have attempted to predict the cost of risky sexual behavior to society, generally in two categories: cost of adolescent pregnancy and cost of HIV/AIDS and STIs.

One study estimated that the annual cost (in 1993 equivalent dollars) of adolescent pregnancy could range from $\$ 25-\$ 30$ billion a year when considering prenatal 
care, childbearing and postnatal care, government assistance in the form of food stamps or other subsidy programs, loss of productivity, and the cost of building correctional facilities to accommodate the children of teenage mothers, who are much more likely to be involved in criminal activity (Miller, 2000). Attempting to estimate the costs of HIV/AIDS and other STIs faces similar challenges, as it is difficult to account for peripheral effects. These include loss of productivity and reliance on government assistance as well as the cost of primary and secondary prevention activities. An estimate of the direct medical costs of eight major STIs (HIV/AIDS, HPV, genital herpes, hepatitis B, chlamydia, gonorrhea, trichomoniasis, and syphilis) among 15-24 year olds living in the United States found the total estimated burden (in 2000 dollars) to be $\$ 6.5$ billion (Chesson, Blandford, Gift, Tao, \& Irwin, 2004). To date, no comprehensive estimate of direct, indirect, and intangible costs of STIs has been reported (Jerman, Constantine, \& Nevarez, 2007). Beyond the monetary and health effects of adolescent pregnancy and STIs, unprotected sexual activity has potential emotional and psychological outcomes for both parties that cannot be easily quantified.

Prevalence. Although adolescent pregnancy rates have been decreasing in recent years (U.S. Department of Health and Human Services, 2011), adolescent sexual risk behavior as a whole is still a major cause for concern. According to the CDC's Youth Risk Behavior Survey, $46 \%$ of high school students report lifetime sexual activity, while $34 \%$ report current sexual activity. Almost $40 \%$ of students reporting current sexual activity did not use a condom at the most recent sexual encounter, and more than $20 \%$ used alcohol or drugs before having sex. More than $13 \%$ of high school students report 
having four or more sexual partners since their sexual debut. Only $5.9 \%$ of students report having sexual intercourse before age 13 , but the numbers are alarmingly varied across racial and ethnic groups, peaking at $15.2 \%$ for black students. The other risk behaviors listed above fall along similar lines: rates are higher among male students, black and Hispanic students, and older students $\left(12^{\text {th }}\right.$ grade vs. $9^{\text {th }}$ grade) $(C D C, 2010 \mathrm{a})$.

Justification. Adolescent sexual risk behavior is a problem that comes at a high cost to individuals and society. In order to gain a better understanding of the most important predictors for such behavior, the most common ways that these behaviors have been addressed in the recent past will be briefly discussed. Adolescents generally receive their information about sex from several sources: peers, parents, schools, or modern media. School-based sexual education is probably the most-discussed of these sources, and the most controversial from the perspective of the media, politicians, and concerned parents. Unfortunately, assessments of sexual risk reduction programs, including abstinence-only, improvements to contraceptives, education for teens and families, youth development programs, and multi-component programs have shown limited efficacy. Miller concluded after a comprehensive literature review that no single approach has yet been proven to truly reduce adolescent pregnancy (2000). In a review of school and sexual education program impact, Kirby (2002) found that sex and HIV prevention programs did not inadvertently increase sexual behavior, as some fear, and some of the programs decreased risky behavior and increased contraceptive use as intended. The study also found that school clinics offering contraceptives did not inadvertently increase sexual behavior, but no conclusions could be drawn as to whether clinics reduced such 
behavior. Kirby also found that the simple act of being engaged in school decreased adolescent pregnancy even when there was no sexual education component (2002).

Parents. Whether or not schools address the sexual education needs of adolescents, an inherent educational opportunity exists within the homes of adolescents. Though research abounds on how parents affect their children's behaviors, there have been glaring inconsistencies in research findings thus far. In their review of communication about sex between parents and adolescents, Jaccard et al. (2002) address prior research with oversaturation in mind. The authors argue that patterns of communication between parents and children are much like patterns of communication between teachers or other educators in an intervention or classroom setting. However, sexual education in classrooms and interventions has been subject to far more scrutiny than that between parents and children, partially because it unfolds in the public arena. For this reason, researchers understand more about the effectiveness of short-term, focused interventions than about the fundamental relationship between parent and child that is being reinforced every day of the child's life. Therefore, it is still important to emphasize parent-child relationships in designing research studies (Jaccard, Dodge, \& Dittus, 2002).

The parent factors included in this study were deliberately chosen based on the literature and theoretical models of parenting. The parent factors discussed withincommunication, connectedness, presence, and activity participation—are associated with abstinence, reductions in unplanned pregnancy, contraceptive use, postponement of intercourse, fewer sexual partners, and other positive outcomes (Miller, 2002; Resnick et 
al., 1997; DiIorio, Kelley, \& Hockenberry-Eaton, 1999; Karofsky, Zeng, \& Kosorok, 2001; Li, Stanton, \& Feigelman, 2000). For operational definitions of the parent factors and other terms, refer to end of this chapter.

Communities. The literature review in the current study addresses the myriad reasons that neighborhood stressors are worth studying, including the potential effects of neighborhoods on health outcomes for persons of all age groups. Examining neighborhood effects on adolescents, more than on other age groups, is particularly important. Researchers note that regardless of where they live, adolescents experience physical, social, cognitive, and emotional changes that are often difficult for themselves and others (Murry, Berkel, Gaylord-Harden, Copeland-Linder, \& Nation, 2011). Adding the difficulty of violence and poverty to these challenges can exacerbate poor decisionmaking among adolescents (D'Amico, Ellickson, Collins, Martino, \& Klein, 2005).

Leventhal and Brooks-Gunn (2000) identify several areas where neighborhood research needs to improve during the next 10 years (2000-2010). Among these directives are two that will be used to justify and guide the current study: researcher must include family and individual variables in order to clarify the often vague effects attributed to neighborhoods, and researchers must use more than socioeconomic status to represent the makeup of a neighborhood.

One neighborhood risk factor that is of particular concern because of its contribution to the unintentional and intentional injury morbidity and mortality is violence. Aisenberg and Herrenkohl note that most violence prevention research has focused on individually protective characteristics (2008). The authors subsequently identify a significant research gap in examining factors that can protect adolescents from 
the effects of violence, including family, school, and community influence. Later in this document, the risks associated with exposure to violence and reported levels of exposure to violence will be analyzed.

Attitudes. Finally, because adolescent sexual behavior is ultimately enacted by an individual, it is important to examine the individual's attitudes towards safe sex. Attitudes about risky sexual behavior and attitudes about condom use have been found to be related to sexual behavior in adolescents and other populations. Studies have found that less favorable attitudes towards risky sexual behavior were correlated to less risky sexual behavior, and that the latter is also true: positive attitudes predict the likelihood of safer sexual behavior (Jemmott, Jemmott, \& Fong, 1992; DeHart \& Birkimer, 1997). Seminal research on attitudes towards condom use and sexual behavior found that one single attitudinal question regarding whether condoms spoiled sex was more predictive of whether the participant was going to practice safe sex than knowledge about AIDS, seropositivity, and sobriety at the time of sex (Sacco, Levine, Reed, \& Thompson, 1991; Valdiserri, Lyter, Leviton, Callahan, Kingsley, \& Rinaldo, 1988). Condom attitudes predict whether a person had or was likely to carry condoms, keep condoms at home, or use condoms during sex. However, condom use is also a product of other complex interactions including impulse control and perceived behavioral control (Sacco, Levine, Reed, \& Thompson, 1991). In 1988, Kegeles et al. found that condom attitudes among adolescents were not associated with increased behavioral intentions or actual condom use. These conflicting findings justify the need for more examination (Kegeles, Adler, \& Irwin, 1988). 


\section{Theoretical Perspective}

This study will examine the sexual behavior of an adolescent, their behavioral intentions preceding the behavior, interactions with their parents, attitudes, and perception of neighborhood influence. Multiple theoretical perspectives were considered for the theoretical framework, including Urie Bronfenbrenner's ecological perspective (1979) whereby the interactions between multiple levels of a health problem are examined in order to identify how an individual moves within their physical and sociocultural environments (National Cancer Institute, 2005). However, because the focus is an individual behavior, the current study proposes that the interactions between these elements is best explained using the Theory of Planned Behavior (TPB).

A meta-analysis of studies utilizing the TPB found that the model explained more than $30 \%$ of behavioral intentions and almost $30 \%$ of behavior (Armitage \& Connor, 2001). A 2007 review found that for adolescents, behavioral intentions, subjective norms, and environmental elements consistently predicted sexual behavior (Buhi \& Goodson, 2007). For example, a study of 219 adolescents in Philadelphia used the TPB to examine mediators including attitudes about sex and parental approval towards sex to predict sexual behavior (Hutchinson, Jemmott, Jemmott, Braverman, \& Fong, 2003).

The TPB asserts that individual behavior is directly influenced by that person's intentions to perform the behavior in question. The model then seeks to explain the source of behavioral intentions, and organizes those sources into three realms: attitudes, subjective norms, and perceived behavioral control (National Cancer Institute, 2005). Subjective norms refer to codes of behavior that have been instilled in the individual; in the current study this will refer to parenting practices. Researchers have argued that 
subjective norms may be the weakest predictor of behavioral intentions (Armitage \& Connor, 2001). By examining many parental variables and attempting to determine which have a significant impact, this study hopes to add to the literature to clarify which normative variables have an effect on variance.

Perceived behavioral control is an element that was added to the model later, and it accounts for whether a person has control over performing a certain behavior (Edberg, 2007). It is a unique element of the model because it influences not only the intention to perform a behavior, but also the behavior itself because even if an individual has the intent to act, they may not have the means to follow through. Perceived behavioral control is composed of two elements: control beliefs and perceived power (Edberg, 2007). Research has hypothesized that neighborhood disorder could lead to feelings or powerlessness among urban residents (Geis \& Ross, 1998). Therefore, in the current study, perceived behavioral control will refer to the neighborhood elements that individuals may or may not have control over. The next section will seek to explain how the subjective norm and behavioral control variables were chosen using parenting and neighborhood theory.

Parenting theory. Within the TPB, more specific theories will be utilized in order to hypothesize how the variables interact with one another. Construct-specific theories will also help determine the how and why of whether the variables ultimately have an outcome on adolescent sexual risk behavior.

Parent-adolescent communication, parent-child connectedness, parental presence, and parent-child activity participation are all concepts that arise from the theory of authoritative parenting. According to Baumrind (1967), the authoritative parent 
establishes standards of behavior, enforces those standards consistently, encourages independence, facilitates verbal communication, and is supportive and involved. This paper will focus on verbal communication by using parent-adolescent communication as a construct. Historical research on parent-adolescent communication is inconclusive; it has been associated with both increases and decreases in sexual activity (Jaccard, Dodge, \& Dittus, 2002). Parental behavioral control, defined as the level of monitoring (Gray \& Steinberg, 1999), is a key element of authoritative parenting and accounts for the parental presence construct. Parental presence and parental monitoring have been shown to have a complex relationship with risk behavior: up to a certain point, parental monitoring is protective, but when parents are too controlling, adolescents may react by increasing risk behaviors (Miller, McCoy, Olson, \& Wallace, 1986). The final parental factor is warmth, acceptance, or involvement, also known as nurturance (Simons-Morton \& Hartos, 2002), which justifies the use of both parent-child connectedness and parent-child activity participation as constructs (Gray \& Steinberg, 1999). Parent-child connectedness has consistently shown to be associated with lower sexual activity, such that a close relationship predicts low risk behavior (Miller, 2002). Parent-adolescent activity participation has too small of a research base to draw consistent conclusions, but insofar as this construct is related to connectedness, the expected outcome is that closer relationships result in less risky behavior.

Authoritative parenting theory is generally applied to cross-sectional studies of outcomes associated with various elements of parenting and is often used in middle or high school settings with sample sizes ranging from 120 students to 8,700 students. Researchers do not typically utilize a single questionnaire or measure for authoritative 
parenting, rather, the theory is measured piecemeal depending on the predictors of interest. Past studies have examined several factors that fall under the umbrella of authoritative parenting, including parental monitoring, negotiated unsupervised time, communication, support, acceptance, and psychological autonomy granting (Borawski, Ievers-Landis, Lovegreen, \& Trapl, 2003; Rai, et al., 2003; Rodgers, 1999; Steinberg, Elmen, \& Mounts, 1989; Gray \& Steinberg, 1999). Authoritative parenting practices have been linked to outcomes including academic success (Gray \& Steinberg, 1999), psychosocial adjustment (Steinberg, Elmen, \& Mounts, 1989), and reductions in substance use, weapon-carrying, and anger (Jackson, Henrikson, \& Foshee, 1998). Numerous studies have also examined the current study's outcome of interest, sexual risk behavior, finding that authoritative parenting principles such as monitoring, trust, support, and communication are associated with lower levels of unsafe sexual activity (Rodgers, 1999; Borawski, Ievers-Landis, Lovegreen, \& Trapl, 2003; Rai, et al., 2003). One study suggests that the mechanism by which authoritative parenting is protective against sexual risk taking is through autonomy-building, which is a core dimension of the theory (Rodgers, 1999). Certain types of parenting practices have been shown to be more effective in high risk neighborhoods; notably, research has found that authoritarian parenting practices including physical punishment, firmness, and low levels of emotional support may actually moderate neighborhood effects (Eamon, 2002; Luthar, 1999). The author suggests that this seemingly contrary finding may be due to social and cultural expectations of different racial and/or ethnic groups (Eamon, 2002).

The use of the authoritative parenting theory within the TPB will offer valuable insight into the scope and applicability of the parenting theory with this particular 
population: mostly non-white, lower-income adolescents in potentially dangerous neighborhoods. Researchers note the importance of both measuring multiple parenting behaviors (Gray \& Steinberg, 1999) and examining parenting in difference ecological environments for maximum understanding (Steinberg, Mounts, Lamborn, \& Dornbusch, 1991).

Neighborhood theory. In their review of neighborhood literature, Leventhal and Brooks-Gunn (2012) address several models for theoretical analysis of neighborhood effects. They maintain that most models account for five different levels that operate together: individual, family, school, peer, and community. Buu et al. (2009), which found that neighborhood instability can contribute to psychopathologies of adolescents, explicitly notes that "an ecological approach to risk reduction that focuses on familial and neighborhood/community factors as well as individual risk is warranted." For the purposes of this study, the focus will be on the individual, family, and community.

Community disorder studies use a wide variety of theoretical models in order to explain how neighborhood characteristics including poverty, housing, limited resources, and violence affect health behavior. Some studies utilize the transactional theory of stress and coping (Lazarus \& Folkman, 1984). In this conceptual approach, individuals appraise a situation or event, and if the individual perceives no threat to their person from the event, no stress should result from witnessing the event. Research has shown that appropriate coping techniques can alleviate some of the negative effects of exposure to violence (Rasmussen, Aber, \& Bhana, 2004). However, this theory is not appropriate for the current study, as the instruments used measured only the frequency of neighborhood 
events experienced, not how participants dealt with such events. Another theory used to link behavior to neighborhood factors is the life opportunity cost framework (Murry, Berkel, Gaylord-Harden, Copeland-Linder, \& Nation, 2011), whereby individuals forgo short-term gains for later potential success. For example, females in low-income neighborhoods may not perceive much return in an educational investment, which may in turn make the prospect of early childbearing not as tragic (Driscoll, Sugland, Manlove, \& Papillo, 2005). However, this theory appears to account only for female behavior and does not consider some of the other important neighborhood elements including unemployment, poverty, and housing instability. Numerous other theories that could explain the link between neighborhoods and behavior exist, including community development theories, community capacity building, and the theory of broken windows.

The theory that best aligns with the elements of neighborhoods and mediators of behavior is the community social disorganization theory (Shaw \& McKay, 1942). This theory posits that neighborhood structural factors can explain behavior through their ability to foster or degrade neighborhood organization. It is most appropriate because it seeks to explain not only how elements of neighborhood disorder affected behavior downstream, but also which social elements mediate the relationship between disorder and behavior. This theory will be used to choose the neighborhood constructs that could have the greatest impact on the outcome behaviors, and therefore will guide data collection in the neighborhood realm.

The social disorganization theory identifies five sources of social disorganization: socioeconomic status, residential mobility, racial and ethnic heterogeneity, family disruption, and urbanization (Sampson \& Groves, 1989). The way that these sources will 
be measured will be discussed more in the Methods chapter. Shaw and McKay are particularly interested in social elements of mediation, or what Sampson and Groves (1989) refer to as intervening dimensions, including gang control, friendship networks, and local participation in voluntary organizations. In the current study, the parent elements identified using the authoritative parenting model will replace those social elements.

The social disorganization theory has typically been applied to much larger scale studies than the current study. The first formal test of the theory, conducted in 1989, utilized a study in Britain that accounted for more than 10,000 households (Sampson \& Groves, 1989), and a follow-up study that replicated Sampson and Groves’ findings involved more than 14,000 households (Lowenkamp, Cullen, \& Pratt, 2003). Further, Sampson and Groves note that from 1942-1989, the theory was generally tested with large samples gleaned from census data. A more recent study from the University of North Carolina, investigating neighborhoods, family influences, and educational behaviors had a sample size of nearly 2,000 (Bowen, Bowen, \& Ware, 2002). However, some relatively small studies have utilized the theory successfully, including a study of neighborhoods, parenting, peers, and delinquency among juvenile offenders, which had 488 participants (Chung \& Steinberg, 2006). Perhaps the closest to the current study was an application of social disorganization theory to parenting quality among rural families which used 207 households (Simons, Johnson, Conger, \& Lorens, 1997). For the current study, though the sample size is small compared to other studies, ZIP Code data will be incorporated in order to offer more representative elements. The fact that the theory has 
been applied to such varied populations as a national sample in Britain and single parents in Iowa speaks to its versatility and appropriateness for the current study.

Attitude theory. Theories that address the formation, development, and changing of attitudes are well-established in the field of social psychology. Perhaps the most wellknown is learning theory, whereby attitudes are formed by evaluating the response to stimuli and subsequent reinforcement (Edberg, 2007). Fishbein and Azjen's groundbreaking work on attitudes suggests that multiple measures of attitudes, when studied in conjunction with other elements including subjective norms, may have the best chance of predicting a linear behavior (1974). In the current study, attitudes about condom use will be measured using two separate instruments: a sexual attitudes scale and a condom attitudes scale. Prior studies have utilized condom and sexual attitudes in order to represent an individual's beliefs about sexual behavior and to predict behavioral intentions (Hutchinson, Jemmott, Jemmott, Braverman, \& Fong, 2003; Buhi \& Goodson, 2007).

\section{Statement of the Problem}

The purpose of this study is to examine the relationship between neighborhood disorder, parenting factors, sexual attitudes, and sexual risk intentions and behavior among adolescents ages 13-18 in Miami-Dade, Broward, and Palm Beach Counties, Florida. 


\section{Research Questions/Hypotheses}

1. What is the relationship between attitudes about sex, parenting practices, behavioral intentions, and adolescent sexual risk behavior by gender, age, race/ethnicity, and family structure?

i. Hypothesis 1: Positive attitudes about safe sex and higher rates of parent-adolescent activities, communication about sex, parent-family connectedness, and parental presence will be associated with lower intention to participate in risky sexual behavior. Lower intention to participate in risky sexual behavior will be associated with lower rates of risk behavior, including sexual activity concurrent with drug/alcohol use and lack of condom use.

ii. Null Hypothesis 1: Positive attitudes about safe sex and higher rates of parent-adolescent activities, communication about sex, parent-family connectedness, and parental presence will not be associated with intention to participate in risky sexual behavior, or of sexual risk behavior including sexual activity concurrent with drug/alcohol use and lack of condom use.

2. What is the relationship between neighborhood stress, behavioral intentions, and risky sexual behavior among adolescents? When neighborhood stress is added to the model, do different attitude and parenting variables emerge as significant?

i. Hypothesis 2: High levels of neighborhood stress factors including disorder, exposure to violence, poverty, racial/ethnic diversity, and residential instability will be associated with lower rates of positive 
behavioral intentions and high rates of sexual risk behavior including sexual activity concurrent with drug/alcohol use and lack of condom use. Neighborhood stress will change the relationship between attitudes, parenting, behavioral intentions, and risky sexual behavior so that a different set of variables is most predictive of the outcomes.

ii. Null hypothesis 2: High levels of neighborhood stress factors, including disorder, exposure to violence, poverty, racial/ethnic diversity, and residential instability will not be related to rates of positive behavioral intentions and sexual risk behavior. Neighborhood stress will not change the relationship between attitudes, parenting, behavioral intentions, and risky sexual behavior.

\section{Delimitations}

The data used in the current study is from a parent study, referred hereafter as LEAP (Let's Educate Adolescents and Parents), which was conducted by the AIDS Prevention Program at Florida International University. The program compared a targeted HIV risk reduction intervention to a control condition and tracked the impact for one year post-intervention. However, because of the confounding effects of an intervention and control condition, the scope of the current study is limited to baseline data and does not include any follow-up time points. The advantages of using baseline data include a larger sample size and more complete data set. Though there are many disadvantages to using cross-sectional data, the complications and potential for errors with longitudinal data were enough to dissuade its use in this case. 


\section{Limitations}

Most of the limitations of the current study are due to boundaries established by the LEAP parent study that have a bearing on the database used for analysis. The study sample was limited to adolescents in Miami-Dade, Broward, and Palm Beach Counties, which make up a large part of the population of southeast Florida. Further, the sample was not randomly selected, but gathered through flyers and outreach at local community centers. As is the nature of nearly all behavioral research, the data gathered was from self-report of both recent (30 days) and not-so-recent ( 8 months) events. Self-report data is biased for a variety of reasons, including a social desirability bias when the adolescent wants the interviewer to think highly of them, and recall bias when the adolescent cannot perfectly remember their past behavior. The data collection for the parent study began as early as 2005 and was completed by 2008, so by the time that the current study was complete, nearly four years had elapsed.

Other inclusion and exclusion criteria for the parent study included: (1) Adolescent is willing to assent for participation in the study. (2) Adolescent is between 14 and 17 years of age. (3) Adolescent is available for full duration of the study (i.e. not in a juvenile detention facility or traveling). (4) Adolescent does not display any signs of psychosis, cognitive impairment, or that they might be a danger to themselves or others. (5) Adolescents must speak English. (6) Adolescents must have an identifiable parent or guardian that speaks Spanish or English. Finally, the end sample analysis was limited to participants that had completed the relevant measures in the questionnaire. 


\section{Assumptions}

The following three conditions are assumed: that participants could read and understand survey instruments, that participants responded honestly to all questions, and that participants' memory recall was accurate.

\section{Operational Definitions}

Many of the terms listed below will be further clarified in Chapters II and III, where they will be strictly defined by the literature base or by a particular scale.

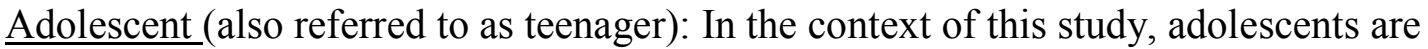
young women and men ages 13 to 18 .

Parent: Many participants had biological parents that participated in the study, and often this was the person that the adolescent referred to when responding to questions about parenting techniques, relationship, activities, or other feedback. However, "parent" could also refer to an adoptive parent, foster parent, aunt or uncle, grandparent, or another responsible friend or relative that the adolescent spends most of their time with. The Adolescent Health Questionnaire (Bearman, Jones, \& Udry, 1997) defines the relationship as such: "this section asks about your mother/father, or the woman/man who lives with you who functions as your mother/father." In most cases, there was no way of knowing the exact relationship between "parent" and child.

Sexual activity: Sexual activity refers to oral, anal, and vaginal penetration. The study also differentiates between lifetime activity, which is whether a person has ever had sex, and current activity, which is sex in the last 30 days. "Risky" sexual behavior refers to any sex act without a condom, sex under the influence of alcohol or drugs, sex with more 
than 4 partners in lifetime, and sex before age 13, for reasons that will be explored in more detail in the literature review.

Parent-child connectedness: Unlike the other parenting constructs that will be discussed throughout the study, parent-child connectedness is less frequently used in colloquial speech. Therefore, in order to clarify, parent-child connectedness is a conglomerate idea that incorporates closeness to mother and father, perceived caring of both parents, satisfaction with relationship, and feeling loved and wanted (Resnick, et al., 1997). Neighborhood disorder: Neighborhood disorder, also known as social disorder, refers to high rates of prostitution, gang violence, drug trafficking, and other disruptive influences in the neighborhood such as home foreclosures and other economic stress (Murry, Berkel, Gaylord-Harden, Copeland-Linder, \& Nation, 2011)

The next chapter will review past and current literature on the subjects relevant to the research questions discussed above, namely, neighborhood disorder, parenting, and sexual risk behavior. 


\section{CHAPTER II}

At the most recent American Public Health Association national conference, Pamela Hyde from SAMHSA singled out behavioral health as the number one public health challenge in the United States (Hyde, 2011). In order to prioritize research, funding, and public focus, the Centers for Disease Control and Prevention release a series of "leading health indicators" every 10 years. The leading health indicators for 2010 were physical activity, overweight/obesity, tobacco use, substance abuse, responsible sexual behavior, mental health, injury/violence, environmental quality, immunizations, and access to health care (CDC, 2011).

For the purpose of this dissertation study, responsible sexual behavior has been chosen as the primary outcome to be examined. Discussions about sexual behavior incite a visceral reaction from parents, teachers, and policy makers, who may feel a moral imperative to defend their position on sexual topics. In the media, sexual behavior is often portrayed in stark contrast: teens are either exposed to messages of abstinence or consequence-free sexual encounters. However, despite the dire picture painted by many politicians, there have actually been some positive trends in sexual behavior. The most recent National Vital Statistics Reports shows a marked decrease in the birth rate for American teens and women in their early 20s (U.S. Department of Health and Human Services, 2011). This trend does not mean that researchers should abandon sexual behavior as an important outcome; indeed, more research should be done to ensure that the trend continues in the right direction.

The following literature review will be organized into several sections that reflect the scope of the problem and exploration of the major research questions: epidemiology 
of adolescent risk behavior, parenting factors, neighborhood factors, individual factors and demographics. A thorough review of the literature has been conducted in each area and outcome trends that have been found in high-quality studies will be discussed. Some topics, including parent-adolescent communication about sex, have a huge literature base to draw from, while parent-child activity participation is sparsely discussed in the literature. For more information on the measures used to define each construct refer to Chapter III, Methods.

\section{Epidemiology of Adolescent Risk Behavior}

Nationwide. Adolescents comprise anywhere from $7 \%$ to $14 \%$ of the United States population. According to the most recent census figures, there are more than 20 million persons ages 10-14 and about 22 million ages 15-19 which amounts to more than 40 million persons during the 2010 census (U. S. Census Bureau, 2012). Behavior during adolescence has been shown to predict adult behavior (Burt, 2002). The importance of the adolescence time frame has even been recognized by the White House with the recent creation of the Office of Adolescent Health (U.S. Department of Health and Human Services, 2010). However, despite the size of this key demographic, no clear consensus exists on the definition of the life phase known as adolescence. Researchers and politicians have used markers such as the start and end of puberty, time spent in middle and high school, and years until the person moves away from the primary home as the boundaries of adolescence, but no consensus exists (Knopf, 2005). This dissension can make adolescents as a group particularly difficult to study as a single entity and is one of 
the main reasons that such a large research base is necessary. In the current study, adolescent participants ranged from ages 13 to 18 .

The Centers for Disease Control and Prevention has identified six risk behaviors that are tracked with the national Youth Risk Behavior Surveillance (YRBS) database: (1) unintentional injuries and violence; (2) tobacco use; (3) alcohol and other drug use; (4) sexual behaviors, specifically those that contribute to pregnancy and STIs; (5) unhealthy diet; and (6) physical inactivity (CDC, 2010a). Sexual behavior was chosen as the outcome of the current study not only because of the potentially serious consequences of unprotected sex, but also because sex is the one topic of the six that will be experienced by almost all persons at some point during adulthood. Further, the arrival of puberty and procession to sexual maturity is one of the hallmarks of adolescence by most definitions. Much research focus is placed on the risk-taking behavior related to sexual initiation and experimentation because adolescents have been shown to have a different profile of risk and vulnerability than adults (Millstein \& Halpern-Felsher, 2002). Laying the groundwork for safe sex at the time of first intercourse or first sexual contact (kissing, touching, and other pre-coital behaviors), can help establish a lifetime of safe activity.

Overall, $46 \%$ of high school students report having had sexual intercourse during their lifetime. Rates of sexual activity vary by gender, race, ethnicity and age, such that male students, students identifying themselves as black, students of Hispanic heritage, and older students $\left(12^{\text {th }}\right.$ grade vs. $9^{\text {th }}$ grade) were more likely to have had sex (CDC, 2010a). Though lifetime sexual activity is a valuable measure, current sexual activity (defined as sex during the past 30 days) may better reflect high-risk populations that will need education and reinforcement regarding consistent condom use, safe sex behavior 
negotiation, and risk awareness for pregnancy and STIs. According to the YRBS, about $34 \%$ of high school students in the United States report current sexual activity. When students enter high school ( $9^{\text {th }}$ grade), a little over one-fifth report being sexually active, but by the time they leave $\left(12^{\text {th }}\right.$ grade), almost $50 \%$ report current sexual activity (CDC, 2010a).

The YRBS measures several behaviors that protect against risky sexual behavior outcomes, including condom use, birth control use (pill or depo-provera), rates of drug and alcohol use prior to sex, and testing for STIs. Of high school students reporting current sexual activity, nearly $40 \%$ did not use a condom during their last sexual encounter (CDC, 2010a). The demographic characteristics of condom users appear to follow a slightly different pattern than that of lifetime or current sexual activity. Males are more likely to use condoms than females (68.6\% vs. $53.9 \%)$; condom use is higher among white $(63.3 \%)$ and black (63.2\%) than Hispanic students $(54.9 \%)$, and it is higher among $9^{\text {th }}$ grade $(64 \%)$ than $12^{\text {th }}$ grade students $(55 \%)$. More than $20 \%$ of the sexually active group also report drinking alcohol or using drugs before the last time they had sex, which could indicate impaired judgment at the time of intercourse. Finally, for all students surveyed nationally, only 12.7\% had been tested for HIV (CDC, 2010a).

Some groups of sexually active adolescents are at higher risk for negative outcomes, particularly adolescents that experience sex at younger ages and those with multiple sexual partners. These two groups are associated - studies have shown that adolescents that have sex before age 13 are likely to have more sexual partners throughout their adolescence and are more inconsistent about condom use (Hutchinson, 2002). Across the United States, 5.9\% of high school students report that their first sexual 
intercourse was prior to age 13 (CDC, 2010a). Groups most at risk for early sexual initiation fall along the same lines as intercourse: persons who identify as black, Hispanic, and male are more likely to have had sex before age 13 . In fact, $15.2 \%$ of African American students, $6.7 \%$ of Hispanic students, and 3.4\% of non-Hispanic white students report having sex before age 13 (CDC, 2010a). The potential impact of having multiple sexual partners can vary depending on the definition of "multiple," the time period over which data is collected, and whether a person is having sex with multiple people at the same time. The YRBS collects data on how many high school students had 4 or more partners during their lifetime. In the United States, $13.8 \%$ of high school students fit this criterion. Predictably, the rate increases as students age, such that $12^{\text {th }}$ graders are more than twice as likely to have had four or more partners $(20.9 \%)$ than $9^{\text {th }}$ graders $(8.8 \%)(\mathrm{CDC}, 2010 \mathrm{a})$.

Local epidemiology. In Florida, 37\% of high school students report current sexual activity, and $65.1 \%$ report condom use at most recent sexual encounter. These rates are comparable to the median rates in the rest of the country: nationwide, $34.2 \%$ and 61.1\%, respectively (CDC, 2010a). However, Miami-Dade County faces unique challenges as a hotspot for both people living with HIV/AIDS and new AIDS cases. In fact, of the metropolitan statistical areas (MSA) studied by the CDC Division of HIV/AIDS Prevention in 2008, the Miami MSA ranks \#1 in HIV (70.3 per 100,000) and AIDS (42.8 per 100,000) diagnoses for adults and adolescents (CDC, 2010b).

The Miami-Dade and Ft. Lauderdale metropolitan area was identified as one of 12 metropolitan areas in the United States carrying the highest burden of HIV and AIDS. Researchers found that the Miami area had the highest rates of HIV diagnosis (77.2 per 
100,000), new diagnoses among blacks/African Americas (197.8 per 100,000), and rates of diagnoses among Hispanics (54.9 per 100,000). In 2007, more than $1 \%$ of the population in the Miami area was living with HIV or AIDS, 1021.8 per 100,000. More than $20 \%$ of the people diagnosed with HIV in the Miami area were less than 30 years old (Hall, Espinoza, Benbow, \& Hu, 2010).

Mode of transmission can still vary greatly between urban regions. In the MiamiDade region in 2007, almost $70 \%$ of diagnoses were due to male-to-male sexual contact, a little over $20 \%$ was attributed to heterosexual contact, and about $5 \%$ was due to injection drug use (Hall, Espinoza, Benbow, \& Hu, 2010).

The CDC's most recent YRBS found that the rates of lifetime sexual activity for high school students were slightly above the national median (46\%) in Miami-Dade (53.4\%), Broward (52.2\%), and Palm Beach (54.7\%) Counties. The rates of high school students that have had sex for the first time prior to age 13 is also higher than the median (5.9\%) for local areas surveyed; Miami-Dade County it is $9.6 \%$, Broward County is $9.2 \%$ and Palm Beach County is 8.3\%. Miami-Dade and Broward Counties are also higher than Florida overall $(8.3 \%)$. Rates of students that had sex with four or more partners during their lifetime are higher in Broward County (19.8\%) and Palm Beach County (18.2\%) than in Miami-Dade (17.7\%), and all are higher than in the state of Florida (16.6\%) and the national median (13.8\%). Rates of current sexual activity follow the same trend: in Florida, $37 \%$ of high school students are sexually active, compared to $38.1 \%$ in MiamiDade, 38.4\% in Broward, and 38.3\% in Palm Beach reporting current sexual activity. Condom use among the sexually active students is lower in Miami-Dade County (63.9\%) 
when compared to Broward County (70.6\%) and Palm Beach County (68.2\%) (CDC, 2010a).

The racial and ethnic makeup of south Florida and the study sample lends itself to examination. In the Miami-Fort Lauderdale-Pompano Beach metropolitan area, as defined by the US Census, the population is $70.3 \%$ white, $21 \%$ black or African American, 2.3\% Asian, 0.3\% American Indian/Alaskan Native, 2.5\% two or more races, and $3.5 \%$ other races. Of any race, $41.6 \%$ are Hispanic or Latino, with most reporting Cuban descent (17.7\%), Puerto Rican (3.7\%), Mexican (2.4\%), and Hispanic/Latinos of other origins (17.8\%) (U.S. Census Bureau, 2010). African American adolescent females, especially those in a low income urban environment, are a particularly at-risk group that experience high rates of early sexual initiation, multiple partners, unprotected sex (Ramirez-Valles, Zimmerman, \& Newcomb, 1998; Miller, Benson, \& Galbraith, 2001), and HIV/AIDS (CDC, 2002). In 2007, the diagnosis rate for HIV was significantly higher for African Americans $(76.7$ per 100,000) than for whites $(9.2$ per 100,000) (CDC, 2007).

\section{Parenting Factors}

Research has found that contrary to popular beliefs, parents still hold significant influence over their adolescents. The Kaiser Family Foundation (1999) found that preadolescents prefer to receive information about sex from their parents. Indeed, more and more studies are confirming that in all arenas (not just sexual communication), parents exert significant influence over their adolescents (Hutchinson, 2002).

Though adolescence is traditionally seen as a difficult period for parents and children and their relationship, parents may retain more influence over their adolescent's 
behavior than they realize. Research has found that risk reduction interventions that incorporate parents can reduce risk behaviors (delinquency, drug-related behavior, and sexual promiscuity) more than an intervention with just the adolescents (Stanton et al., 2004). Analyses of other intervention programs have had similar results, finding that parent-involved interventions can result in significantly increased communication with the child about sex and birth control (Schuster et al., 2008).

Prior research has shown an array of factors associated with adolescent sexual health, including parental monitoring, communication, and parenting style (Huebner \& Howell, 2003). Determining the degree of parent influence, and leveraging this information to design programs to meet the challenges of parents and adolescents could lead to better outcomes. Some may argue that it is not worth committing funds to parent education programs, because such programs would not translate to outcomes among dysfunctional families. The most rational counterargument to this claim is that STIs and unplanned pregnancies are not confined to dysfunctional families (Jaccard, Dodge, \& Dittus, 2002). In order to create the most complete picture of parenting influences, parent-adolescent communication, parent-child connectedness, parental presence, and parent-child activity participation will be examined.

Communication. Research examining whether communication has an impact on sex behavior has found mixed and sometimes contradictory results. Early studies found that there was little correlation between communication and adolescent sex behavior (Jaccard \& Dittus, 1991). However, studies since then have found a positive impact (in that risky behavior was reduced) with increased parent communication (DiIorio, Kelley, \& Hockenberry-Eaton, 1999; Karofsky, Zeng, \& Kosorok, 2001). Some studies have 
even found that parent-adolescent communication increases the likelihood that the adolescent will have sex (Darling \& Hicks, 1982; Widmer, 1997). This could be because some parents wait until a trigger event such as their adolescent having sex to begin the discussion. It could also be due to the specific messaging of any given parent-adolescent dyad. One review addresses why the literature thus far has been so inconsistent by arguing that previous studies oversimplified parent-adolescent communication, without considering other important contextual and environmental factors (Jaccard, Dodge, \& Dittus, 2002). Other studies have found that certain types of communication about sex and birth control have a greater effect on adolescent sex behavior. Notably, parents that discussed sex in a more open and receptive manner had adolescents that displayed less sexual risk taking behavior (Kotchick, Dorsey, Miller, \& Forehand, 1999). For female children, open communication about sex and birth control is linked to more conservative sexual attitudes, and later age of initiation of sex (Hutchinson, 2002; DiIorio, Kelley, \& Hockenberry-Eaton, 1999). Sexual communication that focuses on sexual risk is also associated with later age of initiation, not to mention lower rates of overall sexual activity and more consistent use of condoms (DiIorio, Kelley, \& Hockenberry-Eaton, 1999; Whitaker \& Miller, 2000; Hutchinson, Jemmott, Jemmott, Braverman, \& Fong, 2003). As noted earlier, communication often changes as the adolescent's sexual experience changes, and studies have found that communication with sexually active teens is correlated with both condom use consistency and condom self-efficacy. Among sexually active females, communication with the parents is also correlated to communication with male partners (DiIorio, Kelley, \& Hockenberry-Eaton, 1999; Whitaker \& Miller, 2000). African American female and male college students who reported high levels of parent 
communication about sex were less likely to have had current sexual activity than their counterparts who reported lower levels of communication (Hutchinson \& Montgomery, 2007). Perhaps most importantly, in that same sample, female students reporting high levels of communication were more than $60 \%$ less likely to report having ever been pregnant than those reporting less communication (Hutchinson \& Montgomery, 2007).

Connectedness. Parent-child connectedness is also referred to (either in the literature base or in common terminology) as closeness, warmth, support, or responsiveness (Markham, Tortolero, Escobar-Chaves, Parcel, Harrist, \& Addy, 2003). By adjusting the traditional psychological definition of connectedness to refer specifically to parents and adolescents, for the current study parent-child connectedness refers to when a parent is actively involved with their adolescent such that the involvement results in comfort, well-being, and anxiety-reduction for both parties (Hagerty, Lynch-Sauer, Patusky, \& Bouwsema, 1993). In an outcome paper analyzing the results of the National Longitudinal Study on Adolescent Health, parent-family connectedness was the only family factor that reliably accounted for variability in emotional distress among $7^{\text {th }}$ and $8^{\text {th }}$ graders (Resnick et al., 1997).

Unlike studies on communication, research on connectedness is fairly consistent: a close relationship is associated with positive sexual behavior including abstinence, reductions in unplanned pregnancy, contraceptive use (Miller, 2002), postponement of first intercourse, and fewer sexual partners (Resnick et al., 1997). Farahani et al. (2011) found that parent-child closeness was highly related to premarital sexual activity among a group of female Iranian college students. Resnick et al. found that low levels of connectedness are associated with early onset of sexual activity (1997). Women who 
reported a very close relationship with their parents were much less likely to have had a boyfriend or have had sex. Even when controlling for age and family measures, parentchild closeness was correlated with premarital relationships such that participants reporting a close relationship were less likely to have had a boyfriend (Farahani, Cleland, \& Mehryar, 2011). Markham et al. (2003) found that among adolescents attending alternative high schools, higher scores on parent-child connectedness measures were associated with fewer reports of ever having sex, current sexual activity, and pregnancy. This is particularly notable because teens in alternative high schools are generally in a more high-risk group due to delinquency. The same study found gender differences in outcomes: for females, connectedness was associated with fewer participants reporting early age of sexual initiation and lifetime sexual activity; for males, connectedness was associated with lower rates of fathering a child (Markham, Tortolero, Escobar-Chaves, Parcel, Harrist, \& Addy, 2003).

Some researchers suggest that parent-child closeness and connectedness may act as a conduit for other parent-child relationship factors that can moderate adolescent sexual activity, namely parent-adolescent communication. For example, a close relationship between a mother and child may encourage the type of open, honest communication about sex that will make a lasting impact on an adolescent (Farahani, Cleland, \& Mehryar, 2011). Hutchinson and Montgomery found that for male and female college students, the degree of closeness between them and their parents during middle and high school was associated with higher levels of communication about sexual health (2007). If adolescents report high levels of satisfaction with their relationship with their parents, they are more likely to have positive communication behavior (Jaccard, Dittus, 
\& Gordon, 2000). This pattern was found to hold true more so with male adolescents than with female adolescents, perhaps because female adolescents perceive more disapproval than male adolescents (Frankel, Bryant, Jean-Gilles, Rosenberg, Devieux, \& Malow, 2011). Further, some truths about parenting and parent-child relationships simply lend themselves to less communication regarding issues such as sexual activity that might require listening, understanding, and sensitivity. Studies have found that when parents openly and willingly discuss sexual issues with their children, it has a positive effect throughout the children's lives in terms of confidence and competence (Stone \& Ingham, 2002).

Other studies found that peer influence can increase when the parent-child relationship is less close (Whitbeck, Conger, \& Kao, 1993). Stattin and Kerr (2000) argue that voluntary disclosure of information from adolescent to parent is more important than direct parental control. Therefore, parent-child connectedness may be the mechanism that explains whether communication between parent and adolescent actually impacts risk behavior. Other studies have found that when there is less closeness between parent and child, negative influences from peers are able to make more of an impact (Feldman \& Brown, 1993).

Parental presence. The concept that will be referred to as parental presence in this study measures whether a parent is home with the child at various times in the day. Though it is not a perfect match, parental presence is the closest concept in the current study to parent monitoring, another parent factor that is often studied in regards to adolescents. Parent monitoring becomes especially important as parents start to give their older children more freedom and learn to navigate the desired freedoms of the child. 
Parent monitoring is much more commonly used than parental presence, but it is important to keep in mind that these two concepts do have inherent differences. Monitoring may refer to parental presence as well as creation of rules, control of adolescent activities, and supervision (Meschke, Bartholomae, \& Zentall, 2002), while presence only refers to the parent being home with the child at certain times of the day. Further, some studies define parental monitoring as both supervision of the child (which equates to presence to some degree) and communication with the child (DeVore \& Ginsburg, 2005; Li, Stanton, \& Feigelman, 2000). To make matters more complicated, some studies use the terms "supervision" and "monitoring" interchangeably (Miller, 2002). For the sake of clarity, this literature review will separate parental monitoring from any references to supervision or parental presence.

Studies have found parent monitoring and adolescent sexual activity to have a complex relationship. Low levels of parent monitoring are associated with a variety of risky behaviors, including unprotected sex, drug use, and drug trafficking (Li, Stanton, \& Feigelman, 2000). Parental monitoring has also been shown to correlate to resilience among youths living in poverty, which can lead to more positive outcomes later in life (Buckner, Mezzacappa, \& Beardslee, 2003). One study asked adolescent girls whether during their first sexual experience they were "too young," "too old," or "just right," and found that higher levels of monitoring were associated with girls reporting that the timing was “just right” (Cotton, Mills, Succop, Biro, \& Rosenthal, 2004). Further, when parents score low on a monitoring scale (they monitored their children less), reports of adolescent drug and alcohol use had lower congruence between parent and child (McGillicuddy, 
Rcyhtarik, Morsheimer, \& Burke-Storer, 2007). Essentially, if the parent was less watchful of the child, they knew less about what the child was doing.

Despite all of the positive evidence, it appears as though there is a control and supervision tipping point whereby very low monitoring allows too much freedom to explore sexually and very high monitoring allows too little freedom and causes adolescents to lash out with risky behavior (Miller, McCoy, Olson, \& Wallace, 1986). Studies suggest that key determinants in whether monitoring has gone too far are if it is deemed to be excessive, coercive (Gray \& Steinberg, 1999), intrusive (Dorius \& Barber, 1998), or controlling (Rodgers, 1999).

As noted earlier, the construct known as parental monitoring is generally understood to encompass both supervision and communication. However, the current study will only be examining parental presence as defined by the National Longitudinal Study of Adolescent Health. As such, Resnick et al. (1997) found that presence of the parents was linked to lower rates of adolescent pregnancy, as well as other risky behaviors including drug, alcohol, and tobacco use and emotional distress. In general, researchers agree that when adolescents have less supervision, more sexual activity results (Cohen, Farley, Taylor, Martin, \& Schuster, 2002).

Part of the mechanism of decreased risk behavior due to parental monitoring could be through reduced time with peers. If a parent is spending a large amount of time out of school with the child, they will have less exposure to high-risk peers (Miller, 2002).

Activities. The last element of parental involvement, parent-child activity participation, is both the easiest to define and the most difficult to correlate in the 
literature base. In the current study, this concept refers specifically to whether each parent and adolescent participate together in a series of 10 activities: (1) Going shopping, (2) Playing a sport, (3) Going to a religious service, (4) Talking about topics such as dating or parties, (5) Going to a movie, play, museum, concert, or sporting event, (6) Talking about personal problems, (7) Having a serious argument about behavior, (8) Talking about school work or grades, (9) Working on projects for school, and (10) Talking about other things the child is doing in school. Clearly, these "activities" are not exclusively conducted outside of the home, nor are they all necessarily positive interactions (such as having an argument). Several of them appear to overlap with other constructs being examined: "talking about topics such as dating" could fall under sexual risk communication, and several of the other "talking" activities will presumably contribute to increased parent-child connectedness. In their analysis of outcomes from the National Longitudinal Study of Adolescent Health, Resnick et al. (1997) found that shared activities with parents were moderately protective against emotional distress among adolescents. Participation in activities with the parent could be beneficial to the adolescent through two mechanisms: there could be a benefit to the extracurricular activity itself and/or there could be a benefit to connecting with the parent during an activity, leading to a closer relationship. Both of these possibilities will be addressed below.

Extracurricular activities cover a wide variety of non-school related events that can be completed with a group of other adolescents or by an individual, including playing computer games, walking, hiking, bowling, reading, listening to music, going to parties, and more (Trainor, Delfabbro, Anderson, \& Winefield, 2010). Extracurricular activities 
may also refer to school-sponsored activities such as sports, clubs, or community service groups (Zaff, Moore, Papillo, \& Williams, 2003). Studies have found that extracurricular activity participation is associated with high educational status, competence (Mahoney, Cairns, \& Farmer, 2003), psychological well-being, and better overall life outcomes (Bartko \& Eccles, 2003). Extracurricular activity participation also appears to ameliorate the effects of stress for some adolescents (Trenberth \& Dewe, 2002).

Further, youths that report spending most of their free time "doing nothing in particular" have lower scores on self-esteem and life satisfaction measurements (Trainor, Delfabbro, Anderson, \& Winefield, 2010). Adolescents that are not involved in extracurricular activities also appear to have higher rates of antisocial behaviors and sexual risk behaviors (Eccles \& Barber, 1999; Mahoney \& Cairns, 1997).

There could also be a reciprocal relationship between parent-child activities and a healthy relationship. Researchers propose two theories. Extracurricular activity participation could positively impact adolescents such that they are less inclined towards risky behavior. Conversely, adolescents that are more likely to participate in extracurricular activities could be happier, more engaged in school, more social, respond better to adult leaders, and simply less inclined towards risky behavior (Trainor, Delfabbro, Anderson, \& Winefield, 2010).

\section{Neighborhood Factors}

In order to determine who is at the highest risk for negative outcomes associated with unsafe sex, it is worth examining contextual factors that high risk groups share. Researchers have found correlations between incidence of HIV/AIDS and multiple 
neighborhood characteristics, including income, education, mortality, infant mortality, and rates of other STIs (Peterman, Lindsey, \& Selik, 2005). For example, in counties where incidence of AIDS increased the most, researchers found a higher proportion of low-income households, single mother households, low literacy levels, more residents with less than a $9^{\text {th }}$ grade education, and higher income inequality. In general terms, neighborhoods with high rates of crime, poverty, and a lack of resources often have residents that are at a higher risk for negative health outcomes (Sampson, Morenoff, \& Gannon-Rowley, 2002).

Researchers have long suspected the connection between neighborhood factors and behavior. Data at the neighborhood level has been historically unreliable or not readily available, contained too many confounders to parse out which issues mattered most, or it was simply easier to study and address individual and interpersonal influences on behavior (Sampson, Morenoff, \& Gannon-Rowley, 2002). One of the challenges in studying neighborhood factors is the difficulty in defining specific geographic boundaries for a neighborhood. For example, neighborhood boundaries may vary wildly depending on whether they are being drawn by United States Census Tracts, ZIP (Zone Improvement Plan) codes, or by the residents themselves.

Traditionally, a neighborhood has been defined as a community made up of people and institutions in a geographically limited area that share some degree of ecological, political, cultural, or social norms (Park, 1916), and is defined as such by either the residents within or by outside forces (Suttles, 1972). Keeping this definition in mind while analyzing the current study will be important, as it was one of the most fundamental challenges in choosing the method of study. One of the key instruments, the 
City Stress Inventory, was organized by ZIP Code ${ }^{\mathrm{TM}}$. ZIP Codes represent geographic boundaries established by the United States Postal Service serving primarily to organize mail delivery locations. ZIP Codes rarely represent the natural boundaries of a neighborhood, and they also do not always align with census tracts or other important neighborhood measures such as crime data.

Neighborhood stresses do not exist in a vacuum; that is to say, people living in the neighborhood rarely experience violence, gang activity, or any of the other elements of social unrest without other factors such as poverty and socioeconomic challenges. Disadvantaged neighborhoods are associated with myriad negative outcomes for adolescents, including but not limited to teenage pregnancy, school troubles including dropping out, violence to the child or violence by the child (Brooks-Gunn, Duncan, \& Aber, 1997). The direct effects of neighborhood poverty include early sexual initiation and high rates of teenage pregnancy (Browning, Burrington, Leventhal, \& Brooks-Gunn, 2008; Driscoll, Sugland, Manlove, \& Papillo, 2005). Low socioeconomic status has been consistently associated with increased risk of teen pregnancy (Brooks-Gunn, Duncan, Klebanov, \& Sealand, 1993) and for adolescent males increased poverty is associated with frequency of intercourse, lack of contraceptive use, and, predictably, higher chances of impregnating someone (Ku, Sonenstein, \& Pleck, 1993). Unemployment rates in the neighborhood, another common indicator for neighborhood disorder, have been found to be associated with high levels of impregnating someone and fathering a child among adolescent males (Ku, Sonenstein, \& Pleck, 1993), and high rates of childbirth outside of marriage for female adolescents (Billy \& Moore, 1992). Conversely, female adolescents that participate in the labor force seem to have more positive behavioral outcomes (Billy, 
Brewster, \& Grady, 1994), but authors hypothesize that this could be due to increased monitoring, not increased socioeconomic status (Leventhal \& Brooks-Gunn, 2000).

Studies have also found that economic problems associated with neighborhood disorder can have an indirect effect on adolescent sexual risk behavior. For example, connections have been found between high rates of unemployment, dropping out of school, and becoming a single parent (Ramirez-Valles, Zimmerman, \& Juarez, 2002). Single parenting, in particular, can be a risk factor all its own: adolescents living with a single parent are more likely to have had sex, and to have had sex for the first time before age 13 (Miller, Benson, \& Galbraith, 2001). Further, high marks in school suggest protection against unplanned pregnancy as they are associated with a reduced chance of giving birth among adolescent girls (Driscoll, Sugland, Manlove, \& Papillo, 2005).

Neighborhood stresses must be considered in tandem with parenting and/or family factors, because one cannot ignore the element of familial choice of neighborhood (to the degree that there is a choice, and the family is not wholly limited by financial or other reasons). To disregard the connection between neighborhood and parenting would represent an incomplete analysis (Buu, DiPiazza, Wang, Puttler, Fitzgerald, \& Zucker, 2009). Further, most researchers agree that neighborhood influences are more likely to be indirect than direct, such that limited resources, reduced monitoring, unsafe conditions, and other elements of impoverished neighborhoods place adolescents at higher risk for poor health outcomes (Leventhal \& Brooks-Gunn, 2000).

Parent characteristics that have been found to mediate the effect of neighborhood factors on children include mental health, parental irritability, physical health, coping ability, and efficacy as a parent (Leventhal \& Brooks-Gunn, 2000). Relationship factors 
that are associated with neighborhood stress include responsivity/warmth and harshness/control (Leventhal \& Brooks-Gunn, 2000). In the current study, these measures will be addressed, however imperfectly, with the composites of parental presence (proxy for control), parent-child connectedness (warmth), and parent-child activities. Neighborhood poverty and stress has been associated with lower maternal warmth (Klebanov, Brooks-Gunn, \& Duncan, 1994) and harsher parenting practices (Earls, McGuire, \& Shay, 1994). Various studies have also found that parental monitoring is usually higher in risky neighborhoods, and as noted earlier, monitoring is, in turn, associated with sexual risk behavior (Leventhal \& Brooks-Gunn, 2000). Studies have found that in neighborhoods with high levels of poverty, parental monitoring can decrease the risk of early sexual activity (Roche \& Leventhal, 2009). The neighborhoodmonitoring link is not entirely clear, because higher rates of monitoring generally mean less risk behavior but high-risk neighborhoods are linked to high rates of monitoring and sexual risk.

Parent supervision, support, and engagement with youths (which correlates imperfectly with the measure of parent-child activities) have all been found to mediate the behavioral health outcomes of exposure to violence (Burton \& Jarrett, 2000). Maternal closeness and time spent with family have also been found to be protective against the effects of community violence, specifically on levels of anxiety and depression (Hammack, Richards, Luo, Edlynn, \& Roy, 2004). However, the same study found that the protective effect of social support became less impactful as the levels of violence in the community increased. Time with family appears to be particularly protective against anxiety in female adolescents (Hammack, Richards, Luo, Edlynn, \& 
Roy, 2004), perhaps partially because time spent with family rarely overlaps with time that adolescents can be out in the neighborhood, potentially exposed to community violence. Like time with family, parental monitoring has also been shown to buffer the effects of witnessing violence, such that rates of tobacco and alcohol use are lower for adolescents with higher levels of parent monitoring. Other family elements, including general positive relationships, are associated with lowers levels of violence among adolescents (Blum \& Rinehart, 1997).

High levels of cohesion (another term for family connectedness or closeness) can provide protection from the impact of community violence (Kliewer, Sandler, \& Wolchik, 1994), whereas low levels of family cohesion is associated with anxiety and depression in adolescents who have experienced violence (Gorman-Smith \& Tolan, 1998). Hammack et al. (2004) theorize that this relationship exists because if youths have a caregiver that they trust and rely on, during times of stress they have a source of emotional support. Parental support has also been identified as a protective influence from exposure to violence (Fergus \& Zimmerman, 2005). However, this protective ability appears to become less influential over time (O'Donnell, et al., 2002). Other protective factors for children that had witnessed community violence include maternal closeness, time spent with family, and social support (Hammack, Richards, Luo, Edlynn, \& Roy, 2004).

\section{Individual Behavior Factors}

Predictably, studies on attitudes find that more positive attitudes towards a behavior, whether it be initiation of intercourse or delay of initiation, typically predict the 
behavior. For example, teens that have more positive attitudes about delaying intercourse will typically have a later age of onset of intercourse (Carvajal et al., 1999) and attitudes about condom use are correlated to intention to use condoms (Jemmott et al., 2007). A recent study found that among African American adolescents ages 11-19, negative attitudes towards condoms were correlated with low condom use at three-month followup (Lee, Lewis, \& Kirk, 2011). Researchers hypothesize that sexual attitudes and sexual behavior can affect each other; an adolescent with more sexual experience may have more permissive sexual attitudes and vice versa (Ott, Pfeiffer, \& Fortenberry, 2006).

Some research suggests that the relationship between attitudes and behavior may not be as clear-cut as it appears. For example, a meta-analysis of gender differences in sexuality found that men consistently report more permissive attitudes towards casual sex than women did (Petersen \& Hyde, 2010). But when behavior is examined, the link becomes less straightforward: women have more positive attitudes about condom use but are not more likely to use condoms (Kegeles, Adler, \& Irwin, 1988). This could be linked to perceived behavioral control in that a woman only has so much control over whether her partner uses a condom. Another recent study found that women's attitudes about condoms are more likely to be associated with consistent condom use than men's condom attitudes (Abraham, Sheeran, \& Henderson, 2011). A qualitative study of AsianAmerican Pacific Islanders found that some women that were categorized as high risk due to drug use, risky sexual behavior, and mental health issues reported low gender power, where their partners determined whether they would use condoms or not (Hahm, Lee, Choe, Ward, \& Lundgren, 2011). Sexual and condom attitudes appear to be closely linked to peer norms: adolescents that did not believe that their friends had positive 
attitudes about intercourse were less likely to have had sex (DiIorio, Dudley, Kelly, Soet, Mbwara, \& Sharpe Potter, 2001). Finally, studies have found that attitudes are not necessarily associated with behavior. For example, a 2009 study of young (18-26 years old) Latino gang members found that condom attitudes were not correlated with unprotected vaginal intercourse (Brooks, Lee, Stover, \& Barkley, 2009).

Attitudes about sex have also been linked to parenting practices. In a study of high-risk Hispanic youths, family functioning was found to moderate sexual intentions and behavior through condom use attitudes (Malcolm et al., 2012). Researchers suggest that adolescents absorb parental attitudes about sex through social learning; if parents foster an environment with conservative attitudes, adolescents may adopt those attitudes as their own (Longmore, Eng, Giordano, \& Manning, 2009).

\section{Demographic Factors}

Gender. Differences have been found in parent-child communication, connectedness, presence, and activities depending on the gender of both the child and the parent. Researchers fear that gender differences may reinforce gender-based social stereotypes, namely those that approve of men having casual sexual encounters while women are vilified or ostracized for the same behavior (Miller, Kotchick, Dorsey, Forehand, \& Ham, 1998).

Overall, studies find that both male and female adolescents report talking about a variety of sexual topics more frequently with their mothers than their fathers (Miller, Kotchick, Dorsey, Forehand, \& Ham, 1998). This assertion holds up with African American, Hispanic (Miller, Kotchick, Dorsey, Forehand, \& Ham, 1998), and Caucasian 
families (Nolin \& Petersen, 1992). Researchers theorize that mothers carry the burden of sexual health communication for several reasons: mothers are better at communicating, mothers are generally associated with intimacy, and the topic is "safer" for mothers to talk about than fathers (Kirkman, Rosenthal, \& Feldman, 2002). Adolescents also tend to report that mothers are better sex educators than fathers (Feldman \& Rosenthal, 2000), though this could be a product of the increased number of conversations with their mothers.

The general consensus in the literature base is that female children are more likely to be the recipients of discussions about sex than male children, and the sex discussions are more extensive for females (Jaccard \& Dittus, 1991; Raffaelli, Bogenschneider, \& Flood, 1998). Researchers theorize that communication is focused on girls because girls bear most of the responsibility for sexual consequences, including unplanned pregnancy and sexually transmitted diseases (O'Sullivan, Jaramillo, Moreau, \& Meyer-Bahlburg, 1999; Pistella \& Bonati, 1998). Hutchinson and Montgomery (2007) found that among African American college students (mean age 18), girls report more communication with their mothers while male adolescents report more communication with their fathers.

Unlike communication, the joint construct of parental monitoring does not appear to differ along gender lines (DeVore \& Ginsburg, 2005). Some research suggests that mothers may know more than fathers about daily activities of their adolescent, and that high knowledge of activities is associated with lower risk behavior (Stattin \& Kerr, 2000). However, the construct used in the current study, parental presence, does not equate to simple knowledge of activity but rather whether the parent is with the child during various times of the day. 
Age. Sexual risk communication varies in frequency and content depending on the age of the child. A study by Miller et al. chose to examine barriers to communication in preadolescents (9-12 years old) based on the finding that sexual activity increases with age, and characterized of early sexual initiation as sex prior to age 13 (Miller, Fasula, Dittus, Wiegand, Wyckoff, \& McNair, 2009). The authors found that the mother's responsiveness (i.e. the mother's comfort and ease at discussing sex) was positively correlated with the number of topics addressed with their preadolescents. Mothers in the study were also more likely to communicate with their daughters and with their children if they seemed to be further along in puberty. Jaccard, Dittus, and Gordon (2000) found that most mothers report 10-years-old as the appropriate time to start discussing sex with their children, though they may not actually initiate conversation at this age. When parents begin addressing these issues with their offspring is also related to the frequency of talks throughout adolescence. There is a misperception among parents that one "big talk" prior to or early in adolescence is enough to cover all that adolescents might need to know (Jaccard, Dodge, \& Dittus, 2002).

One study examining how maternal embarrassment affects sexual communication found that the impact decreased as the child got older, perhaps because of either increasing comfort with repeated conversations, or an increasing sense of age appropriateness. Conversely, the study found that as age of the child increased, the mother's fear that she would not be taken seriously during discussions had more of an impact on communication (Jaccard, Dittus, \& Gordon, 2000).

It is to be expected that parental supervision decreases with age, and established earlier, sexual activity increases with age. In their four-year study of parental monitoring 
and risk behavior among African-American youths, Li, Stanton, and Feigelman (2000) found that despite general increases in risky behavior with age, the positive effects of parent supervision persisted. One study described the increase in risky behavior as the "rapid increase in sexual activity of mid-adolescence" (DeVore \& Ginsburg, 2005), and research has shown that monitoring can provide a buffer against this increase (Rai, et al., 2003; Huebner \& Howell, 2003).

Family structure. Family structure in the current study refers to the living situation of the adolescent for the previous year: with both natural parents, with a single parent, with a step-parent, other relatives, or other living situations such as a group home. A review of adolescent sexual behavior correlates found that living with a single parent or in a blended family can increase the risk that an adolescent will have sex at an earlier age (Zimmer-Gembeck \& Helfand, 2008). The impact of family structure appears to vary by gender. For example, being in a household with a single mother places girls at higher risk for having sex. For boys, any disruption of a two-parent household is linked to increased sexual behavior (Newcomer \& Udry, 1987). Girls living in single parent families also fall into a higher risk category for pre-sexual behavior including kissing and touching (Hipwell, Stepp, Keenan, Chung, \& Loeber, 2011). Living with a single parent is also associated with a higher risk for adolescent pregnancy (Miller, 2002).

The links between living with a single parent and sexual behavior outcomes, however, are complicated by other related variables. A single parent may not have as much time or energy to devote to monitoring their child, communicating with their child, or participating in activities in and out of school. Further, single parents households are 
more prevalent among racial and ethnic minorities and in areas with high levels of poverty (McLanahan, 2009).

Race/ethnicity. Race and ethnicity will be included in the current study for several reasons. First, whether due to socioeconomic disparities, cultural differences, or lack of opportunity, rates of STIs and unintended pregnancies (arguably the two most impactful outcomes of risky sexual behavior) differ along racial lines. In a perfect world, every school classroom, community center group, or other gathering where sexual health education could be taught would be a representative microcosm of all races, ethnicities, income levels, and genders. This is not the case in many neighborhoods, especially those which remain segregated. Establishing whether differences in race and ethnicity are seen among the predictors and outcome behaviors in this study is a worthwhile exercise. Second, problems abound in terms of the literature addressing racial and ethnic differences: early studies do not often distinguish between black and white Hispanic or use African-American as a catch-all for black participants. Some studies refer to Latino Americans instead of black or white Hispanics, and some use European Americans in place of white Caucasians. Further, researchers have posited that negative health outcomes associated with a particular race or ethnicity are due not to inherent characteristics at all, but rather to a higher risk of growing up in an impoverished household (Murry, Berkel, Gaylord-Harden, Copeland-Linder, \& Nation, 2011). Parenting styles also vary by race and ethnicity, though researchers agree that these differences may not hold up when overarching factors like socioeconomic status are controlled (Brooks, 1991). Examining racial and ethnic differences through the lens of neighborhood characteristics will add to the literature on this topic. 
In general, researchers agree that the parenting styles of different ethnicities are more alike than they are different. Further, the individualized nature of parenting makes it likely that there are more differences between parents within an ethnic group than between two ethnicities (Julian, McKenry, \& McKelvey, 1994). Studies have found that communication frequency, content, and other patterns can vary by race, ethnicity, or cultural background. For example, African American men report the most parent-son communication, followed by Caucasian adolescents, with Asian male adolescents reporting the least amount of communication about sex (Epstein \& Ward, 2008). Beyond the simple amount of communication about sex, the study found several differences in themes discussed by parents of differences races/ethnicities. The authors ultimately determined that there were more similarities than differences in patterns and themes of discussions (Epstein \& Ward, 2008). As noted above, some studies addressing racial and ethnic differences do not differentiate appropriately between race and ethnicity or offer no information as to the regional origin of the Hispanic families and their racial composure (i.e. whether they considered themselves white Hispanic or black Hispanic). This lack of differentiation can cause confusing results. For example, one study found similar likelihood of sexual communication in Hispanic and African American families, which the authors found surprising considering previous racial/ethnic findings in parenting culture (Forehand \& Kotchick, 1996).

South Florida is a racially diverse region. Because of this diversity, and because from previous experience it is likely that major percentages of the study sample will be of Haitian, Caribbean, and Cuban descent, it is worth examining any potential cultural differences in parenting in these regions. DeSantis and Thomas studied the differences 
between sexual communication in families of Cuban and Haitian heritage, and though the study is more than 20 years old, some of the information gleaned is still relevant. Like many other adolescents, most female Cuban adolescents learn about menstruation and intercourse from either parent-child discussions or at school (DeSantis \& Thomas, 1987). Haitian adolescents tend to learn about menstruation later than Cuban adolescents (13 vs. 10 years old, respectively). Information for Haitian adolescents tends to center on the dangers of menstruation and eventual intercourse, whereas with Cuban families, these processes were described as a part of normal development. Haitian adolescents were also less likely to have discussed intercourse, and half of mothers interviewed did not know where their children learned about intercourse (DeSantis \& Thomas, 1987). The authors theorize that some of these differences are due to health care systems (universal medical care in Cuba vs. traditional medicine in Haiti) and lack of maternal education (median 12 years in Cuba vs. 5 years in Haiti). This type of information is perhaps most useful when considering how to tailor an intervention for a south Floridian population.

A review of parent-child connectedness found that high levels of connectedness meant decreased risk of pregnancy across all races and ethnicities studied (Miller, 1998). Among African-American adolescents, researchers have found that adolescents who report satisfaction in their relationships with their mothers are less likely to initiate sex early and overall less likely to be sexually active (Jaccard, Dittus, \& Gordon, 1998). A study of adolescent health in Caribbean countries found that high levels of connectedness are linked to better ratings of one's health status, protective against suicide attempts and violence, and delay of sexual intercourse for teenagers younger than 16 (Blum, Halcón, Beuhring, Pate, Campell-Forrester, \& Venema, 2003). 
A literature review of parental control (demands and restrictions that parents place on children), found levels of parental monitoring were higher among Latino families than European or Asian American families (Halgunseth, Ispa, \& Rudy, 2006). However, the amount of diversity among Latin groups further complicated the picture of parenting in the review. For example, Cuban American college students reported that their mothers were more protective than college students of Colombian, Venezuelan, or European descent (Escovar \& Escovar, 1985). One study theorized that among Dominican and Puerto Rican families, the tenets of Latino parenting create an environment of close monitoring and a warm, supportive relationship (Guilamo-Ramos, Dittus, Jaccard, Johansson, Bouris, \& Acosta, 2007). A study of parenting styles among African American adolescents living in poverty found poor outcomes associated with disengaged parenting. Specifically, adolescents reporting the lowest levels of warmth, supervision, and monitoring were at the highest risk for delinquency and unsafe sexual behavior (Pittman \& Chase-Lansdale, 2001).

No direct studies of cultural differences in activity participation have been conducted, but one study of the differences between Caucasian, African American, Hispanic, and Asian American parenting found high levels of involvement among fathers in Hispanic and African American families (Julian, McKenry, \& McKelvey, 1994). Fathers that are very involved in their children's lives are more likely to have high levels of the target variables (parental presence and parent-child activity participation.)

Though it is commonly used as a way to define the neighborhood, racial and ethnic diversity has not consistently been found to be predictive of sex behavior. However, racial, ethnic, and gender differences in impact of neighborhood influence 
certainly exist. For example, Crane found that African American females may feel more of the impact of neighborhood effects (Crane, 1991). Further, among African American adolescents living in low-income neighborhoods, a sense of hopelessness is associated with a higher likelihood of current sexual activity, pregnancy, or active attempts to get pregnant (Bolland, 2003). Counties in the United States with the highest incidence of AIDS also have a higher proportion of African American residents (Peterman, Lindsey, \& Selik, 2005). Rates of violent crime are highest in neighborhoods with large minority populations, but researchers theorize that many factors other than race and ethnicity are responsible for this disparity, including socioeconomic status of residents and differential treatment of these residents by police and local judicial systems (Sampson, Morenoff, \& Raudenbush, 2005).

In this study, sexual activity will be examined in conjunction with neighborhood risk, parenting practices, and the demographic factors discussed above. The next chapter will examine how the measures, scales, and instruments used in this study fit into the conceptual model chosen for analysis. 


\section{CHAPTER III}

\section{Purpose of the Study}

The current study is a cross-sectional examination of data collected during an HIV risk reduction intervention in Miami-Dade, Broward, and Palm Beach Counties, Florida. The purpose of the study is to explore the relationships between neighborhood stress, parenting, attitudes, and adolescent sexual behavior. Specifically, the study seeks to examine how parenting skills, including good communication, high levels of involvement and monitoring, and a close caring relationship, and adolescents' attitudes about sex and condoms impacts their intentions and their behavior. The outcomes being investigated are sexual behavior intentions and risky sexual behaviors such as unprotected sex and sex concurrent with drug and alcohol use.

Beyond this basic purpose, several other elements will be incorporated in order to address potential confounders or covariates. Demographic characteristics to be considered include gender, age, race/ethnicity, and family structure. Because the neighborhood disorder and exposure to violence scales measure only a participant's perception and experience of neighborhood problems, the following data will be examined: median household income, racial/ethnic diversity, and number of preforeclosures/number of bank-owned properties in the neighborhood.

\section{Study Participants}

The parent study from which data was analyzed was an NIH-funded communitybased intervention in Miami-Dade, Broward, and Palm Beach Counties, Florida. The parent study was approved by the Florida International University Internal Review Board 
(IRB) with approval number 042503-04. A total of 204 adolescents and 110 parents/guardians were recruited from Youth-Serving Organizations (YSO) via flyers, outreach by YSO employees and direct contact with study recruiters. Only adolescent data was examined, totaling 204 participants. Of the 204 participants, $47.1 \%$ were African American, non-Hispanic; 18.6\% Haitian; 7.8\% other races; $6.4 \%$ Hispanic (of Cuban descent); 4.4\% Hispanic (of Puerto Rican descent); 2.4\% Caribbean, non-Haitian; $0.5 \%$ White, non-Hispanic. Data on race and ethnicity was missing for $11.8 \%$ of the sample. Inclusion criteria included age (13-18), availability for the full duration of the study with no anticipated circumstances impeding study participation, and English fluency, though Spanish-speaking assessors were hired to mitigate language barriers. Adolescents in court-mandated treatment programs for substance abuse or delinquency were excluded, as were adolescents displaying psychotic symptoms, cognitive impairment, or harmful behavior towards themselves or others.

For the current study, no additional recruitment was conducted, and there were no direct risks or benefits to participants that had been enrolled in the parent study. Approval for secondary data analysis was obtained via expedited review by the FIU IRB. The current IRB approval number is $031411-00$.

\section{Procedures}

As noted above, the data utilized in the current study was collected during the LEAP project. Data collection in the field was done with paper and pen, but all instruments were re-created on the computer using Questionnaire Development System (QDS) for data entry. Though using QDS was more time-consuming than imputing data 
directly into a statistical software program such as SPSS, it had several advantages. It was easier and more reliable than the table format of data entry in SPSS, because QDS prompts the data entry person with each question which can then be double-checked against the paper questionnaire. QDS also has an internal quality assurance function: after all questionnaires have been entered, a second person must re-enter the data in order to assure that all responses are accurate. If a response does not match the previously entered one, an error message appears that will prompt the person to carefully check the original questionnaire. Finally, QDS has a one-click translate function for moving data from questionnaire to SPSS.

Data entry was completed over the period of approximately one year. All data was re-entered per the process described above by a second person. Data was then translated into SPSS and cleaned in order to assure that all responses fell in the valid range.

Neighborhood data was gathered separately from the participant data, and was culled from two sources: the Health Council of South Florida, and The Metropolitan Center at FIU. The Health Council of South Florida is a non-profit agency that collects and analyzes data on health indicators in Miami-Dade and Monroe Counties in order to assess the efficacy of current health programs and the future needs of the county. The data was from 2009 and included information organized by ZIP Code on race, ethnicity and median household income. The data was converted from a Microsoft Excel file into the master SPSS file. Foreclosure data was obtained from a housing needs report prepared in 2008 by The Metropolitan Center at FIU for the Greater Miami Chamber of Commerce. The data was transferred from a PDF with ZIP Codes and foreclosure information to the master SPSS file. 
Though 196 participants completed the intake assessment, some participants were missing key pieces of demographic data or only answered a portion of the questions in a given instrument. Composite score were calculated for all participants that had answered at least $80 \%$ of the questions in the composite. Participants that did not report demographic data such as gender, race/ethnicity, or age were excluded from the relevant analyses. However, if a participant did not report their age but did report gender, they were included in gender analyses. This was done in order to ensure that the highest number of participants were included for each analysis.

SPSS 18.0 was used to run all statistical tests and complete all analyses.

\section{Instrumentation}

Parenting measures. Parent-adolescent scales were constructed from an adapted Adolescent Health Questionnaire (Add Health; (Bearman, Jones, \& Udry, 1997). For the purposes of this study, all reporting was from the adolescent's perspective.

Global communication was based on Jaccard et al. (2000) and examined the amount of communication that occurred between parent and adolescent. Previous studies have reported that finding an adequate communication scale can be difficult because of inconsistent and imprecise measurement (Nolin \& Petersen, 1992). Global communication is a two-item scale addressing how much parents have talked to the adolescent about birth control, and about sex, with four possible responses: "not at all" (0), "somewhat" (1), "a moderate amount" (2), and "a great deal" (3). Scores ranged from 0-6, whereby zero represented no communication about sex or birth control and six represented a great deal of communication about both. 
Parental presence is a four-item composite measuring presence of mother and father at various times of the day, such as before or after school (Sieving et al., 2001). Potential responses include "always" (4), "most of the time" (3), "some of the time" (2), "almost never" (1), "never" (0), and a variable response such as "she brings me home from school" or "he takes me to school". For sake of consistency, the variable response was recoded as "Always" because the parent was technically present when bringing the child to or from school. The total number of parental presence questions was actually six, but rather than considering presence of both mother and father separately, only the highest score at each time was tallied, which cut the number of questions to three. For example, if the adolescent went to bed and the mother was present "Some of the time" and the father was "Always" present, only the higher parental score (father) was included in the composite. This method of summation was used for "before school", "after school", and "when you go to bed". In the event that there was a single parent or guardian in the household, the scores for this parent were used. The fourth question in the composite was the number of days per week when at least one parent was present at dinner. The four questions were averaged in order to determine a total score from 0-19. Participants had to have answered three out of four questions in order to be scored and the average was multiplied by four in order to yield an integer score (Resnick et al., 1997). A score of zero suggested that a parent was never present at the relevant times of day and was never present at dinner; a score of 19 signified that a parent was always present at the relevant times and at dinner seven days a week.

Parent-family connectedness is a two-item composite scale from Resnick et al. (1997) measuring closeness between adolescents and parents and perceived caring. 
Individually, many of these factors have been shown to affect adolescent sexual behaviors, including parent-teen closeness (Jaccard, Dittus, \& Gordon, 1996). Closeness addresses the relationship between adolescents and their mothers and/or fathers. Perceived caring asks how much the adolescent thinks the mother and/or father care about them. For both sets of questions, five possible responses included "not at all" (0), "very little" (1), "somewhat" (2), "quite a bit" (3), and "very much" (4), including an " $\mathrm{n} / \mathrm{a}$ " option if there was no resident mother or father. The original Add Health survey also asked questions about satisfaction with the relationship and feeling loved and wanted (Resnick, et al., 1997), but in the parent intervention study, the survey was modified and these questions were removed. The overall score was computed like the parental presence score, in that only the higher score of mother or father was tallied for both closeness and caring. The total score was computed by summing the highest score from closeness and caring, and ranged from 2-8. A higher score suggested a closer relationship between adolescent and parent.

Parent-adolescent activities is a 20 -item checklist whereby the adolescent reports on various activities they participated in with their parents, from shopping to sports to school projects, within the last 30 days (Resnick et al., 1997). The checklist includes both physical activities or outings and topics that the parent and adolescent could discuss, and consists of a simple "yes" or "no" response system. The physical activities/outings were: going shopping, playing a sport, going to a religious service or church-related event, and going to a movie, play, museum, concert, or sports event. The discussion topics included talking about someone whom the adolescent was dating or a party they went to, talking about a personal problem the adolescent was having, having a serious argument about the 
adolescent's behavior, talking about their school work or grades, and talking about other school-related activities. A final item was whether the parent and adolescent worked on a project for school together. In order to calculate the composite score, the number of activities between mother/child and father/child were summed. Finally, these two numbers were summed (Sieving et al., 2001). Total scores ranged from 0-20; zero meant that the parents and child participated in no activities, while 20 meant that the child and both parents participated in all of the listed activities.

\section{Attitude measures.}

Condom Attitudes (St. Lawrence, Brasfield, Jefferson, Alleyne, O'Bannon, \& Shirley, 1994b) were measured using an instrument adapted from St. Lawrence et al., originally from Sacco, Levine, Reed, and Thompson (1991). Questions were posed as declamatory sentences and the four possible responses were "disagree strongly" (1), "disagree somewhat" (2), "agree somewhat" (3), and "agree strongly" (4). Items in which "agree strongly" would indicate a negative attitude, including "condoms are messy" and "condoms take away the pleasure of sex", were reverse coded. The composite score included all 20 questions and ranged from 20-100, with a higher score indicating more positive attitudes about condom use.

Sexual Attitudes about condom use and adolescents' perception of approval for condom use by sexual partners, parents, and friends was measured using an instrument developed by Jemmott, Jemmott, and Fong (1992). The first question in the instrument was "how do you feel about using condoms", with five responses including "very bad idea" (1), "bad idea" (2), "in the middle" (3), "good idea" (4), and "very good idea" (5). All other questions in the instrument asked about approval of condom use by sexual 
partners, parents, and friends, and how important that person's approval is to the participant. Approval questions had responses ranging from "disapprove strongly" (1) to "approve strongly" (5); importance questions had responses from "extremely unimportant" (1) to "extremely important" (5). A composite score was calculated by summing the nine items; total scores ranging from 9-45 whereby a higher score indicates very positive attitudes about condom use and approval of condom use by the people most important to the participant.

Neighborhood measures. Several pieces of neighborhood data were gathered in order to create the most complete picture of neighborhood risk possible for each participant. In their 2000 review, Leventhal and Brooks-Gunn note that neighborhood studies should ideally be only conducted at the national level, include few families per census tract, and have carefully planned sampling in order to be sure that a representative neighborhood sample is gleaned. The current study was designed as an HIV risk reduction intervention and thus attempted to gather participants from a particular geographic region with no consideration as to equal neighborhood representation. By adding neighborhood information gathered by outside sources, the current study attempted to broaden the definition of each neighborhood beyond the limited scope of the City Stress Inventory, which was the only neighborhood measure administered during the study. Supplementary data was chosen based on a 2011 review article (Murry, Berkel, Gaylord-Harden, Copeland-Linder, \& Nation). Literature suggests gathering variables from three different categories: income/SES, racial/ethnic diversity, and residential instability (Leventhal \& Brooks-Gunn, 2000). 
Neighborhood stress (Ewart \& Suchday, 2002) will be measured by the City Stress Inventory (CSI), an 18-item questionnaire in which participants are asked to identify their neighborhood using ZIP Code. ZIP Code is a safer mode of geographic identification than home address, which could compromise anonymity. However, using ZIP Codes to draw conclusions based on the data is challenging: ZIP Code areas are often variable in size, are not limited to one socioeconomic class, and often do not stay constant over time (Thomas, Eberly, Smith, \& Neaton, 2006). The CSI neighborhood stress measurement is composed of two composite scores: neighborhood disorder and exposure to violence.

Neighborhood disorder (ND) is an 11-question composite addressing whether participants have seen various events, types of people, or activities near their primary residences. These situations are: drug dealing, strangers who are drunk or high hanging out nearby, adults arguing in the street, a "shooting gallery," gang fights, speeding cars, and vacant or unoccupied houses. The ND scale also asks whether participants have heard neighbors complaining about crime, being harassed by police, or receiving food stamps. Responses for the ND scale included "never", “once", "a few times", and "often". One final question asks how many people the participant knows that were arrested or went to jail; responses ranged from "none (zero)" to "many (five +)". Total scores ranged from 11-41, with a higher number of responses indicating more neighborhood disorder.

Exposure to violence (EV) is seven questions asking about whether the participant knows family or friends that were the victims of violence in the past year. Questions addressed whether a family member was attacked or beaten, stabbed or shot, 
questioned by police, threatened, or robbed or mugged. The other items asked similar questions about friends, including whether the participant had a friend that was stabbed or shot or robbed or mugged. Possible responses for all questions were "never," "once," "a few times," or "often". Total scores for exposure to violence range from 7-22, with higher scores indicating more exposure to violence.

ZIP Codes were gathered from the CSI measure. Neighborhood data from two external sources, the Health Council of South Florida (HCSF) and a housing needs assessment in Miami-Dade County, was obtained and entered into the master SPSS database by participant ZIP Code. For example, HCSF data showed that for ZIP Code $33142,53.3 \%$ of households reported a median income less than $\$ 25,000$. Therefore, for the "median household income less than $\$ 25,000$ " variable, $53.3 \%$ was entered for each participant living in ZIP Code 33142. All of the following neighborhood data was entered using this method. External neighborhood data was only available for Miami-Dade County; participants from Broward and Palm Beach County were excluded from this analysis.

Income and socioeconomic status was represented by median household income, gathered from 2009 HCSF data. The number of households with a median income of less than $\$ 25,000$ were recorded for each participant's ZIP Code. A median household income of less than $\$ 25,000$ was chosen because it was the lowest possible category in the data set, and though it does not perfectly align with federal poverty guidelines, it does approximate poverty. Further discussion of the use of median household income as a poverty indicator can be found in Chapter V. 
Racial and ethnic diversity was measured with percent minority population and percent Hispanic population, also obtained from HCSF data. Percent minority population was a sum of all non-white populations: Black, Asian, American Indian/Alaskan Native, other, and two or more races. Percent Hispanic was recorded separately from racial identity. Like median household income, these two percentages were recorded for each participant's ZIP Code.

Residential instability data was from a 2008 Miami-Dade County workforce housing needs assessment completed by The Metropolitan Center at FIU for the Greater Miami Chamber of Commerce. Data included number of properties in pre-foreclosure and number of bank-owned properties. All data was organized by ZIP Code. As with median household income, foreclosure information is not a perfect approximation of residential instability. First, many of the properties in the relevant ZIP Codes are rental properties; second, there is no way of knowing whether the foreclosures were second homes or rental properties that were allowed to go into foreclosure. Because ZIP Code data is so limited, foreclosure numbers were the best approximation of residential instability available.

Demographics. Demographic data was collected from the Adolescent Drug Abuse Diagnosis questionnaire (ADAD) (Friedman \& Utada, 1989).

Age. For most parents, communication with their young child about sex and sexuality will be very different than what they say to their adolescent (Nolin \& Petersen, 1992). The differences between how a parent communicates with their young teenager (or "tween") and how they communicate with their older teenager, perhaps one entering high school or preparing for college, may be more nuanced. For this reason, this study 
will examine age as a confounder. Age was calculated by subtracting date of birth from the date that the study was administered. Participants' ages ranged from 13-18. Age information was missing for 24 participants, $11.8 \%$ of the sample. In order to perform appropriate statistical tests, participants were split into two groups: 16 and under (including participants ages $13-16 ; n=97)$, and 17-18 $(n=83)$. Age was missing for 16 participants.

Race. Race is an important factor to consider for a variety of reasons. In terms of communication, studies have found differences in the extent of communication by race, whereby Asian and Hispanic adolescents report significantly less communication about sex than African American and Caucasian adolescents (Kim \& Ward, 2007; Hovell, Sipan, Blumberg, Atkins, Hofstetter, \& Kreitner, 1994; Ford \& Norris, 1991).

One advantage of the parent study was that it asked participants to self-identify, and split race and ethnicity, prompting participants to write their country of origin if it was not included in the list. Options included, in order: White (not of Hispanic origin), African American (not of Hispanic Origin), Caribbean (not Haitian), Haitian, Asian or Pacific Islander, Hispanic- Mexican, Hispanic- Puerto Rican, Hispanic- Cuban, and Other. Information about race was missing for 16 participants, $8.2 \%$ of the sample.

In order to perform appropriate statistical tests, comparison groups must be made up of approximately the same number of participants. Therefore, participants were grouped into "African American (not of Hispanic origin)" and "Not African American", which included Haitian, Cuban, Puerto Rican, Caribbean, White, and participants of other races/ethnicities. 
Family factors. Other family or individual factors that will be examined include family structure, marital status of parents, and parent education. All of these factors have been found to be associated with parent-adolescent communication about sex (Jaccard, Dodge, \& Dittus, 2002). If a child has numerous older siblings, they may have already heard a significant amount of sexual information before the parent initiates discussion. Whether or not having older siblings makes adolescents more or less receptive to the messages is debatable. Parents' education can have a lasting impact on how much sexual communication they have with their children. Highly educated parents may believe that they have the knowledge to address tough issues with their teens, and therefore may be more likely to initiate sexual conversation (Ito, Gizlice, Owen-O'Dowd, Foust, Leone, \& Miller, 2006). Education of the participant could have also been considered, but because most of the population was still in school, gathering this information might be redundant with the age variable. Parent education was assessed by asking the highest grade completed by each parent.

Family structure was assessed by asking about the participants' current living arrangements, with responses ranging from "with both natural parents" to "with other relatives" to "alone". Response options for the parents included never married (living apart), never married (living together), married, separated, divorced, father deceased, mother deceased, father remarried, and mother remarried. For statistical purposes, the family structure variable was recoded into three groups: participants living with both natural parents $(\mathrm{n}=43)$, participants living with their mother only $(\mathrm{n}=59)$, and participants in other living situations $(\mathrm{n}=77)$. During regression analyses, the participants not living with both parents were grouped together so that the resulting variable was dichotomous. 
Regression groupings were: participants living with both natural parents $(\mathrm{n}=43)$, and participants not living with both natural parents $(\mathrm{n}=136)$. Data about living arrangements for the past year was missing for 25 participants ( $12.3 \%$ of the sample.)

\section{Outcome measures.}

Behavioral Intentions. (Otto-Salaj, Heckman, Stevernson, \& Kelly, 1998) Adolescents' intentions regarding sex will be a composite score calculated from the Behavioral Intentions instrument developed by Otto-Salaj et al. Questions were phrased as statements beginning with "I will", and fell into two broad categories: communication with a sex partner about sex, condoms, past sex partners, drug use, and more; and behavior with the sex partner in terms of condom use in various situations such as "in the heat of the moment" and after drug use. The score is a sum of 15 questions with six possible responses: "Definitely will not do" (1), "Not at all likely to do" (2), "Slightly likely not to do" (3), "Slightly likely to do" (4), "Likely will do" (5), and "Definitely will do" (6). Possible scores for the composite range from 15-90. A higher score reflected more positive behavioral intentions regarding safe sex behavior.

Risk Behavior Assessment (National Institute on Drug Abuse, 1991) Sexual behavior outcomes will be collected from an adapted Risk Behavior Assessment (RBA). Outcomes from the RBA included condom use and sexual activity under the influence of alcohol or drugs during the eight months prior to the survey administration (Dévieux et al., 2007). The number of unsafe sex acts, including vaginal sex without condoms, receiving oral sex without a condom, giving oral sex without a condom, and anal sex without a condom, were summed in order to provide a total score for each participant. For participants that reported no lifetime or current sexual activity, responses in the RBA 
were entered as zero (0). Seven participants did not enter any responses on the RBA.

Sexual activity under the influence of alcohol or drugs was a sum of two questions: "how many times have you had sex with someone after you had too much to drink?" and "how many times have you had sex with a person when you were high on drugs?" The RBA has been shown to have adequate test-retest reliability for sexual risk behaviors (Needle et al., 1995).

\section{Data Analytic Plan}

First, t-tests and ANOVAs were conducted to compare adolescent behavioral intentions and behavioral outcomes of various groupings within the population, including male participants $(n=111)$ and female participants $(n=93)$, racial and ethnic groupings, age groups, and groupings based on family structure (i.e. participant's living situation for the previous year). Similar analyses were run for predictor variables in order to assess whether demographic characteristics of the adolescents were associated with differences in the variables discussed above: communication about sex, presence, connectedness, activity participation, condom attitudes, and sexual attitudes.

Next, Pearson's correlation coefficients were calculated between variables of interest and the outcome variables, both to offer directional relationship information and to measure the degree of overlap between concepts. Attitudes and parenting variables were compared to intentions and then separately to behavior. Next, correlations between behavioral intentions and unprotected sexual behavior for the previous eight months were examined. Subsequently, linear regression equations measuring the predictive value of independent variables on adolescent behavioral intentions and sexual risk behavior were 
constructed. The same steps were repeated for neighborhood variables: first correlations were run, and then linear regression equations were constructed in order to determine which neighborhood variables had a significant impact on behavioral intentions and sexual risk behavior. Neighborhood variables from within the dataset, neighborhood disorder and exposure to violence, were run first. After establishing those preliminary relationships, ZIP Code level variables including median household income, percent minority residents, percent Hispanic residents, number of pre-foreclosures, and number of bank-owned properties were added to the analyses in order to explore potential relationships.

Finally, stepwise hierarchical regressions were performed in order to determine the most parsimonious model from all of the control, parenting, attitude, and neighborhood variables on both behavioral intentions and sex behavior.

In the next chapter, results of all statistical analyses will be displayed and discussed in terms of statistical significance. Further discussion and potential impact of results will be addressed in Chapter V. 


\section{CHAPTER IV}

\section{Introduction}

The purpose of the study is to explore the relationships between neighborhood stress, parenting, attitudes, and adolescent sexual behavior. The study examines parenting skills, including good communication, high levels of involvement and monitoring, and a close caring relationship; and attitude factors including condom attitudes and sexual attitudes. Neighborhood data on participants addresses neighborhood disorder and exposure to violence. Several other neighborhood indices, including median household income, percentage of racial and ethnic minorities, and foreclosure data have been added from local ZIP Code data. The outcomes being investigated are behavioral intentions and unprotected sex for the previous eight months.

\section{Study Participants}

Participants were gathered from an NIH-funded study database. All adolescent participants were used for the relevant measures granted that they were not missing data or other key demographic information. Parent participants were excluded from the study. Names, addresses, and other identifying information were collected separately from study data so that it could be retained by project investigators. All identifying information was retained in locked cabinets in a locked room; no individual identifying information was available in the SPSS database utilized for data analysis.

Subject recruitment for the original study was conducted by the AIDS Prevention Program at Florida International University. The research team has a long-standing 
history with Youth-Serving Organizations in Miami-Dade and Broward Counties with whom they partnered for program recruiting and intervention development.

Adolescents were recruited using posted and distributed informational flyers at school and community-based sites. The flyers contained a description of the research program as well as the recruiter name and phone number. Adolescents could either contact the recruiter using the information on the flyer or if they expressed interest during a face-to-face meeting with a recruiter, the recruiter could follow up with the adolescent. Once the participant and recruiter were on the phone call, the recruiter gave basic information about the program and spoke to a parent or guardian about the assent/consent process.

In the original AIDS Prevention Program study, there were a total of 313 parent and adolescent participants: 204 adolescents, and 109 parents. From the 204 adolescents that completed surveys at various time points, 196 completed part or all of the intake survey. Of the 196 adolescent participants, approximately $50 \%(\mathrm{n}=98)$ had parents that completed the corresponding parent survey and participated in the parent intervention.

\section{Results}

Demographic characteristics. The demographic characteristics of the final sample used in the study have been organized into a chart (see Table 1). 
Table 1.: Summary of the Demographic Characteristics of the Sample of South Florida Adolescents $(n=196)$

\begin{tabular}{|c|c|c|}
\hline & Frequency (n) & Percent \\
\hline \multicolumn{3}{|l|}{ Gender } \\
\hline 1. Female & 90 & 44.1 \\
\hline 2. Male & 103 & 50.5 \\
\hline \multicolumn{3}{|l|}{ Race/ethnicity } \\
\hline $\begin{array}{l}\text { 1. African American, non- } \\
\text { Hispanic }\end{array}$ & 96 & 49 \\
\hline 2. Caribbean, non-Haitian & 7 & 3.6 \\
\hline 3. Haitian & 38 & 19.4 \\
\hline 4. Hispanic, Cuban & 13 & 6.6 \\
\hline 5. Hispanic, Puerto Rican & 9 & 4.6 \\
\hline 6. All other races & 16 & 8.2 \\
\hline 7. White, non-Hispanic & 1 & 0.5 \\
\hline \multicolumn{3}{|l|}{ Age } \\
\hline $\begin{array}{ll}1 . & 13\end{array}$ & 4 & 2.0 \\
\hline 2. 14 & 17 & 8.3 \\
\hline 3.15 & 15 & 10.3 \\
\hline 4. 16 & 55 & 27.0 \\
\hline $\begin{array}{ll}5 . \quad 17 \\
\end{array}$ & 77 & 37.7 \\
\hline $6 . \quad 18$ & 6 & 2.9 \\
\hline
\end{tabular}

Demographic characteristics: family factors. Participants reported their living situation for the past year. More than a quarter of respondents $(28.9 \% \mathrm{n}=59)$ report living with their mother only. About one-fifth lived with both natural parents $(21.1 \%$; $=43)$, while $13.7 \%$ lived with their mother and a step-father or other father figure $(n=28)$. Of the remaining participants, $10.8 \%$ lived with other relatives $(n=22), 7.8 \%$ lived with their father only $(\mathrm{n}=16)$, and 3.4\% lived in group quarters such as a boarding school or group home $(n=7)$. Three participants reported living with their father and step-mother or other mother figure $(1.5 \%)$. One participant reported living with friends.

Approximately $88 \%(n=179)$ of adolescents offered information about their parents' marriage and relationship status. Adolescents were allowed to check more than one response in order to accommodate for families that had been divorced and remarried, or had lost a partner and remarried. Of respondents, $30.2 \%$ had parents that were 
divorced, $28.4 \%$ were never married, $25.7 \%$ were married at the time of interview, and 19.6\% were separated. In this survey, separated could refer to either a formal separation of a married couple or a break-up of a non-married, dating couple that may or may not be living together. About 5\% were never married but living together. Another 5\% of adolescents had fathers that were deceased, while $4.5 \%$ had mothers that were deceased. The same percentage of participants $(1.1 \%)$ had mothers or fathers that remarried after a divorce or the death of their spouse.

Data regarding parent education was not reported by many participants, possibly because the participant was unsure of the highest grade completed. More participants omitted data on their fathers' education (41.2\%) than mothers' education (27.9\%). The highest percentage of participants reported that their mothers had some high school education $(43.1 \%, \mathrm{n}=88)$. About a fifth of mothers had more than a high school education $(21.1 \%, n=43)$ and $7.8 \%$ reported that their mothers completed $8^{\text {th }}$ grade or less $(n=16)$. Likewise, the greatest number of participants reported that their fathers had some high school education $(38.2 \%, \mathrm{n}=78)$. Participants reported that $16.2 \%$ of their fathers had more than a high school education $(n=33)$, and $4.4 \%$ had completed $8^{\text {th }}$ grade or less $(n=9)$.

\section{Variables of interest.}

Parenting factors. (Add Health) Composite scores were calculated as detailed in Chapter III, Methods, for all predictor variables: global communication, parent-family connectedness, parent-adolescent activities, and parental presence. Using Cronbach's alpha, the global communication subscale was found to be moderately reliable ( 2 items, $\alpha$ 
$=.78$ ). The 20 -item parent-adolescent activities subscale and 2-item parent-family connectedness were both found to be highly reliable ( $\alpha=.86$ and $\alpha=.82$, respectively). A reliability estimate was not calculated for parental presence because internal consistency on the individual questions was not expected (Sieving et al., 2001).

Table 2.: Summary of Parent Variables

\begin{tabular}{|l|l|l|l|l|}
\hline & $\begin{array}{l}\text { Global } \\
\text { communication }\end{array}$ & $\begin{array}{l}\text { Parent-family } \\
\text { connectedness }\end{array}$ & $\begin{array}{l}\text { Parent-adolescent } \\
\text { activities }\end{array}$ & $\begin{array}{l}\text { Parental } \\
\text { presence }\end{array}$ \\
\hline N & 187 & 186 & 187 & 176 \\
\hline Mean & 2.81 & 7.56 & 5.67 & 13.53 \\
\hline Median & 2 & 8 & 5 & 14 \\
\hline SD & 1.90 & 1.01 & 3.98 & 3.85 \\
\hline Range & $0-6$ & $2-8$ & $0-18$ & $0-19$ \\
\hline
\end{tabular}

Attitude factors. Composite scores were calculated for sexual attitudes and condom attitudes per the process described in Chapter III. For sexual attitudes, scores ranged from 19-45 $(M=38.33 ; S D=4.98)$; for condom attitudes scores ranged from 43$80(M=68.46 ; S D=6.66)$. Using Cronbach's alpha, the sexual attitudes score was found to be moderately reliable ( 9 items; $\alpha=.78$ ). Condom attitudes had 20 items and $\alpha=.67$.

Neighborhood factors (City Stress Inventory). Neighborhood disorder scores ranged from 11 to 41, with a mean of 23.79 and a standard deviation of 7.816. Exposure to violence scores ranged from 7 to 22 , with a mean of 11.02 and a standard deviation of 3.694. A total of 18 participants were missing data for the exposure to violence score; 19 participants were missing data for neighborhood disorder.

Participants reported living in 48 different ZIP Codes in the South Florida region. The ZIP Codes were concentrated in Miami-Dade County $(77 \%, \mathrm{n}=151)$, with $13.3 \%$ 
$(\mathrm{n}=26)$ in Broward and $1.5 \%(\mathrm{n}=3)$ in Palm Beach Counties. Neighborhood indices were only available for the 151 participants living in Miami-Dade County. The mean race/ethnicity percentage for neighborhoods was $58.4 \%$ non-white residents and $44.9 \%$ of residents reporting Hispanic heritage. A little more than a third (36.7\%) of households in relevant ZIP Codes reported a median household income of less than $\$ 25,000$ per year. In terms of residential instability of the neighborhoods, the mean of pre-foreclosure properties was $707.71(S D=77.74)$; the mean of bank-owned properties was $283.40(S D$ $=41.19)$.

Outcomes. The reliability of the behavioral intentions score was tested using Cronbach's alpha. The score was highly reliable (15 items, $\alpha=.87)$. Behavioral intentions for having safe sex ranged from 15-90; $M=76.30, S D=13.08$.

Almost two-thirds of the sample $(66.8 \%, \mathrm{n}=131)$ reported lifetime sexual intercourse. Overall, $42.3 \%(n=83)$ of respondents responded positively to the question "Are you sexually active now? (That means you occasionally have vaginal, oral or anal sex with a partner)." Of the respondents that reported lifetime sexual activity, $62.6 \%$ $(n=82)$ were currently sexually active. For sexually active participants, age of sexual initiation ranged from 8 years old to 18 years old. Mean age of initiation was 14.18 and the standard deviation was 1.730 .

The risk behavior assessment (RBA) measured unsafe (without condoms) sex acts for the previous eight-month period. A Cronbach's alpha was calculated, and the composite score was not found to be of adequate reliability ( 4 items, $\alpha=.60$ ). However, adolescents were not expected to answer the set of questions reliably, so the scale was 
used as calculated. About a third (36.7\%) of the sample reported having ever had oral sex $(\mathrm{n}=72), 63.3 \%$ reported ever having vaginal sex $(\mathrm{n}=124)$, and $7.7 \%$ reported ever having anal sex $(n=15)$. The average number of sexual partners for male participants was 1.64 $(S D=2.63)$, while for female participants the average was .62 $(S D=.94)$. For males, the number of partners ranged from $0-14$; for females it ranged from $0-5$. One participant reported having sex with multiple partners at the same time.

Analysis of sex acts during the previous eight months for participants reporting lifetime sexual activity can be found in Table 3 . As noted above, 32.7\% ( $\mathrm{n}=64)$ of participants reported never having sex. Another 37.8\% $(n=74)$ reported no unsafe vaginal, anal, or oral sex; $29.6 \%(n=58)$ reported at least one unsafe vaginal, anal, or oral sex act during the past eight months. The average number of unsafe sex acts in the previous eight months was 8.07 ; $(S D=32.64)$. The large standard deviation is most likely a product of the wide range of unsafe sex acts, from 0 to 360 . No participants reported any sexual activity concurrent with drug or alcohol use.

Table 3.: Summary of Sexual Behavior, by Sex Act

\begin{tabular}{|l|l|l|l|l|l|l|}
\hline & \multicolumn{2}{|l|}{ Vaginal sex } & Oral sex & Anal sex & \\
\cline { 2 - 7 } & Safe & Unsafe & Safe & Unsafe & Safe & Unsafe \\
\hline $\mathrm{n}$ & 80 & 31 & 13 & 44 & 7 & 4 \\
\hline$\%$ (of current) & $71.0 \%$ & $25.0 \%$ & $10.5 \%$ & $35.5 \%$ & $5.6 \%$ & $3.2 \%$ \\
\hline $\begin{array}{l}\text { Mean number } \\
\text { of acts (8M) }\end{array}$ & 6.53 & 1.74 & .83 & 6.23 & .60 & .11 \\
\hline SD of acts & 17.09 & 7.52 & 7.87 & 31.29 & 5.95 & .77 \\
\hline Range & $0-106$ & $0-81$ & $0-107$ & $0-360$ & $0-80$ & $0-7$ \\
\hline
\end{tabular}

\section{Statistical Analyses}


Research Question 1: What is the relationship between attitudes about sex, parenting practices, behavioral intentions, and adolescent sexual risk behavior by gender, age, race/ethnicity, and family structure?

Hypothesis 1: Positive attitudes about safe sex and higher rates of parentadolescent activities, communication about sex, parent-family connectedness, and parental presence will be associated with lower intention to participate in risky sexual behavior. Lower intention to participate in risky sexual behavior will be associated with lower rates of risk behavior, including, sexual activity concurrent with drug/alcohol use and lack of condom use.

$\mathrm{T}$ tests were performed in order to compare groups on the continuous predictor and outcome variables. Chi square tests were performed for comparisons with nominal data.

Gender. There were no significant differences between males and females for parent or attitude predictor variables. However, a difference was found for behavioral intentions whereby males $(M=73.32, S D=12.06)$ were less likely than females $(M=$ 79.93, $S D=13.24)$ to report positive behavioral intentions for having safe sex, $t(186)=$ $3.56, p<.001$. No significant differences were found by gender for unprotected sex behavior.

Race. As noted in descriptive statistics above, the sample was primarily composed of African American participants that were not of Hispanic origin, $n=96$. The balance of the sample was composed of Haitian ( $n=38)$, Cuban ( $n=13)$, Puerto Rican ( $=9)$, Caribbean $(\mathrm{n}=7)$, White $(\mathrm{n}=1)$, and participants identifying as "Other" $(\mathrm{n}=16)$. 
African American participants ( $\mathrm{n}=96)$ were compared to non-African American participants (including Haitian, Cuban, Puerto Rican, Caribbean, White, and Other races) $(\mathrm{n}=84)$. A significant difference was found between parent-adolescent activities, $t(172)$ $=2.25, p=.03$ by race; African American participants had lower numbers of activities $(M=4.98, S D=3.65)$ than non-African American participants $(M=6.31, S D=4.18)$. No significant differences were found by race for outcome variables.

Age. Participants ages 16 and under were compared to participants that were 1718 years old. A significant difference was found between age groups for behavioral intentions; participants 16 and under $(M=78.47, S D=10.99)$ had significantly higher intentions than participants ages $17-18(M=73.47, S D=14.80), t(173)=2.56, p=.01$. No significant differences were found for parenting variables, attitude variables, and unprotected sex behavior.

Table 4.: Statistical Outcomes for Parent and Attitude Variables by Age, Gender, and Race.

\begin{tabular}{|c|c|c|c|c|c|c|c|}
\hline & \multicolumn{2}{|c|}{ Age } & \multicolumn{2}{|c|}{ Gender } & \multicolumn{2}{|c|}{ Race } \\
\hline & & $\begin{array}{l}16 \text { and } \\
\text { under }\end{array}$ & $17-18$ & M & $\mathbf{F}$ & $\begin{array}{c}\text { African } \\
\text { American } \\
\end{array}$ & Other \\
\hline \multirow[t]{2}{*}{ Global communication } & $\begin{array}{l}M \\
S D\end{array}$ & $\begin{array}{l}2.73 \\
1.86\end{array}$ & $\begin{array}{l}2.87 \\
1.95\end{array}$ & $\begin{array}{l}2.71 \\
2.00\end{array}$ & $\begin{array}{l}2.92 \\
1.80\end{array}$ & $\begin{array}{l}2.69 \\
1.95\end{array}$ & $\begin{array}{l}2.93 \\
1.82\end{array}$ \\
\hline & $\begin{array}{l}t \\
p\end{array}$ & \multicolumn{2}{|l|}{-.49} & \multicolumn{2}{|c|}{$\begin{array}{l}-.74 \\
.46\end{array}$} & \multicolumn{2}{|l|}{$\begin{array}{l}.81 \\
.42\end{array}$} \\
\hline \multirow[t]{2}{*}{$\begin{array}{l}\text { Parent-adolescent } \\
\text { activities }\end{array}$} & $\begin{array}{l}M \\
S D\end{array}$ & $\begin{array}{l}5.63 \\
4.05\end{array}$ & $\begin{array}{l}5.63 \\
3.95\end{array}$ & $\begin{array}{l}5.89 \\
4.15\end{array}$ & $\begin{array}{l}5.38 \\
3.81\end{array}$ & $\begin{array}{l}4.98 \\
3.65\end{array}$ & $\begin{array}{l}6.31 \\
4.18\end{array}$ \\
\hline & $\begin{array}{l}t \\
p\end{array}$ & \multicolumn{2}{|l|}{$\begin{array}{l}-.01 \\
.996\end{array}$} & \multicolumn{2}{|c|}{$\begin{array}{l}.86 \\
.39\end{array}$} & \multicolumn{2}{|l|}{$\begin{array}{l}2.25^{*} \\
.03\end{array}$} \\
\hline \multirow[t]{2}{*}{ Parental presence } & $\begin{array}{l}M \\
S D\end{array}$ & $\begin{array}{l}13.74 \\
3.51\end{array}$ & $\begin{array}{l}13.05 \\
4.35\end{array}$ & $\begin{array}{l}13.22 \\
4.10\end{array}$ & $\begin{array}{l}13.87 \\
3.55\end{array}$ & $\begin{array}{l}13.03 \\
4.03\end{array}$ & $\begin{array}{l}13.86 \\
3.66\end{array}$ \\
\hline & $\begin{array}{l}t \\
p\end{array}$ & \multicolumn{2}{|l|}{$\begin{array}{l}1.12 \\
.27\end{array}$} & \multicolumn{2}{|l|}{$\begin{array}{l}-1.13 \\
.26\end{array}$} & \multicolumn{2}{|l|}{$\begin{array}{l}1.36 \\
.18\end{array}$} \\
\hline $\begin{array}{l}\text { Parent-family } \\
\text { connectedness }\end{array}$ & $\begin{array}{l}M \\
S D\end{array}$ & $\begin{array}{l}7.53 \\
1.13\end{array}$ & $\begin{array}{l}7.58 \\
.91\end{array}$ & $\begin{array}{l}7.67 \\
.90\end{array}$ & $\begin{array}{l}7.44 \\
1.12\end{array}$ & $\begin{array}{l}7.54 \\
1.03\end{array}$ & $\begin{array}{l}7.56 \\
1.05\end{array}$ \\
\hline
\end{tabular}




\begin{tabular}{|c|c|c|c|c|c|c|c|}
\hline & $\begin{array}{l}t \\
p\end{array}$ & \multicolumn{2}{|l|}{$\begin{array}{l}-.33 \\
.74\end{array}$} & \multicolumn{2}{|l|}{$\begin{array}{l}1.49 \\
.14\end{array}$} & \multicolumn{2}{|l|}{$\begin{array}{l}.09 \\
.93\end{array}$} \\
\hline \multirow[t]{2}{*}{ Condom attitudes } & $\begin{array}{l}M \\
S D\end{array}$ & $\begin{array}{l}68.59 \\
6.38\end{array}$ & $\begin{array}{l}68.62 \\
6.79\end{array}$ & $\begin{array}{l}67.63 \\
6.53\end{array}$ & $\begin{array}{l}69.27 \\
6.71\end{array}$ & $\begin{array}{l}69.25 \\
5.91\end{array}$ & $\begin{array}{l}67.92 \\
7.23\end{array}$ \\
\hline & $\begin{array}{l}t \\
p\end{array}$ & \multicolumn{2}{|l|}{$\begin{array}{l}-.03 \\
.98\end{array}$} & \multicolumn{2}{|l|}{$\begin{array}{l}-1.70 \\
.09\end{array}$} & \multicolumn{2}{|l|}{$\begin{array}{l}-1.35 \\
.18 \\
\end{array}$} \\
\hline \multirow[t]{2}{*}{ Sexual attitudes } & $\begin{array}{l}M \\
S D\end{array}$ & $\begin{array}{l}38.48 \\
5.34\end{array}$ & $\begin{array}{l}38.46 \\
4.24\end{array}$ & $\begin{array}{l}38.25 \\
4.78\end{array}$ & $\begin{array}{l}38.46 \\
5.23\end{array}$ & $\begin{array}{l}39.05 \\
4.32\end{array}$ & $\begin{array}{l}37.88 \\
5.56\end{array}$ \\
\hline & $\begin{array}{l}t \\
p\end{array}$ & \multicolumn{2}{|l|}{$\begin{array}{l}.04 \\
.97\end{array}$} & \multicolumn{2}{|l|}{$\begin{array}{l}-.29 \\
.77\end{array}$} & \multicolumn{2}{|l|}{$\begin{array}{l}-1.54 \\
.13\end{array}$} \\
\hline \multirow[t]{2}{*}{$\begin{array}{l}\text { Behavioral intentions for } \\
\text { safe sex }\end{array}$} & $\begin{array}{l}M \\
S D\end{array}$ & $\begin{array}{l}78.47 \\
10.99\end{array}$ & $\begin{array}{l}73.47 \\
14.80\end{array}$ & $\begin{array}{l}73.32 \\
12.06\end{array}$ & $\begin{array}{l}79.93 \\
13.24\end{array}$ & $\begin{array}{l}76.63 \\
11.65\end{array}$ & $\begin{array}{l}75.84 \\
14.74\end{array}$ \\
\hline & $\begin{array}{l}t \\
p\end{array}$ & \multicolumn{2}{|l|}{$\begin{array}{l}2.56^{*} \\
.01\end{array}$} & \multicolumn{2}{|c|}{$\begin{array}{l}-3.59 * * \\
<.001\end{array}$} & \multicolumn{2}{|l|}{$\begin{array}{l}-.39 \\
.70\end{array}$} \\
\hline \multirow[t]{2}{*}{ Unsafe sex behavior } & $\begin{array}{l}M \\
S D\end{array}$ & $\begin{array}{l}3.63 \\
17.22\end{array}$ & $\begin{array}{l}13.55 \\
45.87\end{array}$ & $\begin{array}{l}11.19 \\
42.54\end{array}$ & $\begin{array}{l}4.67 \\
14.94\end{array}$ & $\begin{array}{l}12.84 \\
46.63\end{array}$ & $\begin{array}{l}3.93 \\
13.55\end{array}$ \\
\hline & $\begin{array}{l}t \\
p\end{array}$ & $\begin{array}{l}-1.81 \\
.07\end{array}$ & & $\begin{array}{l}1.43 \\
.15\end{array}$ & & $\begin{array}{l}1.66 \\
.10\end{array}$ & \\
\hline
\end{tabular}

* Significant at $\alpha=.05$

$* *$ Significant at $\alpha=.01$

Family structure. One-way ANOVAs were conducted in order to analyze the differences between participants living with both natural parents $(n=43)$, participants living with their mother only $(n=59)$, and participants in other living situations $(n=77)$ groups for predictor and outcome variables. No significant differences were found between groups for condom attitudes, $F(2,173)=.43, p=.65$, or sexual attitudes, $F(2,172)=.62, p=.54$. Statistically significant differences were found between groups for parent activities, $F(2,170)=9.33, p<.001$, and parental presence, $F(2,159)=6.97, p$ $=.001$. Participants living with both natural parents reported significantly more activities $(M=7.81, S D=4.41)$ than those living with their mothers $(M=4.67, S D=3.07)$ or in other living situations $(M=5.11, S D=3.99)$. Likewise, participants living with both natural parents reported significantly more parental presence $(M=15.24, S D=3.35)$ than those living with their mothers $(M=12.51, S D=4.07)$ or in other living situations $(M=$ 
$12.98, S D=3.72$ ). No significant differences were found between groups for global communication, $F(2,170)=.882, p=.42$, or parent-family connectedness, $F(2,170)=$ $2.18, p=.12$. For outcome variables, no significant differences were found for either behavioral intentions, $F(2,171)=.55, p=.58$, or unsafe sex behavior for the past eight months, $F(2,170)=2.29, p=.10$.

Prior to constructing a regression equation, Pearson product-moment correlation coefficients $(r)$ were calculated between predictor variables and behavioral intentions. Condom attitudes and sexual attitudes were significantly correlated, $r=.432, p<.001$. Further, though significant associations were found between behavioral intentions and both condom attitudes, $r=.315, p<.001$, and sexual attitudes, $r=.321, p<.001$, neither was associated with unprotected sex behavior in the past eight months (condom attitudes: $r=.002, p=.98$; sexual attitudes: $r=.0004, p=.996$ ).

Global communication was significantly correlated with parent-adolescent activities, $r=.215, p<.01$, parental presence, $r=.248, p<.01$, and parent-family connectedness, $r=.153, p=.04$. Parent-adolescent activities was separately associated with parental presence, $r=.412, p<.001$, and parent-family connectedness, $r=.287, p<$ .001. Parental presence and parent-family connectedness were also correlated, $r=.206, p$ $<.01$. Parent presence was the only parental measure that correlated with both behavioral intentions, $r=.212, \mathrm{p}<.01$, and unprotected sex behavior in the past eight months, $r=$ $.176, p=.02$.

Pearson's correlation coefficients were calculated and a linear regression analysis was conducted in order to determine whether behavioral intentions predicted unsafe sexual behavior. Behavioral intentions were not correlated with unprotected sexual 
behavior in the previous eight months, $r=-.005, \mathrm{p}=.95$. Further, behavioral intentions did not explain a significant proportion of the variance in unsafe sexual behavior, $R^{2}=$ .13 , adjusted $R^{2}=.005, F(1,183)=.004, p=.95$.

Two multiple regression analyses were conducted to predict behavioral intentions for having safe sex. One analysis included the two attitude variables as predictors (condom attitudes and sexual attitudes), while the second analysis included the four parenting variables (global communication, parent-family connectedness, parental presence, and parent-adolescent activity participation). The regression equation with attitude measures predicted a significant percentage of the variance in behavioral intentions, $R^{2}=.13$, adjusted $R^{2}=.12, F(2,167)=12.45, p<.001$. It was found that both condom attitudes, $\beta=.20, p=.01$, and sexual attitudes, $\beta=.22, p=.006$, significantly predicted behavioral intentions. The regression equation with parenting measures was also significant, $R^{2}=.09$, adjusted $R^{2}=.07, F(4,165)=4.13, p=.003$. Within the parenting regression equation, parental presence $(\beta=.27, p=.002)$ and parent-family connectedness $(\beta=-.18, p=.02)$ were significant.

Next, multiple regression analyses were conducted in order to examine the degree that parenting and attitude variables predicted unprotected sex behavior for the previous eight months. The regression equation with parenting variables predicting sex behavior was not significant, $R^{2}=.04$ adjusted $R^{2}=.01, F(4,165)=1.60, p=.18$. Likewise, condom attitudes and sexual attitudes did not predict a significant percent of the variance in sex behavior, $R^{2}=.00001$, adjusted $R^{2}=-01, F(2,181)=.002, p=.998$.

A hierarchical multiple regression was then conducted in order to analyze whether the relationships between attitude variables and parenting variables and outcomes 
changed when controlling for demographic factors including age, gender, race, and family structure in the study. Demographic variables were run in a separate block in order to examine the effect of control variables on outcomes, subsequently, predictor variables were added in to the analysis. The regression indicated that demographic factors in the study accounted for $10 \%$ of the variance, $R^{2}=.10, F(4,166)=4.61, p=.001$. After controlling for age, gender, race, and family structure, attitude variables accounted for a significant proportion of the variance in behavioral intentions, $R^{2}$ change $=.11, F(2,164)$ $=11.82, p<.001$. Results of the analysis for unprotected sex behavior during the past eight months found that demographic variables explained a significant percent of the variance, $R^{2}=.06, F(4,164)=2.81, p=.03$. However, after controlling for age, gender, race, and family structure, attitudes about sex did not significantly explain a higher proportion of the variance in behavior, $R^{2}$ change $=.00005, F(2,162)=.013, p=.987$.

For parenting variables and behavioral intentions, the results of the analysis indicated that control variables accounted for a significant amount of variability, $R^{2}=.10$, $F(4,152)=4.20, p=.003$. However, the four parenting variables did not account for a significant proportion of the behavioral intention variance after controlling for the effects of age, gender, race, and family structure, $R^{2}$ change $=.05, F(4,148)=2.39, p=.05$. For unprotected sex behavior in the previous eight months, control variables accounted for approximately $6 \%$ of the variance, $R^{2}=.06, F(4,151)=2.54, p=.04$. After controlling for the effects of age, gender, race, and family structure in the study, parenting variables (global communication, parental presence, parent-family connectedness, and parentadolescent activities) did not account for a significantly higher proportion of the variance in sex behavior, $R^{2}$ change $=.02, F(4,147)=.94, p=.44$. 
Finally, multiple regression analyses were conducted with all six predictor variables (two attitude and four parenting). The linear combination of the six variables explained $21 \%$ of the variance in behavioral intentions, $R^{2}=.21$, adjusted $R^{2}=.19$, $F(6,163)=7.45, p<.0001$. Significant predictors included parental presence $(\beta=.26, p=$ $.001)$, parent-family connectedness $(\beta=-.29, p=.01)$, condom attitudes $(\beta=.23, p=$ $.004)$, and sexual attitudes $(\beta=.20, p=.01)$. The linear combination of the six variables did not explain a significant proportion of the variance in unprotected sex behavior, $R^{2}=$ .04 , adjusted $R^{2}=.002, F(6,160)=1.09, p=.40$. Hierarchical regression analyses showed that age, gender, race, and family structure explained approximately $10 \%$ of the variance in behavioral intentions, $R^{2}=.10, F(4,150)=4.32, p=.002$. After controlling for demographics, parenting and attitude variables explained a statistically significant higher proportion of the variance in behavioral intentions, $R^{2}$ change $=.16, F(6,144)=5.02, p<$ .001. For unprotected sex behavior in the previous eight months, control variables accounted for $6 \%$ of the variance, $R^{2}=.06, F(4,148)=2.49, p=.046$. After controlling for age, race, gender, and family structure, parenting and attitude variables did not account for a significantly higher proportion of the variance, $R^{2}$ change $=.03, F(6,142)=$ $.68, p=.67$.

Research Question 2: What is the relationship between neighborhood stress, behavioral intentions, and risky sexual behavior among adolescents? When neighborhood stress is added to the model, do different attitude and parenting variables emerge as significant? 
Hypothesis 2: High levels of neighborhood stress factors including disorder, exposure to violence, poverty, racial/ethnic diversity, and residential instability will be associated with lower rates of positive behavioral intentions and high rates of sexual risk behavior including sexual activity concurrent with drug/alcohol use and lack of condom use. Neighborhood stress will change the relationship between attitudes, parenting, behavioral intentions, and risky sexual behavior so that a different set of variables is most predictive of the outcomes.

T-tests and one-way ANOVAs were conducted between control variable groups in order to determine whether the means differed for neighborhood disorder and exposure to violence. Statistical tests were only run on those two scores because other neighborhood indices were gathered from local data sources and coordinated only with the participant's ZIP Code. When comparing participants that were 16 and under to those between 17 and 18 years old, no significant differences were found for neighborhood disorder ( 16 and under: $M=23.25, S D=7.57 ; 17-18: M=24.27, S D=8.32, t(171)=$ $.85, p=.40$ ) or exposure to violence, 16 and under: $M=10.87, S D=3.67 ; 17-18: M=$ $11.21, S D=3.86, t(171)=-.58, p=.56$. No differences existed between males $(M=$ $24.63, S D=7.64)$ and females $(M=22.69, S D=7.95)$ for neighborhood disorder, $t(181)$ $=1.68, p=.10$, or between males $(M=10.96, S D=3.43)$ and females $(M=11.01, S D=$ 4.01) for exposure to violence, $t(182)=-.10, p=.92$. No racial differences were found by neighborhood disorder (African American: $M=24.52, S D=8.38$, other race: $M=22.81$, $S D=7.42), t(171)=-1.43, p=.15$, or exposure to violence, (African American: $M=$ $11.48, S D=3.77$, other race: $M=10.44, S D=3.69), t(171)=-1.84, p=.07$. Finally, no significant differences in means were observed for neighborhood disorder between 
participants living with both parents $(M=22.48, S D=8.38)$, those living with their mothers only $(M=24.36, S D=7.43)$, and those in other living situations, $(M=23.91, S D$ $=8.00), F(2,170)=.72, p=.49$. Likewise, no significant differences in means were observed for exposure to violence between participants living with both parents $(M=$ $10.90, S D=4.03)$, those living with their mothers only $(M=11.05, S D=3.98)$, and those in other living situations, $(M=11.07, S D=3.24), F(2,170)=.03, p=.97$.

Pearson product-moment correlation coefficients $(r)$ were calculated between neighborhood variables and outcome variables, behavioral intentions and unprotected sex behavior for the previous eight months. For complete correlation data, see Table 5. Neighborhood disorder and exposure to violence scores were highly associated, $r=.597$, $p<.001$. Neighborhood disorder was also associated with the number of pre-foreclosure properties, $r=.241, p<.01$, and bank-owned properties, $r=.234, p<.01$, in the participants' neighborhoods. Likewise, exposure to violence was associated with the number of pre-foreclosure properties, $r=.219, p<.01$, and bank-owned properties, $r=$ $.209, p<.05$, in the participants' neighborhoods. Within other neighborhood indices, the percent of non-white residents in the neighborhood had a highly significant relationship with the percent of Hispanic residents, $r=-.944, p<.001$, and was correlated to the number of pre-foreclosure properties $(r=.180, p=.03)$. Number of pre-foreclosures was associated with number of bank-owned properties, $r=.755, p<.001$. No neighborhood indices were correlated with behavioral intentions, but the percentage of non-white residents, $r=-.237, p=.004$, and percentage of Hispanic residents, $r=.247, p=.001$, were associated with unsafe sexual behavior in the past eight months. 
Table 5: Statistical Outcomes for Neighborhood Indices, Behavioral Intentions for Safe Sex and Unsafe Sex

\begin{tabular}{|c|c|c|c|c|c|c|c|c|c|c|}
\hline & & ND & EV & MHI & NWR & HR & PFP & BOP & BI & USS \\
\hline \multirow{9}{*}{$\begin{array}{l}\text { Correlation } \\
\text { coefficient }\end{array}$} & ND & 1.000 & $.597^{* *}$ & .100 & .125 & -.125 & $.241^{* *}$ & $.234^{* *}$ & .064 & .015 \\
\hline & EV & & 1.000 & .083 & .103 & -.085 & $.219^{* *}$ & $.209^{*}$ & .063 & .018 \\
\hline & MHI & & & 1.000 & .045 & .159 & $\begin{array}{l}.062 \\
\end{array}$ & .135 & .109 & -.027 \\
\hline & NWR & & & & 1.000 & $-.944^{* *}$ & $.180^{*}$ & .079 & .019 & $-.237 * *$ \\
\hline & HR & & & & & 1.000 & -.159 & -.009 & .018 & $.274 * *$ \\
\hline & PFP & & & & & & 1.000 & $.755^{* *}$ & -.031 & .026 \\
\hline & $\mathrm{BOP}$ & & & & & & & 1.000 & .036 & .025 \\
\hline & BI & & & & & & & & 1.000 & -.005 \\
\hline & USS & & & & & & & & & 1.000 \\
\hline \multirow{9}{*}{$\begin{array}{l}\text { Significance } \\
(p)\end{array}$} & ND & & $<.001$ & .226 & .130 & .130 & .003 & .004 & .064 & .845 \\
\hline & EV & & & .318 & .214 & .305 & .008 & .011 & .399 & .812 \\
\hline & MHI & & & & .583 & .053 & .453 & .101 & .192 & .743 \\
\hline & NWR & & & & & $<.001$ & .028 & .335 & .822 & .004 \\
\hline & HR & & & & & & .053 & .913 & .830 & .001 \\
\hline & PFP & & & & & & r & $<.001$ & .713 & .757 \\
\hline & BOP & & & & & & & ${ }^{\circ}$ & $\begin{array}{l}.663 \\
\end{array}$ & .764 \\
\hline & BI & & & & & & & & r & .950 \\
\hline & USS & & & & & & & & & \\
\hline
\end{tabular}

$*$ = Correlation is statistically significant at .05 level (2-tailed)

** = Correlation is statistically significant at .01 level (2-tailed)

$\mathrm{ND}=$ neighborhood disorder composite

$\mathrm{EV}=$ exposure to violence

MHI $=$ percent of households with a median household income of $<\$ 25,000$ per year

NWR $=$ percent of non-white residents

$\mathrm{HR}=$ percent of Hispanic residents

$\mathrm{PFP}=$ number of pre-foreclosure properties

$\mathrm{BOP}=$ number of bank-owned properties

$\mathrm{BI}=$ behavioral intentions for having safe sex

USS = unsafe sex behavior, previous eight months

Multiple regression analyses were conducted to evaluate how well neighborhood measures predicted behavioral intentions. The first analysis included the two neighborhood variables collected during the parent study (neighborhood disorder and exposure to violence). A subsequent exploratory analysis included ZIP Code data (percent of households with a median income of less than $\$ 25,000$ per year, percent of non-white residents, percent of Hispanic residents, number of pre-foreclosure properties, 
and number of bank-owned properties). Criterion variables were behavioral intentions and unprotected sex behavior for the past eight months.

Neighborhood disorder and exposure to violence did not explain a significant proportion of the variance in behavioral intentions, $R^{2}=.01$, adjusted $R^{2}=-.01, F(2,177)$ $=.41, p=.66$. Likewise, the variables did not explain a significant proportion of the variance in unsafe sex behavior, $R^{2}=.0003$, adjusted $R^{2}=-.01, F(2,176)=.03, p=.97$. The linear combination of neighborhood measures and ZIP Code data did not significantly predict behavioral intentions, $R^{2}=.02$, adjusted $R^{2}=-.03, F(7,135)=.41, p$ $=.89$. However, they did predict a significant percentage of the variance in unprotected sex behavior, $R^{2}=.11$, adjusted $R^{2}=.06, F(7,135)=2.32, p=.03$. In the model, only the percent of Hispanic residents in the neighborhood was found to be significant, $\beta=.66, p$ $=.01$.

A hierarchical multiple regression was conducted in order to examine the relationship between control variables, neighborhood indices, and outcomes. For behavioral intentions, control variables (age, race, gender, and family structure) explained $12 \%$ of the variance, $R^{2}=.12, F(4,128)=4.15, p=.003$. After controlling for demographic variables, neighborhood disorder and exposure to violence did not explain a statistically significant proportion of the variance in behavioral intentions, $R^{2}$ change $=$ $.01, F(2,161)=.03, p=.29$. When ZIP Code data was added, neighborhood elements did not explain a statistically significant proportion of variance in behavioral intentions, $R^{2}$ change $=.02, F(7,121)=.45, p=.87$. Similarly, though control variables explained $8 \%$ of the variance in unprotected sex behavior for the past eight months, $R^{2}=.08, F(4,127)$ 
$=2.71, p=.03$, adding neighborhood disorder and exposure to violence did not explain a significantly higher proportion of the variance, $R^{2}$ change $=.001, F(2,159)=.12, p=.88$. Adding ZIP Code indices to the neighborhood measures did not explain a significantly higher proportion of the variance, $R^{2}$ change $=.08, F(7,120)=1.65, p=.13$.

Multiple regression analyses were conducted in order to examine how much of the variance in outcomes was explained by all predictors: parenting, attitude, neighborhood disorder, and exposure to violence. The variables predicted $22 \%$ of the variance in behavioral intentions, $R^{2}=.22$, adjusted $R^{2}=.18, F(8,155)=5.60, p<.001$. Significant variables included condom attitudes $(\beta=.43, p<.01)$, sexual attitudes ( $\beta=$ $.50, p=.02)$, parental presence $(\beta=.93, p=.001)$, and parent-family connectedness $(\beta=$ $-2.28, p=.02)$. The linear combination of parenting, attitudes, neighborhood disorder, and exposure to violence did not explain a significant proportion of the variance in unprotected sex behavior, $R^{2}=.04$, adjusted $R^{2}=-.01, F(8,153)=.80, p=.60$.

Exploratory analyses that included ZIP Code level data followed a similar pattern. For behavioral intentions, the variables predicted $26 \%$ of the variance in behavioral intentions, $R^{2}=.26$, adjusted $R^{2}=.18, F(13,117)=3.14, p<.001$. Significant variables included condom attitudes $(\beta=.23, p=.02)$, parental presence $(\beta=.32, p=.002)$, and parent-family connectedness $(\beta=-.18, p=.04)$. However, for unprotected sex behavior, variables did not explain a significant proportion of the variance, $R^{2}=.11$, adjusted $R^{2}=$ $.007, F(13,116)=1.07, p=.40$.

Control variables, including age, race, gender, and family structure, were regressed in order to examine their relationship to intentions and behavior. Control variables accounted for $10 \%$ of the variance in behavioral intentions, $R^{2}=.10, F(4,147)=$ 
$3.99, p=.004$. After controlling for demographic variables, attitudes, parenting, neighborhood disorder, and exposure to violence explained a significantly higher proportion of the variance in behavioral intentions, $R^{2}$ change $=.18, F(8,139)=4.42, p<$ .001 . For unsafe sex behavior, demographic variables explained $7 \%$ of the variance, $R^{2}=$ $.07, F(4,145)=2.50, p<.05$. After controlling for demographics, attitudes, parenting, neighborhood disorder, and exposure to violence did not explain a significantly higher proportion of the variance in unsafe sex behavior, $R^{2}$ change $=.03, F(8,137)=.50, p=$ .85 .

As noted previously, neighborhood ZIP Code indices were only available for Miami-Dade County, so control variable analyses had to be repeated with the slightly smaller sample size $(n=151)$. Control variables explained approximately $12 \%$ of the variance in behavioral intentions, $R^{2}=.12, F(4,116)=4.00, p=.004$. After controlling for those factors, attitude, parenting, neighborhood variables and ZIP Code data explained a statistically significant proportion of the variance, $R^{2}$ change $=.21, F(13,103)$ $=2.55, p=.004$. Age, race, gender, and family structure did not significantly explain the variance in unprotected sex behavior, $R^{2}=.08, F(4,115)=2.34, p=.05$. After controlling for those factors, attitude, parenting, neighborhood variables and ZIP Code data did not explain a higher proportion of the variance, $\mathrm{R}^{2}$ change $=.08, F(13,102)=.77, p=70$.

Finally, a stepwise multiple regression was conducted to evaluate which of the independent variables were necessary to predict the outcomes of interest, behavioral intentions and unprotected sex behavior for the previous eight months. When control variables, parenting variables, attitudes, neighborhood disorder and exposure to violence 
were used to predict behavioral intentions, they explained $26 \%$ of the variance, $R^{2}=.26$, $F(6,145)=8.43, p<.001$. See Table 6 for regression results.

Table 6.: Summary of Multiple Regression Analysis for Behavioral Intentions for Safe Sex $(n=151)$

\begin{tabular}{lllll}
\hline Variable & B & SE(B) & $\boldsymbol{\beta}$ & $\boldsymbol{t}$ \\
\hline Gender & 5.32 & 1.97 & 0.20 & $2.71^{* *}$ \\
\hline Sexual attitudes & 0.47 & 0.21 & 0.18 & $2.23^{*}$ \\
\hline Condom attitudes & 0.42 & 0.16 & 0.21 & $2.57^{*}$ \\
\hline Parental presence & 0.73 & 0.25 & 0.22 & $2.92^{* *}$ \\
\hline $\begin{array}{l}\text { Parent-family } \\
\text { connectedness }\end{array}$ & -1.92 & 0.97 & -0.15 & -1.98 \\
\hline Neighborhood disorder & 0.27 & 0.12 & 0.17 & $2.27^{*}$ \\
\hline
\end{tabular}

$*=\mathrm{p}<.05$

$* *=\mathrm{p}<.01$

The most parsimonious model for unprotected sex behavior included only one variable, living situation for the previous year, and explained $3 \%$ of the variance; $R^{2}=$ $.03, F(1,148)=4.59, p=.03$.

When ZIP Code data was included for exploratory purposes, the final models were similar to those without ZIP Code data. The most parsimonious model for behavioral intentions included gender, sexual attitudes, condom attitudes, parental presence, and neighborhood disorder and explained $29 \%$ of the variance in behavioral intentions, $R^{2}=.29, F(5,115)=9.24, p<.001$. See Table 7 for regression results.

Table 7.: Summary of Multiple Regression Analysis for Behavioral Intentions for Safe Sex, including ZIP Code level data $(n=115)$

\begin{tabular}{lllll}
\hline Variable & B & SE(B) & $\boldsymbol{\beta}$ & $\boldsymbol{t}$ \\
\hline Gender & 7.86 & 2.05 & 0.31 & $3.83^{* *}$ \\
\hline Sexual attitudes & 0.47 & 0.22 & 0.19 & $2.14^{*}$ \\
\hline
\end{tabular}




\begin{tabular}{lllll}
\hline Condom attitudes & 0.33 & 0.16 & 0.18 & $2.02^{*}$ \\
\hline Parental presence & 0.69 & 0.25 & 0.22 & $2.73^{* *}$ \\
\hline Neighborhood disorder & 0.27 & 0.13 & 0.17 & $2.11^{*}$ \\
\hline$*=\mathrm{p}<.05$ & & & & \\
$* *=\mathrm{p}<.01$ & & & &
\end{tabular}

The most parsimonious model for unprotected sex behavior included two variables, living situation for the previous year, and percent of Hispanic residents in the neighborhood, and explained $7 \%$ of the variance; $R^{2}=.07, F(2,117)=4.60, p=.01$. See Table 8 for unprotected sex behavior regression results.

Table 8.: Summary of Multiple Regression Analysis for Unsafe Sex Behavior (n = 117), including ZIP Code data

\begin{tabular}{lllll}
\hline Variable & $\mathbf{B}$ & $\mathbf{S E}(\mathbf{B})$ & $\boldsymbol{\beta}$ & $\boldsymbol{T}$ \\
\hline Living situation & 11.4 & 8.06 & 0.13 & 1.42 \\
\hline $\begin{array}{l}\text { Percent Hispanic residents } \\
\text { in neighborhood }\end{array}$ & 0.30 & 0.14 & 0.20 & $2.20^{*}$ \\
\hline & & & & \\
$* \begin{array}{l}* \\
* * 05\end{array}$ & & & & \\
$* \mathrm{p}<.01$ & & & &
\end{tabular}

The next chapter will discuss and analyze the results found in Chapter IV. Limitations of the study, practical implications of the findings, and recommendations for future research will also be addressed. 


\section{CHAPTER V}

\section{Introduction}

The purpose of this study was to examine the relationship between neighborhood disorder, parenting factors, sexual attitudes, sexual risk intentions and overall behavior among adolescents ages 13-18 in Miami-Dade, Broward, and Palm Beach Counties, Florida. The study examined how parenting skills, including good communication, high levels of involvement and monitoring, and a close caring relationship impact adolescent safe sex behavioral intentions compared to their actual sex behaviors in the previous eight months. Adolescents' attitudes regarding sex and condom use were also investigated in order to establish whether there was a link to intentions and sex behavior. Next, the study explored how neighborhood elements, including neighborhood disorder, exposure to violence, median household income, racial/ethnic diversity, and number of preforeclosures/number of bank-owned properties impacted behavioral intentions and sex behavior.

\section{Conclusions}

Statistically significant findings are summarized below. For behavioral intentions to have safe sex, several group differences and correlations were found. Males reported less favorable behavioral intentions for safe sex than females, and participants younger than 16 reported more favorable intentions than those 17 and older. A low correlation was found between both condom attitudes and sexual attitudes and behavioral intentions. Behavioral intentions were also associated with parental presence. Sexual attitudes and 
condom attitudes predicted a significant proportion of the variance in behavioral intentions. The relationship remained when controlling for age, gender, race, and family structure. Parenting variables explained a significant proportion of the variance in behavioral intentions, but only parental presence and parent-family connectedness were significant in the regression equation. However, after controlling for demographic variables, the relationship did not hold. When examining all six attitude and parenting variables in conjunction, parental presence, parent-family connectedness, condom attitudes, and sexual attitudes explained a significant proportion of the variance in behavioral intentions. The relationship held when controlling for age, gender, race, and family structure. Finally, it was found that when examining all parenting, attitude, and neighborhood variables, a statistically significant proportion of the variance in behavioral intentions was found. Significant variables included condom attitudes, parental presence, and parent-family connectedness. The relationship held when controlling for demographics. The most parsimonious model for behavioral intentions included the following variables: gender, sexual attitudes, condom attitudes, parental presence, and neighborhood disorder.

Behavioral intentions for having safe sex was not associated with the number of unsafe sex acts that a participant reported in the previous eight months. Of all the parenting and attitude predictors, unsafe sexual behavior was only associated with parental presence. Of the seven neighborhood variables, percentage of non-white residents and percentage of Hispanic residents were associated with unsafe sex behavior. Neighborhood indices predicted a significant percentage of the variance in unsafe sex 
behavior, but this relationship did not hold when controlling for age, gender, race, and family structure. The most parsimonious model for unprotected sex behavior only included two variables: whether the participant lived with both natural parents for the previous year and the percentage of Hispanic residents in the neighborhood.

\section{Research Questions}

Hypothesis 1: Positive attitudes about safe sex and higher rates of parentadolescent activities, communication about sex, parent-family connectedness, and parental presence will be associated with lower intention to participate in risky sexual behavior. Lower intention to participate in risky sexual behavior will be associated with lower rates of risk behavior.

Statistical findings offer partial support for hypothesis 1. Results indicated that both sexual attitudes and condom attitudes predicted behavioral intentions and were a part of the model that predicted the highest proportion of variance in behavioral intentions. This finding supports the use of the Theory of Planned Behavior (TPB) for the current study, in that attitudes are presumed to directly influence behavioral intentions. However, attitudes were not correlated with or predictive of the number of unsafe sex encounters in the previous eight months. The sexual attitudes scale used in the current study measured perceived peer and family attitudes with questions like, "would your friends approve or disapprove of you using a condom," and "how important is their approval or disapproval?" A recent study of adolescent females found that personal attitudes were highly correlated with sexual behaviors, but perceived peer and family 
attitudes had an inconsistent relationship with various sexual behaviors (Akers, Gold, Bost, Adimora, Orr, \& Fortenberry, 2011). Though in the current study attitudes did not predict sexual behavior in a cross-sectional sample, studies have found that attitudes are even less likely to predict behavior longitudinally because attitudes change in response to previous risk behavior (Huebner, Neilands, Rebchook, \& Kegeles, 2011).

For parenting variables, parental presence and parent-family connectedness predicted behavioral intentions, but parental presence was the only independent parenting variable that remained in the final model for predicting behavioral intentions once demographic variables were taken into account. The lack of significant findings for other parenting variables suggests that more appropriate subjective norms variables may exist. Typically, within the framework of the TPB, subjective norms include the extent to which other people in the individual's life approve of a behavior, and to what degree the individual wants to align their behavior with that approval (Mathews, Aarø, Flisher, Mukoma, Wubs, \& Schaalma, 2009). This definition is slightly different from the perspective of the current study, which examined adolescent's perception of parenting variables but did not directly measure the extent to which an adolescent was motivated to honor their parents' wishes. A 2007 review by Buhi and Goodson noted many variables that were categorized as subjective norms in the literature base, including perception of peer sex behaviors, perception of peer or parent disapproval of sex, self-efficacy, proabstinence self-standards, and more. Social norms, which generally refer to peer interactions, have been consistently linked to sexual behavior outcomes (Kirby, 2001).

Though parental presence was not ultimately retained in the model for unsafe sexual behavior, it is worth noting that presence was the only parenting factor that was 
independently correlated with both intentions and unsafe sexual behavior. This finding lends credence to the inclusion of parental presence as a component of the subjective norms element of the TPB. Parental presence was also correlated with all of the other parenting variables - global communication, parent-family connectedness, and parentadolescent activities, suggesting that a parent that spends time with their child is practicing other healthy parenting behaviors. Interestingly, parental presence is positively correlated with unsafe sexual behavior, indicating that higher levels of presence were associated with higher reported numbers of unsafe sex acts. The positive correlation could be due to over-monitoring of adolescents such that the adolescent feels the need to exert their independence through risky behavior. For example, if a parent does not allow their adolescent some measure of autonomy, the adolescent may consider the parent to be overly controlling and act out with risk behaviors (Miller, McCoy, Olson, \& Wallace, 1986). There is also a temporal element missing from the analyses. Parents that are aware of their adolescents' risk behavior may increase presence in the home in order to curb the undesirable behavior (Aisenberg \& Herrenkohl, 2008). Alternatively, the finding could indicate poor construct validity for parental monitoring. As noted in the literature review, parental presence does not perfectly align with parental monitoring, which includes not only measures of presence but also rule creation, control of activities in and out of the home, and daily supervision (Meschke, Bartholomae, \& Zentall, 2002). The variable in the current study measured presence of a parent at three times: when the adolescent leaves for school, returns from school, and goes to bed. There are plenty of hours between those three times for adolescents to participate in risk behavior. A parental monitoring variable that better encompasses presence, boundaries, control, and awareness 
of activities could clarify the relationship with unsafe sexual behavior. A recent review from de Graaf et al. (2011) argues that the relationship between parental control and condom use may not be the best measure of sexual health. Other decisions can translate to safe sex behavior, including delay of intercourse, contraceptive use, and monogamous sex with a partner that has never had sex before (de Graaf, Vanwesenbeeck, Woertman, $\&$ Meeus, 2011). Research also suggests that attitudes and subjective norms may not be as predictive as expected because condom use is a complex interaction that involves impulse control and perceived behavioral control (Sacco, Levine, Reed, \& Thompson, 1991).

For demographic variables, group differences were found between males and females and between age groups. Further, gender remained a part of the best model for predicting behavioral intentions when considering all of the possible independent variables. The finding that males report less positive behavioral intentions indicates that males might be less likely to have safe sex. This both supports and refutes current data regarding gender-based differences in sexual behavior. According to the $\mathrm{CDC}$, males are more likely to have had sex ( $46.1 \%$ males vs. $45.7 \%$ females), but also more likely to report condom use at the most recent sexual encounter (68.6\% males vs. $53.9 \%$ females) (CDC, 2010a). This could be because males have more behavioral control over whether to use condoms during a sexual encounter. One study theorizes that gender differences are rooted in societal roles; males are encouraged to have sex while women are encouraged to delay sex as long as possible (Archibald, Gillmore, Graham, Hoppe, Morrison, \& Murowchick, 2001). A male adolescent that felt societal pressure to have sex may express lower behavioral intentions for safe sex than a female who is encouraged 
to be "pure". Studies show that males and females report different sources of messaging regarding sexual behavior, which may explain how they internalize the messages. For example, females report significantly more than males that the media, peers, and parents are their sources of sexual information (Bleakley, Hennessy, Fishbein, Coles, \& Jordan, 2009).

Age differences are supported by recent CDC data - in high school, the percentage of students that have ever had sex increases with each grade level; approximately $31.6 \%$ of $9^{\text {th }}$ graders have ever had sex compared to $62.3 \%$ of $12^{\text {th }}$ graders. This relationship holds for current sexual activity (CDC, 2010a). In terms of age differences, the current study found that 17- and 18-year-old participants had lower scores on behavioral intentions, indicating that they might be less likely to have safe sex. The age differences may be related to the phenomenon of emerging adulthood, the period of transition after puberty ends and before a stable, mature life phase is reached (Jensen, 2011). In the literature, adolescents and emerging adults are often studied in tandem despite their inherent differences (Smahel, Brown, \& Blinka, 2012). Some studies suggest that emerging adults are in their early twenties (Lam \& Lefkowitz, 2012), but emerging adulthood is a concept that can vary widely by culture, country, family, and even individual (Jensen, 2011). At 17 and 18, adolescents that are soon to be out of their parents' house may have a different profile of risk than adolescents 16 and younger.

Perhaps most importantly, the study found that behavioral intentions for safe sex were not associated with reported unsafe sexual behavior in the previous eight months and did not explain a significant proportion of the variance in sexual behavior. This finding is contrary to both conventional wisdom and other research findings. For 
example, a 2007 review of adolescent sexual behavior literature found intentions to be one of only three stable predictors of adolescent sexual behavior (Buhi \& Goodson, 2007). Researchers suggest that when there are discrepancies between intentions and behavior, it could be due to the type of behavior, type of intention, and a host of other personality variables (Sheeran, 2002).

The finding suggests one of two possibilities: adolescents over-reported positive behavioral intentions, or mechanisms other than behavioral intentions have an impact on whether an adolescent will practice unsafe sex. Because questionnaires were administered to adolescents by an assessor, participants may have felt social pressure to represent themselves in the most positive way by over-reporting behavioral intentions and/or under-reporting unsafe sexual behavior. Recent studies have found that utilizing self-administered surveys, such as computerized questionnaires, can reduce social desirability bias and increase concurrent validity (Chang \& Krosnick, 2010). The framework of the TPB suggests that the other explanation for why intentions did not predict behavior is because perceived behavioral control had more influence on sexual behavior than behavioral intentions. Though sexual attitudes and condom attitudes were related to behavioral intentions, neither were associated with or predictive of unsafe sexual behavior, which supports the argument that attitudes are more predictive of intentions than of actual behavior (Kegeles, Adler, \& Irwin, 1988). Studies suggest that intentions are more likely to be linked to behavior in samples of older persons and those in steady relationships compared to those casual relationships, regardless of age (Sheeran $\&$ Orbell, 1998). Both of these factors may explain why intentions were not predictive of 
condom use: the population was 13-18 years old and may have been more likely to be in casual relationships because of the nature of adolescent dating.

Finally, the finding that there was no link between intentions and behavior could indicate that the TPB was not the best theoretical model to explain sexual behavior in the population. An integrative model of behavior change, whereby behavioral intentions in combination with skills and environmental constraints affect individual behavior, may be more appropriate.

It is possible that findings were not highly predictive of the variance in sexual behavior because there were confounding variables that were not examined. One such variable is peer influence. Parents recognize that peers have a huge influence over their children's lives, but sometimes parents do not understand how they can mediate the relationships between their adolescents and new friends (Lebese, Davhana, \& Obi, 2010). Jaccard et al. (2002) argue that adolescents may see parents, peers, and medical professionals as experts in different realms of communication about sex. For example, one study found that adolescents trusted parents more than peers or the media for biological information about anatomy, pregnancy, and other similar topics (Epstein \& Ward, 2008). Another study found that peers may have a more significant influence over short-term choices like hair style, clothing, and music, but parents often hold more influence over long-term behaviors including substance use and sexual activity (Wang, Peterson, \& Morphey, 2007).

Indeed, in the struggle between parents and peers, though peer influence usually comes out on top (Kinsman, Romer, Furstenberg, \& Schwarz, 1998), research appears to be agreeing that parents can and do have a significant influence on behavior. Stanton et 
al. (2004) argue that parents could have more of a long-term impact than peers because parents are a much more stable presence than friends, especially as the child moves from middle to high school, and high school to college (Blake, Simkin, Ledsky, Perkins, \& Calabrese, 2001). There is a case to be made for both peer influence and parental influence in shaping the behavior of an adolescent.

In addition to parenting and peers, genes are arguably the third arm that determines behavior. While genetics sometimes seems like an easy scientific explanation for an outcome, (i.e. if you have Gene $\mathrm{X}, \mathrm{Y}$ will happen to you) the field simply adds another layer of complexity to the puzzle of behavior (Collins, Maccoby, Steinberg, Hetherington, \& Bornstein, 2000). Research has revealed traits that may increase or decrease the propensity for risk behavior. Genes have been linked to some behaviors, especially those predicting certain psychopathologies, and the interaction between genes and the environment is being increasingly cited as a predictor for health outcomes (Collins, Maccoby, Steinberg, Hetherington, \& Bornstein, 2000). Environmental factors have has been shown to affect even such highly heritable traits as height (Angoff, 1988). Recent developments in the field of epigenetics have shown that the interaction between genetic code and the environment may work both ways: starvation, overeating, smoking, excessive drinking, and other behaviors have been shown to change epigenetic mechanisms, which are then passed on to children within one generation (Cloud, 2010). The current study did not examine genetic code as a precursor to behavior but it is important to consider heredity as an equally important piece of the puzzle moving forward. 
Another potential confounding variable is religious affiliation and commitment to religion of the parents and child. A recent study found that religious parents are less likely to have a sexually promiscuous child. The researchers theorize that this link is due to more authoritative parenting, more religious commitment among the adolescent, and fewer negative peer influences for the adolescent (Landor, Simons, Simons, Brody, \& Gibbons, 2011). In the surveys administered in this study, few questions were asked about religious affiliation or extent of participation. The only relevant question asked to adolescents in the Adolescent Health Questionnaire was whether the teen had attended a religious service with either parent in the last 30 days. Religiosity could be an important part of subjective norms and should be considered in future research.

Ultimately, due to inconsistencies in the findings, hypothesis 1 must be rejected. Though positive sexual attitudes, condom attitudes, and parental presence predicted behavioral intentions, the other three parenting variables (global communication, parentadolescent activities, and parent-family connectedness) were not associated with behavioral intentions. Further, behavioral intentions were not correlated with the number of unsafe sex acts that an adolescent has reported in the previous eight months.

Hypothesis 2: High levels of neighborhood stress factors including disorder, exposure to violence, poverty, racial/ethnic diversity, and residential instability will be associated with lower rates of positive behavioral intentions and high rates of sexual risk behavior including multiple partners, sexual activity concurrent with drug/alcohol use, and lack of condom use. Neighborhood stress will change the relationship between 
attitudes, parenting, behavioral intentions, and risky sexual behavior so that a different set of variables is most predictive of the outcomes.

Statistical findings offer partial support for hypothesis 2 . The most parsimonious model explained $29 \%$ of the variance in behavioral intentions and included gender, sexual attitudes, condom attitudes, parental presence, and neighborhood disorder. The significant variables represent each category in the TPB: attitudes (condom and sexual), subjective norms (parental presence), and perceived behavioral control (neighborhood disorder). Attitudes and parenting variables were discussed above, so this section will focus on the contribution of neighborhood disorder to behavioral intentions. As discussed in the literature review, neighborhood stress has both direct and indirect links to adolescent sex behavior (Browning, Burrington, Leventhal, \& Brooks-Gunn, 2008; Driscoll, Sugland, Manlove, \& Papillo, 2005; Ramirez-Valles, Zimmerman, \& Newcomb, 1998). However, neighborhood disorder was not included in the final model for unsafe sexual behavior. Another recent study had similar findings: once demographics were controlled for, neighborhood disorder did not predict sexual onset of adolescents (Roche \& Leventhal, 2009). It is possible that environmental factors other than neighborhood stress have a more significant impact on sexual health behavior. In a study of racial differences in the age of onset of sexual behavior, authors found significant effects of concentrated neighborhood poverty, a scale score composed by percent residents with incomes below the poverty line, percent receiving public assistance, percent unemployed, and percent of households headed by females (Browning, Leventhal, \& Brooks-Gunn, 2004). Concentrated poverty explained residual differences between African American, European American, and Latino youths that were not 
explained by individual factors. The same study found significant effects of collective efficacy, which measured elements of trust between neighbors, whether neighbors shared the same value system, whether adults in the neighborhood recognized local children, and other similar items (Browning, Leventhal, \& Brooks-Gunn, 2004). A study utilizing National Longitudinal Study of Adolescent Health (Add Health) data studied similar poverty measures but also examined norms and opportunity structure by looking at proportions of youth who were not in school, the armed forces, had not graduated from high school, and did not report any work (Cubbin, Santelli, Brindis, \& Braveman, 2005). The study also measured social organization through the proportion of households that had married couples living with their children under 18 years old. Though all neighborhood indices were associated with sexual initiation, the authors also found gender differences. For example, males living in areas with a high concentration of poverty or a high proportion of idle youth were more likely to have initiated sex (Cubbin, Santelli, Brindis, \& Braveman, 2005). Potential neighborhood variables abound, and more research is needed in order to parse out which indices have the most significant effects on sexual behavior.

Percent of non-white residents, percent of Hispanic residents and unsafe sex behavior were found to be correlated. As percent of non-white residents in the neighborhood increased, percent of Hispanic residents decreased. This finding could indicate that ZIP Code areas in Miami-Dade County were highly segregated, with nonwhite residents clustering in different ZIP Codes from Hispanic residents. Literature provides support for this theory, finding "severe racial isolation of Blacks in Miami" (Eitle \& Taylor, 2008). There was a low negative correlation between percent of non- 
white residents and unsafe sexual behavior and a low positive correlation between percent of Hispanic residents and unsafe sexual behavior. Percentage of Hispanic residents in the neighborhood was also one of the only two variables left in the best-fit model for unsafe sex behavior when considering all possible predictors. The current sample included 22 participants that reported Hispanic ancestry, which was not a large enough group to statistically compare to other racial or ethnic groups. However, recent data from the CDC shows a conflicting trend: black students consistently reported more sex behaviors than Hispanic or white students (CDC, 2010a). The discrepancy may lie in the level of data analysis: percent of Hispanic residents was a measure linked to ZIP Code, not individually reported behavior. Therefore, the differences in ethnicity are more likely representative of a community issue than an individual one. Research on ethnicity and sexual behavior among adolescents reveals a trend whereby risk behavior profile changes based the generational immigrant status. For example, first-generation Latino adolescents displayed the lowest levels of sexual risk behavior in the Add Health sample (Guarini, Marks, Patton, \& Coll, 2011). Other studies have found that among Hispanic youths, being a second-generation immigrant is protective, but Hispanics that are thirdgeneration fall into a higher risk category (Spence \& Brewster, 2010). Neighborhoods in Miami-Dade County that have long been home to Hispanic immigrants may have adolescents that are several generations removed, which could potentially place them in a higher risk category.

The other predictor variable that remained in the best-fit model was whether the adolescent reported living with both natural parents in the previous year. Literature regarding family structure reports mixed outcomes. For example, studies have shown that 
living with single parents or blended families increases the risk of early onset of sexual initiation (Zimmer-Gembeck \& Helfand, 2008). Other studies found that family structure variables in ethnic minority samples did not predict adolescent sexual risk behavior (Miller, Forehand, \& Kotchick, 1999). The current study also found that adolescents living with both natural parents reported more parental presence and participated in more activities with their parents than adolescents in other living situations. This could be the mechanism by which family structure is related to unsafe sexual behavior: if a parent is spending less time with their child because there is only one parent in the household, the child would have more unsupervised time, which is independently associated with sexual behavior (Li, Stanton, \& Feigelman, 2000).

As noted above, disorder was the only neighborhood variable that remained in the predictor model for behavioral intentions and percent of Hispanic residents was the only neighborhood variable that remained for unsafe sex behavior. It is possible that a different set of variables better represents the perceived behavioral control arm of the TPB. For example, many studies include self-efficacy as a part of perceived behavioral control (Azjen, 2002; Terry \& O'Leary, 1995), but self-efficacy was not measured in the current study. A meta-analysis of studies utilizing the TPB represented perceived behavioral control with questions including, "whether or not I do [behavior] is entirely up to me", "how much personal control do you feel you have over [behavior]" and "how much do you feel that whether you do [behavior] is beyond your control" (Armitage \& Connor, 2001). These types of questions are much more specific and linked to the outcome variable than the broad neighborhood elements investigated in the current study. 
Additionally, the City Stress Inventory (CSI), from which neighborhood disorder and exposure to violence were gathered, may not be the best measure of neighborhood stress. Aisenberg and Herrenkohl refer to a simple scoring method, as used in the CSI, as "rudimentary", and note that simply adding up the number of violent events that an adolescent has been exposed to discounts the differential impact of a more violent event (i.e. assault) versus a less violent event (i.e. family member being stopped by police for questioning) (2008). Further, the CSI measures frequency of events experienced, not the degree to which participants were affected by events of neighborhood stress or violence. Researchers have noted that the interpretation of a threat to safety is more associated with negative health outcomes than the threat itself (Rasmussen, Aber, \& Bhana, 2004). In other words, it only matters how a person interprets violence, not the violence itself.

Alternatively, neighborhood stress may not have been best variable to represent the community environment. The community environment can also be captured with models of community capacity, natural helpers, and social capital theory (DiClemente, Crosby, \& Kegler, 2002). Social capital, in particular, captures elements of the community that are not addressed by neighborhood stress, including collective efficacy, neighborhood cohesion, community competence, and the psychological sense of community (Lochner, Kawachi, \& Kennedy, 1999). Studies have found that like neighborhood stress, social capital is related to both poverty and income inequality (Holtgrave \& Crosby, 2004). The difference between social capital and neighborhood stress is that social capital involves social structures and personal interactions between residents (Hyyppä \& Mäki, 2003), while neighborhood stress reflects more of the physical environment that residents experience on a daily basis. Social capital is still an 
emerging theory (Carlson \& Chamberlain, 2003), and more research in this area could strengthen future studies of neighborhood stress and individual behavior.

Studies have shown associations between exposure to violence, parental variables, and negative health outcomes (Hammack, Richards, Luo, Edlynn, \& Roy, 2004). However, in the current study, the other CSI element, exposure to violence, was not associated with any behavioral outcomes. The CSI does not distinguish between victims of violence and witnesses to violence and instead asks whether the adolescent has known someone to be the victim of theft, assault, rape, or murder. Researchers have not found consistent differences between children who were witnesses to violence compared to children who were the victims of violence (Aisenberg \& Herrenkohl, 2008), but there could be a different pattern of outcome risk for victims versus witnesses. Further, most studies of community violence are based only on parents or children reporting an experience that has happened to them or someone they know. This way of asking about violence and disorder is partially based on how the parent or child perceive their experience, and therefore could either under or over-report the actual crime rates in the community (Lynch, 2003). The resident's experience of the violence may be all that matters, as studies have found methods of coping with violence is ultimately what determines the association with health outcomes (Rasmussen, Aber, \& Bhana, 2004). Examining absolute crime rates as collected by police officers and reporting databases both in order to compare them to the personal reports and to examine the effects on behavior could provide valuable insight into neighborhood stress as a predictor.

Some evidence was found to support hypothesis 2, including neighborhood disorder as a predictor of behavioral intentions and percent of Hispanic residents in the 
neighborhood as a predictor of unsafe sexual behavior. However, because the remaining neighborhood indices were not correlated with or predictive of either sex outcome, hypothesis 2 must be rejected.

\section{Limitations}

Beyond the limitations discussed above regarding each hypothesis, there are several overarching limitations that relate to study design and methods. One notable limitation is the lack of temporal context in this study. Researchers have noted that the timing and duration of certain parental factors should ideally be addressed in order to measure their impact in the most accurate way (Aisenberg \& Herrenkohl, 2008). For example, if increased parental monitoring is only undertaken in response to a negative behavior, perhaps a temporal element should be added to the parental presence construct. The same concept could be applies to parent communication: a parent may increase their communication about sex after they discover that their child is sexually active.

All data in this study was from the adolescent perspective. However, adolescent perspective is not necessarily correlated $100 \%$ with parent perspective. Therefore, the adolescent reporting of parent factors may or may not reflect actual parenting practices. Beyond this perspective problem, there is also the general problem of the validity of selfreporting about behavior. Like the current study, previous studies have found when using the TPB as a model, behavioral intentions are highly correlated with self-report behaviors, but not necessarily observed behaviors. This is fairly convenient for sexual behavior studies, which never include observed behavior. However, this could skew 
results, explaining more variance than would be explained in reality (Armitage \& Connor, 2001).

Analyses were also limited by sample size and sampling method. In the LEAP parent study, participants were convenience sampled using flyers and outreach in the local community. Convenience sampling does not ensure that the sample is representative of the population (Trochim, 2005). In this case, study adolescents may not represent typical adolescents in south Florida. For example, perhaps study participants were encouraged to participate by their parents because the parents had learned that the teen was sexually active or engaging in other risk behaviors. The total number of adolescent participants in the LEAP study was 204, but the final number of participants that completed intake questionnaires was 196. The sample was further limited by incomplete data on individual instruments. All composite scores required that at least $80 \%$ of the individual questions were answered for a score to be recorded; this excluded some participants from each construct calculation. As noted previously, ZIP Code analyses were limited to Miami-Dade County, which reduced the available sample size to 151 participants. Additionally, ZIP Code analyses were severely limited because of the small sample size and uneven distribution of participants throughout south Florida. Some ZIP Codes were represented by only one participant, whereas others had 20 participants. Gathering a representative sample is paramount to sound research

Another limitation is in regards to one of the primary dependent variables, behavioral intentions for having safe sex. The composite score calculated for behavioral intentions addresses the participant's intentions for several behaviors: intention to communicate about HIV/AIDS, intention to use a condom, intention to use a condom 
even when under the influence of alcohol and drugs, intention to discuss the number of sex partners, and more. In order for behavioral intentions to correctly predict behavior, the intention must be targeted to one particular behavior. This limitation may explain why in the current study behavioral intentions to have safe sex were not predictive of unsafe sexual behavior. Future research with this dataset should utilize the single question "I will use a condom the next time I have sex" when attempting to predict condom use among adolescents.

Other limitations involve the neighborhood measures, organized by ZIP Code, for participants residing in Miami-Dade County. As noted in previous chapters, researchers have found that the most useful representation of neighborhood stress include poverty, amount of racial and ethnic diversity, and residential instability (Aisenberg \& Herrenkohl, 2008). Data added to the current study was limited because participants were organized by ZIP Code. ZIP Code boundaries are fairly fluid and do not perfectly align with census tracts, so census data could not be utilized. Instead, data from local sources was leveraged in order to provide a more comprehensive picture of neighborhood influences. For the current study, poverty was represented by the percentage of households with a median income of less than $\$ 25,000$. The weighted poverty threshold from 2009 (the year of the ZIP Code median household income data) was $\$ 10,956$ (United States Census Bureau, 2009). For a household with four people, this number jumped to $\$ 21,954$. In the current study, number of residents in the household was not measured, so for some households $\$ 25,000$ might mean abject poverty, while for others it might mean living more comfortably. Therefore, median household income is not a perfect measure of poverty. Residential instability was represented by two measures: 
number of pre-foreclosure properties, and number of bank-owned properties. While foreclosures would certainly indicate that residents in the neighborhoods are not financially stable, this may be a better representation of poverty or economic stress than residential instability. Additionally, considering the present depressed economic climate and the nature of housing in south Florida, a traditional vacation destination, it is possible that the number of foreclosures is inflated because people allowed second homes to go into foreclosures. Because the study population was not gathered from the wealthiest regions of south Florida, this is likely not a concern, but should be a consideration. Local data was from 2008 (housing data) and 2009 (median household income and racial/ethnic percentages), while data collection for the current study occurred between 2004 and 2008. According to the United States Postal Service, ZIP Codes occasionally change based on population and operational needs (2012). It is possible that because of the range of years, ZIP Code boundaries may have shifted and altered the placement of some participants. Finally, as noted in the data analytic plan and results, analyses that included ZIP Code data were purely of an exploratory nature. Complete neighborhood analyses must control for the difference between community and individual-level variables and include a mixed multi-level model. Additionally, some ZIP Codes were only made up of one participant, while some had almost 20 participants. Assigning weights to ZIP Codes could have provided a more accurate representation of community patterns in health. Studies have found difficulties in assigning group-level variables to individual health measures (Roux, 2004), and more research in this area is warranted. 


\section{Recommendations}

The findings provided in the current study could be a valuable addition to the development of intervention programs for adolescent sexual behavior. Specifically, the group differences in behavioral intentions for gender and age offer a unique opportunity for tailoring intervention programs to different groups of students. Examining children before they reach the more at-risk adolescent years is a valuable research opportunity. As noted by Archibald et al., gender differences in sexual behavior intentions, actual behavior, and age of sexual initiation often exist. However, these differences are not accounted for during sex education program planning (Archibald, Gillmore, Graham, Hoppe, Morrison, \& Murowchick, 2001). Sex education in schools may benefit from agebased tailoring; for $9^{\text {th }}$ and $10^{\text {th }}$ graders focus could be on pre-coital behavior, whereas for $11^{\text {th }}$ and $12^{\text {th }}$ graders, the focus could be on negotiating condom use in long-term relationships. Beyond school sex education, there is an opportunity for improving interventions aimed at parent-child relationships. An intervention that addressed the changing relationship as the adolescent moves into young adulthood could improve behavioral intentions for safe sex and lower risky sexual behavior. Study opportunities within adolescent age groups have been noted by other researchers as well: in their study of neighborhood types and behavioral problems, Plybon and Kliewer (2001) note that almost no research has been conducted linking neighborhoods, parenting, and health outcomes among preadolescents.

One limitation of the current study that warrants more research is the problem with perspective and temporality. The study was cross-sectional, so no longitudinal changes could be observed. However, the study was also limited to the adolescent's 
perspective, which excludes a key player in the equation: parents. Significantly more bidirectional parenting research needs to be conducted. A discussion about the changing relationship between parents and their children as they navigate these changes would be valuable.

Subjective norms have long been considered the weakest link in the TPB (Armitage \& Connor, 2001). Though several parenting variables were explored in the current study with the hopes that they would make an impact on the literature regarding subjective norms, only parental presence was found to be predictive of behavioral intentions. No parenting elements were predictive of unsafe sexual behavior. This finding warrants more research into subjective norm variables that may impact behavioral intentions and, downstream, sexual risk behavior.

The findings in the current study add to the growing literature base on the interplay between neighborhoods, family factors, and adolescent outcomes. Devoting research funds to discovering significant neighborhood and parenting variables will lead to more efficacious interventions among vulnerable populations such as adolescents. Ultimately, effective interventions could guide the development of sexual education programs in schools, so that every adolescent would have an equal opportunity to reach adulthood happy and healthy and whole. 


\section{REFERENCES}

Abraham, C., Sheeran, P., \& Henderson, M. (2011). Extending social cognition models of health behaviour. Health Education Research, 26(4), 624-637.

Aisenberg, E., \& Herrenkohl, T. (2008). Community violence in context: risk and resilience in children and families. Journal of Interpersonal Violence, 23(3), 296315.

Akers, A., Gold, M., Bost, J., Adimora, A., Orr, D., \& Fortenberry, J. (2011). Variation in sexual behaviors in a cohort of adolescent females: The role of personal, perceived peer and family attitudes. Journal of Adolescent Health, 48(1), 87-93.

Angoff, W. (1988). The nature-nurture debate, aptitudes, and group differences. American Psychologist, 43(9), 713-720.

Archibald, M., Gillmore, M. R., Graham, L., Hoppe, M., Morrison, D. M., \& Murowchick, E. (2001). Difference by gender and sexual experience in adolescent sexual behavior: Implications for education and HIV prevention. Journal of School Health, 71(4), 153-158.

Armitage, C., \& Connor, M. (2001). Efficacy of the Theory of Planned Behaviour: A meta-analytic review. British Journal of Social Psychology, 40, 471-499.

Azjen, I. (2002). Perceived behavioral control, self-efficacy, locus of control, and the Theory of Planned Behavior. Journal of Applied Social Psychology, 32(4), 665683.

Bartko, W., \& Eccles, J. (2003). Adolescent participation in structured and unstructured activities: A person-oriented analysis. Journal of Youth and Adolescence, 32(4), 233-241.

Baumrind, D. (1967). Child care practices anteceding three patterns of preschool behavior. Genetic Psychology Monographs, 75(1), 43-88.

Bearman, P. S., Jones, J., \& Udry, J. R. (1997). The National Longitudinal Study of Adolescent Health: Research Design. Chapel Hill, NC: Carolina Population Center.

Billy, J., \& Moore, D. (1992). A multilevel analysis of marital and nonmarital fertility in the U.S. Social Forces, 70(4), 977-1011.

Billy, J., Brewster, K., \& Grady, W. (1994). Contextual effects on the sexual behavior of adolescent women. Journal of Marriage and the Family, 56, 387-404.

Blake, S. M., Simkin, L., Ledsky, R., Perkins, C., \& Calabrese, J. M. (2001). Effects of a parent-child communications intervention on young adolescents' risk for early onset of sexual intercourse. Family Planning Perspectives, 33(2), 52-61. 
Bleakley, A., Hennessy, M., Fishbein, M., Coles, H. C., \& Jordan, A. (2009). How sources of sexual information relate to adolescents' beliefs about sex. American Journal of Health Behavior, 33(1), 37-48.

Blum, R. W., Halcón, L., Beuhring, T., Pate, E., Campell-Forrester, S., \& Venema, A. (2003). Adolescent health in the Caribbean: Risk and protective factors. Research and Practice, 93(3), 456-460.

Blum, R., \& Rinehart, P. (1997). Reducing the risk: Connections that make a difference in the lives of youth. Bethesda, MD: Add Health c/o Burness Communications.

Bolland, J. (2003). Hopelessness and risk behaviour among adolescents living in highpoverty inner-city neighbourhoods. Journal of Adolescence, 26, 145-158.

Borawski, E. A., Ievers-Landis, C. E., Lovegreen, L. D., \& Trapl, E. S. (2003). Parental monitoring, negoriated unsupervised time, and parental trust: The role of perceived parenting practices in adolescent health risk behaviors. Journal of Adolescent Health, 33(2), 60-70.

Bowen, N., Bowen, G., \& Ware, W. (2002). Neighborhood social disorganization, families, and the educational behavior of adolescents. Journal of Adolescent Research, 17(5), 468-490.

Bronfenbrenner, U. (1979). The ecology of human development. Cambridge, MA: Harvard University Press.

Brooks, J. (1991). The Process of Parenting. Toronto: Mayfield Publishing.

Brooks, R., Lee, S., Stover, G., \& Barkley, T. (2009). Condom attitudes, perceived vulnerability, and sexual risk behaviors of young Latino male urban street gang members: Implications for HIV prevention. AIDS Education and Prevention, 21(SB), 80-87.

Brooks-Gunn, J., Duncan, G., \& Aber, J. (Eds.). (1997). Neighborhood Poverty: Context and consequences for children (Vol. 1). New York: Russell Sage Foundation.

Brooks-Gunn, J., Duncan, G., Klebanov, P., \& Sealand, N. (1993). Do neighborhoods influence child and adolescent development? American Journal of Sociology, 99(2), 353-395.

Browning, C., Burrington, L., Leventhal, T., \& Brooks-Gunn, J. (2008). Neighborhood structural inequality, collective efficacy, and sexual risk behavior among urban youth. Journal of Health and Social Behavior, 49(3), 269-285.

Browning, C., Burrington, L., Leventhal, T., \& Brooks-Gunn, J. (2008). Neighborhood structural inequality, collective efficacy, and sexual risk behavior among urban youth. Journal of Health and Social Behavior, 49(3), 269-285. 
Browning, C., Leventhal, T., \& Brooks-Gunn, J. (2004). Neighborhood context and racial differences in early adolescent sexual activity. Demography, 41(4), 697-720.

Buckner, J. C., Mezzacappa, E., \& Beardslee, W. R. (2003). Characteristics of resilient youths living in poverty: The role of self-regulatory processes. Development and Psychopathology, 15, 139-162.

Buhi, E., \& Goodson, P. (2007). Predictors of adolescent sexual behavior and intention: A theory-guided systematic review. Journal of Adolescent Health, 40, 4-21.

Burt, M. (2002). Reasons to invest in adolescents. Journal of Adolescent Health, 31, 136152.

Burton, L., \& Jarrett, R. (2000). In the mix, yet on the margins: The place of families in urban neighborhood and child development research. Journal of Marriage and Family, 62(4), 1114-1135.

Buu, A., DiPiazza, C., Wang, J., Puttler, L. I., Fitzgerald, H. E., \& Zucker, R. A. (2009). Parent, family, and neighborhood effects on the development of child substance use and other psychopathology from preschool to the start of adulthood. Journal of Studies on Alcohol and Drugs, 70, 489-498.

Carlson, E., \& Chamberlain, R. (2003). Social capital, health, and health disparities. Journal of Nursing Scholarship, 35(4), 325-331.

Carvajal, S., Parcel, G., Basen-Engquist, K., Banspach, S., Coyle, K., Kirby, D., et al. (1999). Psychosocial predictors of delay of first sexual intercourse by adolescents. Health Psychology, 18(5), 443-452.

CDC. (2002). Cases of HIV infaction and AIDS in the United States, by race/ethnicity, 1998-2002. 10(1), 28-29; 34-35.

CDC. (2007). HIV/AIDS Surveillance Report. Cases of HIV infection and AIDS in the United States and Dependent Areas, 19. Department of Health and Human Services.

CDC. (2010a). MMWR weekly: Youth Risk Behavior Surveillance 2009.

CDC. (2010b, June). HIV Surveillance Report, 2008. Retrieved from http://www.cdc.gov/hiv/topics/surveillance/resources/reports/

CDC. (2011, August 26). Healthy People 2010 Leading Health Indicators at a Glance. Retrieved from Centers for Disease Control and Prevention: http://www.cdc.gov/nchs/healthy_people/hp2010/hp2010_indicators.htm

CDC. (2012, July 24). Sexual risk behavior: HIV, STD, \& teen pregnancy prevention. Retrieved October 9, 2012, from Centers for Disease Control and Prevention: http://www.cdc.gov/HealthyYouth/sexualbehaviors/ 
Chang, L., \& Krosnick, J. (2010). Comparing oral interviewing with self-administered computerized questionnaires: An experiment. Public Opinion Quarterly, 74(1), 154-167.

Chase-Lansdale, P. L., \& Vinovskis, M. A. (1993). Adolescent Pregnancy and Child Support. In R. Wollons (Ed.), Children at Risk in America: History, Concepts, and Public Policy (pp. 202-229). Albany, NY: State University of New York.

Chesson, H. W., Blandford, J. M., Gift, T. L., Tao, G., \& Irwin, K. L. (2004). The estimated direct medical cost of sexually transmitted diseases among American youth, 2000. Perspectives on Sexual and Reproductive Health, 36(1), 11-19.

Chung, H. L., \& Steinberg, L. (2006). Relations between neighborhood factors, parenting behaviors, peer deviance, and delinquency among serious juvenile offenders. Developmental Psychology, 42(2), 319-331.

Cloud, J. (2010, January 6). Why your DNA isn't your destiny. Time.

Cohen, D., Farley, T., Taylor, S., Martin, D., \& Schuster, M. (2002). When and where do youths have sex? The potential role of adult supervision. Pediatrics, 110(6), e66.

Collins, W. A., Maccoby, E. E., Steinberg, L., Hetherington, M. E., \& Bornstein, M. H. (2000). Contemporary research in parenting: The case for nature and nurture. American Psychologist, 55(2), 218-232.

Cotton, S., Mills, L., Succop, P. A., Biro, F. M., \& Rosenthal, S. L. (2004). Adolescent girls perception of the timing of their sexual initiation: 'too young' or 'just right'? Journal of Adolescent Health, 34, 453-458.

Crane, J. (1991). The epidemic theory of ghettos and neighborhood effects on dropping out and teenage childbearing. American Journal of Sociology, 96(5), 1226-1259.

Cubbin, C., Santelli, J., Brindis, C., \& Braveman, P. (2005). Neighborhod context and sexual behaviors among adolescents: Findings from the National Longitudinal Study of Adolescent Health. Perspectives on Sexual and Reproductive Health, 37(3), 125-134.

Dailard, C. (2000). Reviving interest in policies and programs to help teens prevent repeat births. 3(3). The Guttmacher Report on Public Policy.

D'Amico, E., Ellickson, P., Collins, R., Martino, S., \& Klein, D. (2005). Processes linking adolescent problems to substance-use problems in late young adulthood. Journal of Studies on Alcohol, 66(6), 766-775.

Darling, C. A., \& Hicks, M. W. (1982). Parental influence on adolescent sexuality: Implications for parents as educators. Journal of Youth and Adolescence, 11(3), 231-245. 
de Graaf, H., Vanwesenbeeck, I., Woertman, L., \& Meeus, W. (2011). Parenting and adolescents' sexual development in western societies. European Psychologist, 16(1), 21-31.

DeHart, D., \& Birkimer, J. (1997). Trying to practice safer sex: Development of the sexual risks scale. Journal of Sex Research, 34, 11-25.

DeSantis, L., \& Thomas, J. T. (1987). Parental attitudes toward adolescent sexuality: Transcultural perspectives. Nurse Practitioner, 12(8), 43-48.

Dévieux, J. G., Malow, R., Lerner, B. G., Dyer, J. G., Baptista, L., Lucenko, B., et al. (2007). Triple Jeopardy for HIV: Substance Using Severely Mentally Ill Adults. Journal of Prevention \& Intervention in the Community, 33(1-2), 5-18.

DeVore, E. R., \& Ginsburg, K. R. (2005). The protective effects of good parenting on adolescents. Current Opinion in Pediatrics, 17, 460-465.

DiClemente, R., Crosby, R., \& Kegler, M. (Eds.). (2002). Emerging Theories in Health Promotion Practice and Research. San Francisco: John Wiley \& Sons.

Dilorio, C., Dudley, W., Kelly, M., Soet, J., Mbwara, K., \& Sharpe Potter, J. (2001). Psychosocial predictors of delay of first sexual intercourse by adolescents. Journal of Adolescent Health, 29(3), 208-216.

DiIorio, C., Kelley, M., \& Hockenberry-Eaton, M. (1999). Communication about sexual issues: Mothers, fathers, and friends. Journal of Adolescent Health, 24(3), 181189.

Dorius, G., \& Barber, B. (1998). Parental support and control and the onset of sexual intercourse. Unpublished manuscript. Provo, Utah: Department of Sociology, Brigham Young University.

Driscoll, A., Sugland, B., Manlove, J., \& Papillo, A. (2005). Community opportunity, perceptions of opportunity, and the odds of an adolescent birth. Youth Society, $37(1), 33-61$.

Eamon, M. (2002). Poverty, parenting, peer, and neighborhood influences on young adolescent antisocial behavior. Journal of Social Service Research, 28(1), 1-23.

Earls, F., McGuire, J., \& Shay, S. (1994). Evaluating a community intervention to reduce the risk of child abuse: Methodological strategies in conducting neighborhood surveys. Child Abuse and Neglect, 18(5), 473-485.

Eccles, J., \& Barber, B. (1999). Student council, volunteering, basketball, or marching band: What kind of extracurricular participation matters? Journal of Adolescent Research, 14(1), 10-43.

Edberg, M. (2007). Essentials of Health Behavior: Social and Behavioral Theory in Public Health. Sudbury, MA: Jones and Bartlett Publishers. 
Eitle, D., \& Taylor, J. (2008). Are Hispanics the new 'threat'? Minority group threat and fear of crime in Miami-Dade County. Social Science Research, 37(4), 1102-1115.

Epstein, M., \& Ward, L. M. (2008). "Always use protection": Communication boys receive about sex from parents, peers, and the media. Journal of Youth and Adolescence, 37, 113-126.

Escovar, L., \& Escovar, P. (1985). Retrospective perception of parental child-rearing practices in three culturally different college grouns. International Journal of Intercultural Relations, 9, 31-49.

Ewart, C. K., \& Suchday, S. (2002). Discovering how urban poverty and violence affect health: development and validation of a neighborhood stress index. Health Psychology, 21(3), 254-262.

Farahani, F. K., Cleland, J., \& Mehryar, A. H. (2011). Associations between family factors and premarital heterosexual relationships among female college students in Tehran. International Perspectives on Sexual and Reproductive Health, 37(1), 30-39.

Feldman, S. S., \& Rosenthal, D. A. (2000). The effect of communication characteristics on family members' perceptions of parents as sex educators. Journal of Research on Adolescence, 10(2), 119-150.

Feldman, S., \& Brown, N. L. (1993). Family influences on adolescent male sexuality: the mediational role of self-restraint. Social Development, 2(1), 15-35.

Fergus, S., \& Zimmerman, M. (2005). Adolescent resilience: A framework for understanding healthy development in the face of risk. Annual Review of Public Health, 26, 399-419.

Fishbein, M., \& Azjen, I. (1974). Attitudes towards objects as predictors of single and multiple behavioral criteria. Psychological Review, 81(1), 59-74.

Ford, L., \& Norris, A. (1991). Urban African American and Hispanic adolescents and young adults: Who are they talking to about AIDS and what are they learning? AIDS Education and Prevention, 3(3), 197-206.

Forehand, R., \& Kotchick, B. (1996). Cultural diversity: A wake-up call for parent training. Behavior Therapy, 27(2), 187-206.

Frankel, A., Bryant, V., Jean-Gilles, M., Rosenberg, R., Devieux, J., \& Malow, R. M. (2011, August 14-17). Gender differences in parent-adolescent sexual health communication and parent awareness of sexual activity. 2011 National HIV Prevention Conference Proceedings, Poster 023M. Atlanta, GA.

Friedman, A., \& Utada, A. (1989). Adolescent Drug Abuse Diagnosis. Philadelphia, PA: Belmont Center for Comprehensive Treatment. 
Geis, K., \& Ross, C. (1998). A new look at urban alienation: The effect of neighborhood disorder on perceived powerlessness. Social Psychology Quarterly, 61(3), 232246.

Gorman-Smith, D., \& Tolan, P. (1998). The role of exposure to community violence and developmental problems among inner-city youth. Development and Psychopathology, 10(1), 101-116.

Gray, M. R., \& Steinberg, L. (1999). Unpacking authoritative parenting: Reassessing a multidimensional construct. Journal of Marriage and Family, 61(3), 574-587.

Guarini, T., Marks, A., Patton, F., \& Coll, C. (2011). The immigrant paradox in sexual risk behavior among Latino adolescents: Impact of immigrant generation and gender. Applied Developmental Science, 15(4), 201-209.

Guilamo-Ramos, V., Dittus, P., Jaccard, J., Johansson, M., Bouris, A., \& Acosta, N. (2007). Parenting practices among Dominican and Puerto Rican mothers. Social Work, 52(1), 17-30.

Hagerty, B., Lynch-Sauer, J., Patusky, K., \& Bouwsema, M. (1993). An emerging theory of human relatedness. Image-Journal of Nursing Scholarship, 25, 291-296.

Hahm, H., Lee, C., Choe, J., Ward, A., \& Lundgren, L. (2011). Sexual attitudes, reasons for forgoing condom use, and the influence of gender power among AsianAmerican women: A qualitative study. Journal of AIDS \& Clinical Research, S1.

Halgunseth, L. C., Ispa, J. M., \& Rudy, D. (2006). Parental control in Latino families: An integrated review of the literature. Child Development, 77(5), 1282-1297.

Hall, H. I., Espinoza, L., Benbow, N., \& Hu, Y. W. (2010). Epidemiology of HIV infection in large urban areas in the United States. PLOS ONE, 5(9), epublication.

Hammack, P. L., Richards, M. H., Luo, Z., Edlynn, E. S., \& Roy, K. (2004). Social support factors as moderators of community violence exposure among inner-city African American young adolescents. Journal of Clinical Child and Adolescent Psychology, 450-462.

Hipwell, A. E., Stepp, S. D., Keenan, K., Chung, T., \& Loeber, R. (2011). Parsing the heterogeneity of adolescent girls' sexual behavior: Relationships to individual and interpersonal factors. Journal of Adolescence, 34(3), 589-592.

Holtgrave, D., \& Crosby, R. (2004). Social determinants of tuberculosis case rates in the United States. American Journal of Preventive Medicine, 26(2), 159-162.

Hovell, M., Sipan, C., Blumberg, E., Atkins, C., Hofstetter, C., \& Kreitner, S. (1994). Family influences on Latino and Anglo adolescents' sexual behavior. Journal of Marriage and the Family, 56, 973-986. 
Huebner, A. J., \& Howell, L. W. (2003). Examining the relationship between adolescent sexual risk-taking and perceptions of monitoring, communication, and parenting styles. Journal of Adolescent Health, 33, 71-78.

Huebner, D., Neilands, T., Rebchook, G., \& Kegeles, S. (2011). Sort through chickens and eggs: A longitudinal examination of the associations between attitudes, norms, and sexual risk behavior. Health Psychology, 30(1), 110-118.

Hutchinson, M. K. (2002). The influence of sexual risk communication between parents and daughters on sexual risk behaviors. Family Relations, 51(3), 238-247.

Hutchinson, M. K., \& Montgomery, A. K. (2007). Parent communication and sex risk among African Americans. Western Journal of Nursing Research, 29(6), 691-707.

Hutchinson, M., Jemmott, J., Jemmott, L., Braverman, P., \& Fong, G. (2003). The role of mother-daughter sexual risk communication in reducing sexual risk behaviors among urban adolescent females: a prospective study. Journal of Adolescent Health, 33, 98-107.

Hyde, P. S. (2011, October 30). Behavioral Health: Public Health Challenge; Public Health Opportunity. 139th Annual Meeting and Exposition. Washington, DC: American Public Health Association.

Hyyppä, M., \& Mäki, J. (2003). Social participation and health in a community rich in stock of social capital. Health Education Research, 18(6), 770-779.

Ito, K., Gizlice, Z., Owen-O'Dowd, J., Foust, E., Leone, P., \& Miller, W. (2006). Parent opinion of sexuality education in a state with mandated abstinence education: Does policy match parental preference. Journal of Adolescent Health, 39(5), 634641.

Jaccard, J., \& Dittus, P. (1991). Parent-teenager communication: Towards the prevention of unintended pregnancies. New York: Springer-Verlag.

Jaccard, J., Dittus, P. J., \& Gordon, V. V. (2000). Parent-teen communication about premarital sex: Factors associated with the extent of communication. Journal of Adolescent Research, 15(2), 187-208.

Jaccard, J., Dittus, P., \& Gordon, V. (1996). Maternal correlates of adolescent sexual and contraceptive behavior. Family Planning Perspectives, 28(4), 159-185.

Jaccard, J., Dittus, P., \& Gordon, V. (1998). Parent-adolescent congruency in reports of adolescent sexual behavior and in communication about sexual behavior. Child Development, 69, 247-261.

Jaccard, J., Dodge, T., \& Dittus, P. (2002). Parent-adolescent communication about sex and birth control: a conceptual framework. New Directions for Child and Adolescent Dvelopment(97), 9-41. 
Jackson, C., Henrikson, L., \& Foshee, V. A. (1998). The authoritative parenting index: Predicting health risk behaviors among children and adolescents. Health Education and Behavior, 25(3), 319-337.

Jemmott, J., Heeren, G., Ngwane, Z., Hewitt, N., Jemmott, L., Shell, R., et al. (2007). Theory of planned behaviour predictors of intention to use condoms among Xhosa adolescents in South Africa. AIDS Care, 19(5), 677-684.

Jemmott, J., Jemmott, L., \& Fong, G. (1992). Reductions in HIV risk associated sexual behaviors among black male adolescents: Effects of an AIDS prevention intervention. American Journal of Public Health, 82, 372-377.

Jensen, L. A. (2011). Bridging Cultural and Developmental Approaches to Psychology. New York, New York: Oxford University Press, Inc.

Jerman, P., Constantine, N. A., \& Nevarez, C. R. (2007). Sexually transmitted infections among California youth: Estimated incidence and direct medical cost, 2005. California Journal of Health Promotion, 3(3), 80-91.

Julian, T. W., McKenry, P. C., \& McKelvey, M. W. (1994). Cultural variations in parenting: Perceptions of Caucasian, African American, Hispanic, and AsianAmerican parents. Family Relations, 43, 30-37.

Kaiser Family Foundation. (1999). Kids are ready to talk about today's tough issues before their parents are: Sex, AIDS, violence, and drugs/alcohol.

Karofsky, P. S., Zeng, L., \& Kosorok, M. R. (2001). Relationship between adolescentparental communication and initiation of first intercourse by adolescents. Journal of Adolescent Health, 28(1), 41-45.

Kegeles, S., Adler, N., \& Irwin, C. (1988). Sexually active adolescents and condoms: Changes over one year in knowledge, attitudes and use. American Journal of Public Health, 78, 460-461.

Kim, A., Martinez, A., Klausner, J., Goldenson, J., Kent, C., Liska, S., et al. (2009). Use of sentinal surveillance and Geographic Information Systems to monitor trends in HIV prevalence, incidence, and related risk behavior among women undergoing syphilis screening in a jail setting. Journal of Urban Health, 86(1), 79-92.

Kim, J., \& Ward, L. (2007). Silence speaks volumes: Parental sexual communication among Asian American emerging adults. Journal of Adolescent Research, 22(1), 3-31.

Kinsman, S. B., Romer, D., Furstenberg, F. F., \& Schwarz, D. F. (1998). Early sexual initiation: the role of peer norms. Pediatrics, 102, 1185-1192.

Kirby, D. (2001). Understanding what works and what doesn't in reducing adolescent sexual risk-taking. Family Planning Perspectives, 33(6), 276-281. 
Kirby, D. (2002). The impact of schools and school programs upon adolescent sexual behavior. The Journal of Sex Research, 39(1), 27-33.

Kirkman, M., Rosenthal, D. A., \& Feldman, S. S. (2002). Talking to a tiger: Fathers reveal their difficulties in communicating about sexuality with adolescents. New Directions for Child and Adolescent Development(97), 57-74.

Klebanov, P., Brooks-Gunn, J., \& Duncan, G. (1994). Does neighborhood and family poverty affect mothers' parenting, mental health, and social support? Journal of Marriage and the Family, 56, 441-455.

Kliewer, W., Sandler, I., \& Wolchik, S. (1994). Family socialization of threat appraisal and coping: Coaching, modeling, and family context. In F. Nestmann, \& K. Hurrelman (Eds.), Social Networks and Social Support in Childhood and Adolescence (pp. 271-292). Berlin: Walter de Gruyter \& Co.

Knopf, D. (2005). Improving Adolescent Health. In J. B. Kotch, Maternal and Child Health: Programs, Problems, and Policy in Public Health (2nd Edition ed., pp. 243-296). Sudbury, MA: Jones and Bartlett Publishers.

Kotchick, B., Dorsey, S., Miller, K., \& Forehand, R. (1999). Adolescent sexual risktaking behavior in single-parent ethnic minority families. Journal of Family Psychology, 13(1), 93-102.

Ku, L., Sonenstein, F., \& Pleck, J. (1993). Neighborhood, family, and work: Influences on the premarital behaviors of adolescent males. Social Forces, 72(2), 479-503.

Lam, C., \& Lefkowitz, E. (2012). Risky sexual behaviors in emerging adults: Longitudinal changes and within-person variations. Archives of Sexual Behavior, Epub ahead of print.

Landor, A., Simons, L. G., Simons, R. L., Brody, G. H., \& Gibbons, F. X. (2011). The role of religiosity in the relationship between parents, peers, and adolescent risky sexual behavior. Journal of Youth and Adolescence, 40(3), 296-309.

Lazarus, R., \& Folkman, S. (1984). Stress, Appraisal, and Coping. New York: Springer Publishing Company, Inc.

Lebese, R., Davhana, M., \& Obi, C. (2010). Sexual health dialogue between parents and teenagers: An imperative in the HIV/AIDS era. Curationis, 3, 33-42.

Lee, F., Lewis, R., \& Kirk, C. (2011). Sexual attitudes and behaviors among adolescets. Journal of Prevention \& Intervention in the Community, 39(4), 277-288.

Leventhal, T., \& Brooks-Gunn, J. (2000). The neighborhoods they live in: The effects of neighborhood residence on child and adolescent outcomes. Psychological Bulletin, 126(2), 309-337. 
Li, X., Stanton, B., \& Feigelman, S. (2000). Impact of perceived parental monitoring on adolescent risk bheavior over 4 years. Journal of Adolescent Health, 27, 49-56.

Lochner, K., Kawachi, I., \& Kennedy, B. (1999). Social capital: A guide to its measurement. Health \& Place, 5(4), 259-270.

Longmore, M., Eng, A., Giordano, P., \& Manning, W. (2009). Parenting and adolescents' sexual initiation. Journal of Marriage and Family, 71(4), 969-982.

Lowenkamp, C., Cullen, F., \& Pratt, T. (2003). Replicating Sampson and Groves's Test of Social Disorganization Theory: Revisiting a Criminological Classic. Journal of Research in Crime and Delinquency, 40, 351-373.

Luthar, S. (1999). Poverty and Children's Adjustment. Thousand Oaks, CA: Sage Publications, Inc.

Lynch, M. (2003). Consequences of children's exposure to community violence. Clinical Child and Family Psychology Review, 6(4), 265-274.

Mahoney, J. L., Cairns, B. D., \& Farmer, T. W. (2003). Promoting interpersonal competence and educational success through extracurricular activity participation. Journal of Educational Psychology, 95(2), 409-418.

Mahoney, J., \& Cairns, R. (1997). Do extracurricular activities protect against early school dropout? Developmental Psychology, 33, 241-253.

Malcolm, S., Huang, S., Cordova, D., Freitas, D., Arzon, M., Jimenez, G., et al. (2012, May 4). Predicting condom use attitudes, norms, and control beliefs in Hispanic problem behavior youth: The effects of family functioning and parent-adolescent communication about sex on condom use. Health Education and Behavior, Epub ahead of print.

Markham, C. M., Tortolero, S. R., Escobar-Chaves, S. L., Parcel, G. S., Harrist, R., \& Addy, R. C. (2003). Family connectedness and sexual risk-taking among urban youth attending alternative high schools. Perspectives on Sexual and Reproductive Health, 35(4), 174-179.

Mathews, C., Aarø, L., Flisher, A., Mukoma, W., Wubs, A., \& Schaalma, H. (2009). Predictors of early first sexual intercourse among adolescents in Cape Town, South Africa. Health Education Research, 24(1), 1-10.

McGillicuddy, N. B., Rcyhtarik, R. G., Morsheimer, E. T., \& Burke-Storer, M. R. (2007). Agreement between parent and adolescent reports of adolescent substance use. Journal of Child and Adolescent Substance Abuse, 16(4), 59-78.

McLanahan, S. (2009). Fragile families and the reproduction of poverty. Annals of the American Academy of Political and Social Science, 621(1), 111-131. 
Meschke, L. L., Bartholomae, S., \& Zentall, S. R. (2002). Adolescent sexuality and parent-adolescent processes: Promoting healthy teen choices. Journal of Adolescent Health, 31, 264-279.

Miller, B. (1998). Families Matter: A Research Synthesis of Family Influences on Adolescent Pregnancy. Washington, DC: National Campaign to Prevent Teen Pregnancy.

Miller, B. (2002). Family influences on adolescent sexual and contraceptive behavior. The Journal of Sex Research, 39(1), 22-26.

Miller, B. C., Benson, B., \& Galbraith, K. A. (2001). Family relationships and adolescent pregnancy risk: A research synthesis. Developmental Review, 21(1), 1-38.

Miller, B., McCoy, J., Olson, T., \& Wallace, C. (1986). Parental discipline and control attempts in relation to adolescent sexual attitudes and behavior. Journal of Marriage and Family, 48, 503-512.

Miller, F. C. (2000). Impact of adolescent pregnancy as we approach the new millenium. Journal of Pediatric Adolescent Gynecology, 13, 5-8.

Miller, K. S., Forehand, R., \& Kotchick, B. A. (1999). Adolescent sexual behavior in two ethnic minority samples: The role of family variables. Journal of Marriage and Famiyl, 61(1), 85-98.

Miller, K. S., Kotchick, B. A., Dorsey, S., Forehand, R., \& Ham, A. Y. (1998). Family communication about sex: What are parents saying and are their adolescents listening? Family Planning Perspectives, 30(5), 218-222 \& 235.

Miller, K., Fasula, A., Dittus, P., Wiegand, R., Wyckoff, S., \& McNair, L. (2009). Barriers and facilitators to maternal communication with preadolescents about age-relevant sexual topics. AIDS and Behavior, 13(2), 365-374.

Millstein, S., \& Halpern-Felsher, B. (2002). Perceptions of risk and vulnerability. Journal of Adolescent Health, 31S, 10-37.

Murry, V. M., Berkel, C., Gaylord-Harden, N. K., Copeland-Linder, N., \& Nation, M. (2011). Neighborhood poverty and adolescent development. Journal of Research on Adolescence, 21(1), 114-128.

National Cancer Institute. (2005). Theory at a Glance: A Guide for Health Promotion Practice. National Institutes of Health: U.S. Department of Health and Human Services.

National Institute on Drug Abuse. (1991). Risk Behavior Assessment. Rockville, MD.

Needle, R., Fisher, D. G., Weatherby, N., Chitwood, D., Brown, B., Cesari, H., et al. (1995). Reliability of self-reported HIV risk behaviors of drug users. Psychology of Addictive Behaviors, 9(4), 242-250. 
Newcomer, S., \& Udry, J. R. (1987). Parental Marital Status Effects on Adolescent Sexual Behavior. Journal of Marriage and Family, 49(2), 235-240.

Nolin, M. J., \& Petersen, K. K. (1992). Gender differences in parent-child communication about sexuality: An exploratory study. Journal of Adolescent Research, 7(1), 59-79.

O'Donnell, L., Stueve, A., O'Donnell, C., Duran, R., Doval, A., Wilson, R., et al. (2002). Long-term reductions in sexual initiation and sexual activity among urban middle schoolers in the Reach for Health service learning program. Journal of Adolescent Health, 31(1), 93-100.

O'Sullivan, L., Jaramillo, B., Moreau, D., \& Meyer-Bahlburg, H. (1999). Motherdaughter communication about sexuality in a clinical sample of Hispanic adolescent girls. Hispanic Journal of Behavioral Sciences, 21(4), 447-469.

Ott, M., Pfeiffer, E., \& Fortenberry, J. (2006). Perceptions of Sexual Abstinence among High-Risk Early and Middle Adolescents. Journal of Adolescent Health, 39, $192-$ 198.

Otto-Salaj, L., Heckman, T., Stevernson, L., \& Kelly, J. (1998). Patterns, predictors and gender differences in HIV risk among severely mentally ill men and women. Community Mental Health Journal, 34(2), 175-190.

Park, R. (1916). Suggestions for the investigations of human behavior in the urban environment. American Journal of Sociology, 5, 577-612.

Peterman, T. A., Lindsey, C. A., \& Selik, R. M. (2005). This place is killing me: A comparison of counties where the incidence rates of AIDS increased the most and least. Journal of Infectious Diseases, 191(Suppl 1), S123-S126.

Petersen, J., \& Hyde, J. (2010). A meta-analytic review of research on gender differences in sexuality, 1993-2007. Psychological Bulletin, 136(1), 21-38.

Pistella, C., \& Bonati, F. (1998). Communication about sexual behavior among adolescent women, their family, and peers. Families in Society, 79(2), 206-211.

Pittman, L. D., \& Chase-Lansdale, P. L. (2001). African American adolescent girls in impoverished communities: Parenting style and adolescent outcomes. Journal of Research on Adolescents, 11(2), 199-224.

Plybon, L. E., \& Kliewer, W. (2001). Neighborhood types and externalizing behavior in urban school-age children: tests of direct, mediated, and moderated effects. Journal of Child and Family Studies, 10(4), 419-437.

Raffaelli, M., Bogenschneider, K., \& Flood, M. (1998). Parent-teen communication about sexual topics. Journal of Family Issues, 19(3), 315-333. 
Rai, A. A., Stanton, B., Wu, Y., Li, X., Galbraith, J., Cottrell, L., et al. (2003). Relative influences of perceived parental monitoring and perceived peer involvement on adolescent risk behaviors: An analysis of six cross-sectional data sets. Journal of Adolescent Health, 33, 108-118.

Ramirez-Valles, J., Zimmerman, M. A., \& Newcomb, M. D. (1998). Sexual risk behavior among youth: Modeling the influence of prosocial activities and socioeconomic factors. Journal of Health and Social Behavior, 39, 237-253.

Ramirez-Valles, J., Zimmerman, M., \& Juarez, L. (2002). Gender differences of neighborhood and social control processes. Youth \& Society, 33(3), 418-441.

Rasmussen, A., Aber, M. S., \& Bhana, A. (2004). Adolescent coping and neighborhood violence: Perceptions, exposure, and urban youths' efforts to deal with danger. American Journal of Community Psychology, 33(1/2), 61-75.

Resnick, M. D., Bearman, P. S., Blum, R. W., Bauman, K. E., Harris, K. M., Jones, J., et al. (1997). Protecting Adolescents from Harm: Findings from the National Longitudinal Study on Adolescent Health. Journal of the American Medical Association, 278, 823-832.

Roche, K. M., \& Leventhal, T. (2009). Beyond neighborhood poverty: Family management, neighborhood disorder, and adolescents' early sexual onset. Journal of Family Psychology, 23(6), 819-827.

Rodgers, K. B. (1999). Parenting processes related to sexual risk-taking behaviors of adolescent males and females. Journal of Marriage and the Family, 61, 99-109.

Roux, A.V.D. (2004). The study of group-level factors in epidemiology: Rethinking variables, study designs, and analytical approaches. Epidemiologic Reviews, 26(1): 104-111.

Sacco, W., Levine, B., Reed, D., \& Thompson, K. (1991). Attitudes about condom use as an AIDS-related behavior: Their factor structure and relation to condom use.

Psychological Assessment: A Journal of Consulting and Clinical Psychology, 3, 265-272.

Sampson, R. J., \& Groves, W. B. (1989). Community Structure and Crime: Testing Social-Disorganization Theory. American Journal of Sociology, 94(4), 774-802.

Sampson, R. J., Morenoff, J. D., \& Gannon-Rowley, T. (2002). Assessing "Neighborhood Effects": Social processes and new directions in research. Annual Review of Sociology, 28, 443-478.

Sampson, R. J., Morenoff, J. D., \& Raudenbush, S. (2005). Social anatomy of racial and ethnic disparities in violence. American Journal of Public Health, 95(2), 224-232. 
Schuster, M. A., Corona, R., Elliott, M. N., Kanouse, D. E., Eastman, K. L., Zhou, A. K., et al. (2008). Evaluation of Talking Parents, Health Teens, a new worksite based parenting programme to promote parent-adolescent communication about sexual health: Randomized controlled trial. BMJ, 1-9.

Shaw, C., \& McKay, H. (1942). Juvenile Delinquency and Urban Areas. Chicago: University Press.

Sheeran, P. (2002). Intention-behavior relations: A conceptual and empirical review. European Review of Social Psychology, 12(1), 1-36.

Sheeran, P., \& Orbell, S. (1998). Do intentions predict condom use? Metaanalysis and examination of six moderator variables. British Journal of Social Psychology, $37(2), 231-250$.

Sieving, R. E., Beuhring, T., Resnick, M. D., Bearinger, L. H., Shew, M., Ireland, M., et al. (2001). Development of Adolescent Self-Report Measures from the National Longitudinal Study of Adolescent Health. Journal of Adolescent Health, 28, 7181 .

Simons, R. L., Johnson, C., Conger, R. D., \& Lorens, F. O. (1997). Linking community context to quality of parenting: A study of rural families. Rural Sociology, 62(2), 207-230.

Simons-Morton, B., \& Hartos, J. (2002). Application of the authoritative parenting model to adolescent health behavior. In R. J. Diclemente, R. A. Crosby, \& M. C. Kegler (Eds.), Emerging Theories in Health Promotion Practice and Research:

Strategies for improving public health (pp. 100-125). San Francisco: Jossey-Bass.

Smahel, D., Brown, B. B., \& Blinka, L. (2012). Associations between online friendship and internet addiction among adolescents and emerging adults. Developmental Psychology, 48(2), 381-388.

Spence, N. J., \& Brewster, K. L. (2010). Adolescents' sexual initiation: The interaction of race/ethnicity and immigrant status. Population Research and Policy Review, 29(3), 339-362.

St. Lawrence, J., Brasfield, T., Jefferson, K., Alleyne, E., O'Bannon, R., \& Shirley, A. (1994b). Social support as a factor in African-American adolescents' sexual risk behavior. Journal of Adolescent Research, 9, 292-310.

Stanton, B., Cole, M., Galbraith, J., Li, X., Pendleton, S., Cottrel, L., et al. (2004). Randomized trial of a parent intervention. Archives of Pediatric Adolescent Medicine, 158, 947-955.

Stattin, H., \& Kerr, M. (2000). Parental monitoring: a reinterpretation. Child Development, 71, 1072-1085. 
Steinberg, L., Elmen, J. D., \& Mounts, N. S. (1989). Authoritative parenting, psychosocial maturity, and academic success among adolescents. Child Development, 60, 1424-1436.

Steinberg, L., Mounts, N. S., Lamborn, S. D., \& Dornbusch, S. M. (1991). Authoritative parenting and adolescent adjustment across varied ecological niches. Journal of Research on Adolescents, 1(1), 19-36.

Stone, N., \& Ingham, R. (2002). Factors affecting British teenagers' contraceptive at first intercourse: The importance of partner communication. Perspectives on Sexual and Reproductive Health, 34(4), 191-197.

Suttles, G. (1972). The Social Construction of Communities. Chicago: University of Chicago Press.

Terry, D., \& O'Leary, J. (1995). The theory of planned behaviour: The effects of perceived behavioural control and self-efficacy. British Journal of Social Psychology, 34(2), 199-220.

The Metropolitan Center. (2008). Miami-Dade Count Workforce Housing Needs Assessment. Florida International University. Miami: Greater Miami Chamber of Commerce.

Thomas, A., Eberly, L., Smith, G., \& Neaton, J. (2006). ZIP-Code-based versus tractbased income measures as long-term risk-adjusted mortality predictors. American Journal of Epidemiology, 164(6), 586-590.

Trainor, S., Delfabbro, P., Anderson, S., \& Winefield, A. (2010). Leisure activities and adolescent psychological well-being. Journal of Adolescence, 33, 173-186.

Trenberth, L., \& Dewe, P. (2002). The importance of leisure as a means of coping with work related stress: An exploratory study. Counselling Psychology Quarterly, 15(1), 59-72.

Trochim, W. (2005). Research Methods: The Concise Knowledge Base. Mason, OH: Thomson.

U.S. Census Bureau. (2012). Statistical Abstract of the United States.

U.S. Census Bureau. (2010). Profile of General Population and Housing Characteristics; 2010 Demographic Profile.

U.S. Census Bureau. (2009). Poverty Thresholds.

U.S. Department of Health and Human Services. (2010). Office of Adolescent Health $(O A H)$. Retrieved September 27, 2010, from HHS.gov: http://www.hhs.gov/ophs/oah/ 
U.S. Department of Health and Human Services. (2011, November). Births: Final Data for 2009. National Vital Statistics Reports, 60, 1. Centers for Disease Control and Prevention.

U.S. Postal Service. (2012). ZIP Code information. Retrieved September 22, 2012, from Frequently Asked Questions: https://www.usps.com/

Valdiserri, R., Lyter, D., Leviton, L., Callahan, C., Kingsley, L., \& Rinaldo, C. (1988). Variables influencing condom use in a cohort of gay and bisexual men. American Journal of Public Health, 78, 801-805.

Wang, A., Peterson, G. W., \& Morphey, L. K. (2007). Who is more important for early adolescents' developmental choices? Peers or parents? Marriage and Family Review, 42(2), 95-122.

Whitaker, D. J., Miller, K. S., May, D. C., \& Levin, M. L. (1999). Teenage partners' communication about sexual risk and condom use: the importance of parentteenagers discussions. Family Planning Perspectives, 31(3), 117-121.

Whitaker, D., \& Miller, K. (2000). Parent-adolescent discussions about sex and condoms: Impact on peer influences of sexual risk behavior. Journal of Adolescent Research, 15, 251-273.

Whitbeck, L., Conger, R., \& Kao, M. (1993). Parental support, depressed affect, and peers on the sexual behaviors of adolescent girls. Journal of Family Issues, 14, 261-278.

Widmer, E. D. (1997). Influence of older siblings on initiation of sexual intercourse. Journal of Marriage and Family, 59(4), 928-938.

Zaff, J. F., Moore, K. A., Papillo, A. R., \& Williams, S. (2003). Implications of extracurricular activity participation during adolescent on positive outcomes. Journal of Adolescent Research, 18(6), 599-630.

Zimmer-Gembeck, M. J., \& Helfand, M. (2008). Ten years of longitudinal research on U.S. adolescent sexual behavior: Developmental correlates of sexual intercourse, and the importance of age, gender and ethnic background. Developmental Review, 28(2), 153-224. 


\section{APPENDIX}

\section{ACRONYMS AND ABBREVIATIONS}

\begin{tabular}{ll} 
ADAD & Adolescent Drug Abuse Diagnosis \\
Add Health & National Longitudinal Study of Adolescent Health \\
AIDS & Acquired Immunodeficiency Syndrome \\
CDC & Centers for Disease Control and Prevention \\
CSI & City Stress Index \\
EV & Exposure to Violence \\
HCSF & Health Council of South Florida \\
HIV & Human Immunodeficiency Virus \\
LEAP & Let's Education Adolescents and Parents \\
MSA & Metropolitan Statistical Area \\
ND & Neighborhood Disorder \\
QDS & Questionnaire Development System \\
RBA & Risk Behavior Assessment \\
STI & Sexually Transmitted Infection \\
TPB & Theory of Planned Behavior \\
YRBS & Youth Risk Behavior Survey \\
YSO & Youth-Serving Organizations \\
ZIP & Zone Improvement Plan \\
\hline
\end{tabular}


VITA

\section{ANNE FRANKEL}

1982

Born, Chevy Chase, Maryland

2000-2004

B.S., Animal Sciences

University of Maryland

College Park, Maryland

2005

Louisiana State Teaching Certificate

University of New Orleans

New Orleans, Louisiana

2008-2012

Doctoral Candidate in Public Health

Florida International University

Miami, Florida

\section{PUBLICATIONS AND PRESENTATIONS}

Malow, R.M., McMahon, R.C., Dévieux, J., Rosenberg, R., Frankel, A., Bryant, V., Lerner, B., Miguez, M.J. (2012). Cognitive behavioral HIV risk reduction in those receiving psychiatric treatment: A clinical trial. AIDS and Behavior 16 (5), 1192-1202.

Bryant, V., \& Frankel, A.S. (2012). National Institutes of Health. In M. Gellman \& J.R. Turner (eds.), Encyclopedia of Behavioral Medicine. New York: Springer.

Frankel, A.S., Bryant, V., Jean-Gilles, M., Rosenberg, R., Dévieux, J.G., Malow, R.M. (2011, August). Gender differences in parent-adolescent sexual health communication patterns and parent awareness of sexual activity. Poster presented at the National HIV Prevention Conference, Atlanta, GA.

Frankel, A.S., Bryant, V., Jean-Gilles, M., Lerner, B., Dévieux, J., Malow, R.M. (2011, October-November). Parent awareness of adolescent exposure to violence: Health outcomes and protective factors. Poster presented at the American Public Health Association $139^{\text {th }}$ Annual Meeting, Washington, DC.

Catherwood, A.S., Jean, P.C., Pelletier, V., Jean-Gilles, M., Rosenberg, R., Dévieux, J.G., Malow, R. (2009, November). Relationships between educational attitudes, parental caring, parental communication and risk behavior among Haitian adolescents in Miami-Dade County. Poster presented at the American Public Health Association $137^{\text {th }}$ Annual Meeting, Philadelphia, PA. 